\title{
Primary open-angle glaucoma and ocular hypertension : cost-effectiveness of early detection and treatment
}

Citation for published version (APA):

Peeters, A. (2007). Primary open-angle glaucoma and ocular hypertension : cost-effectiveness of early detection and treatment. [Doctoral Thesis, Maastricht University]. Datawyse / Universitaire Pers Maastricht. https://doi.org/10.26481/dis.20080116ap

Document status and date:

Published: 01/01/2007

DOI:

10.26481/dis.20080116ap

Document Version:

Publisher's PDF, also known as Version of record

\section{Please check the document version of this publication:}

- A submitted manuscript is the version of the article upon submission and before peer-review. There can be important differences between the submitted version and the official published version of record.

People interested in the research are advised to contact the author for the final version of the publication, or visit the DOI to the publisher's website.

- The final author version and the galley proof are versions of the publication after peer review.

- The final published version features the final layout of the paper including the volume, issue and page numbers.

Link to publication

\footnotetext{
General rights rights.

- You may freely distribute the URL identifying the publication in the public portal. please follow below link for the End User Agreement:

www.umlib.nl/taverne-license

Take down policy

If you believe that this document breaches copyright please contact us at:

repository@maastrichtuniversity.nl

providing details and we will investigate your claim.
}

Copyright and moral rights for the publications made accessible in the public portal are retained by the authors and/or other copyright owners and it is a condition of accessing publications that users recognise and abide by the legal requirements associated with these

- Users may download and print one copy of any publication from the public portal for the purpose of private study or research.

- You may not further distribute the material or use it for any profit-making activity or commercial gain

If the publication is distributed under the terms of Article $25 \mathrm{fa}$ of the Dutch Copyright Act, indicated by the "Taverne" license above, 


\title{
Primary open-angle glaucoma and ocular hypertension
}

\author{
Cost-effectiveness \\ of early detection and treatment
}


ISBN 9789052786759

Lay-out: Andrea Peeters

Cover Illustration: Oko (Samuel), Pavel Piekar, 2007

Production: Datawyse | Universitaire Pers Maastricht

(C) Copyright A. Peeters, Maastricht 2007

All rights reserved. No part of this thesis may be reproduced or transmitted in any form or by any means, electronic or mechanical, including photocopying, recording or any information storage or retrieval system, without permission in writing from the author, or, when appropriate, from the publishers of the publications. 


\title{
Primary open-angle glaucoma and ocular hypertension
}

\author{
Cost-effectiveness \\ of early detection and treatment
}

\author{
PROEFSCHRIFT
}

ter verkrijging van de graad van doctor

aan de Universiteit Maastricht,

op gezag van de Rector Magnificus,

Prof. mr. G.P.M.F. Mols

volgens het besluit van het College van Decanen,

in het openbaar te verdedigen

op woensdag 16 januari 2008 om 14.00 uur

door

Andrea Peeters

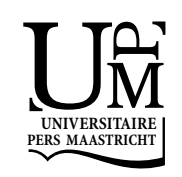




\section{Promotores}

Prof. dr. M.H. Prins

Prof. dr. F. Hendrikse

\section{Copromotores}

Dr. J.S.A.G. Schouten

Dr. C.A.B. Webers

\section{Beoordelingscommissie}

Prof. dr. M. Limburg (voorzitter)

Dr. M. Busch (Catharina Ziekenhuis Eindhoven)

Prof. dr. J.A. Knottnerus

Prof. dr. G.P.M. Luyten (Universiteit Leiden)

Prof. dr. O. van Schayck

Delen van dit onderzoek werden gefinancierd door het College voor Zorgverzekeringen (CvZ) te Diemen 
I have heard many years of telling, And many years should see some change.

The ball I threw while playing in the park Has not yet reached the ground.

Dylan Thomas, Should lanterns shine 



\section{Contents}

$\begin{array}{ll}\text { Abbreviations } & 8\end{array}$

1. Introduction 9

2. Quantifying the effect of the reduction of intraocular pressure on 19 the occurrence and progression of glaucoma

3. The effect of early detection of ocular hypertension and primary 35 open-angle glaucoma on the occurrence of blindness $A$ casereferent study

4. Cost-effectiveness of early detection and treatment of ocular 45 hypertension and primary open-angle glaucoma by the ophthalmologist

5. The clinical impact of two different strategies for initiating therapy 61 in patients with ocular hypertension

6. Latanoprost versus timolol as first choice therapy in patients with 75 ocular hypertension $A$ cost-effectiveness analysis

7. General discussion 93

$\begin{array}{ll}\text { Summary } & 101\end{array}$

$\begin{array}{ll}\text { Samenvatting } & 105\end{array}$

Dankwoord 111

$\begin{array}{ll}\text { Curriculum vitae } & 115\end{array}$ 


\section{Abbreviations}

$\begin{array}{ll}\text { bid } & \text { twice daily } \\ \text { CI } & \text { confidence interval } \\ \text { EGPS } & \text { European Glaucoma Prevention Study } \\ \text { EMGT } & \text { Early Manifest Glaucoma Trial } \\ \text { IOP } & \text { intraocular pressure } \\ \text { mm Hg } & \text { millimeters of mercury } \\ \text { OH } & \text { ocular hypertension } \\ \text { OHTS } & \text { Ocular Hypertension Treatment Study } \\ \text { POAG } & \text { primary open-angle glaucoma } \\ \text { qd } & \text { once daily } \\ \text { RCT } & \text { randomized controlled trial } \\ \text { RR } & \text { relative risk } \\ \text { SD } & \text { standard deviation } \\ \text { tid } & \text { three times daily }\end{array}$




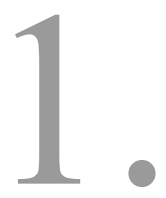

\section{Introduction}



In this thesis ocular hypertension $(\mathrm{OH})$ and primary open-angle glaucoma (POAG) are the main subjects of study. This introduction gives a brief description of $\mathrm{OH}$ and POAG, an explanation of the study methods and a detailed outline of the thesis.

\section{Ocular hypertension}

Data from large epidemiologic studies indicate that the mean intraocular pressure (IOP) is approximately $16 \mathrm{~mm} \mathrm{Hg}$, with a standard deviation of $3 \mathrm{~mm} \mathrm{Hg}{ }^{1}$ The IOP distribution is skewed towards higher pressures, especially in individuals over the age of 40. The probability of glaucoma development increases with higher IOP levels. ${ }^{2-6}$ A value for the IOP of more than $21 \mathrm{~mm} \mathrm{Hg}$ is used by clinicians to define patients with ocular hypertension $(\mathrm{OH})$, even though below this level individuals still can develop glaucoma. Individuals with $\mathrm{OH}$, by definition, have an elevated IOP and no detectable glaucomatous damage as assessed by standard clinical eye examination and additional visual field examination. They have no symptoms due to $\mathrm{OH}$ and they have an increased risk of developing POAG. ${ }^{7}$ The prevalence of ocular hypertension found in population studies in several European countries is $2.2 \%{ }^{8-10}$ Presently, the intraocular pressure is the only risk factor for POAG that is amenable to medical intervention.

\section{Primary open-angle glaucoma}

Primary open-angle glaucoma (POAG) is a progressive, chronic optic neuropathy in adults where intraocular pressure (IOP) and other currently unknown factors contribute to damage and in which, in the absence of other identifiable causes, there is a characteristic acquired atrophy of the optic nerve and a loss of retinal ganglion cells and their axons. ${ }^{11}$ In open-angle glaucoma, by definition, the anterior chamber angle is open by gonioscopic appearance. When no underlying cause of an elevated IOP and a consequent glaucomatous damage can be found, glaucoma is classified as primary. In this thesis, primary open-angle glaucoma is referred to as glaucoma.

\section{Diagnosis}

An initial glaucoma evaluation includes a comprehensive eye evaluation, including history to establish risk factors, and physical examination. The IOP, the appearance of the optic nerve, and the status of visual field can be evaluated by tonometry, ophthalmoscopy and perimetry, retrospectively. In addition, there are several instruments available for optic nerve imaging which use computer algorithms, such as the scanning laser ophthalmoscope, the retinal nerve fiber analyser, and the optical coherence tomograph.

\section{Prevalence and incidence}

Primary open-angle glaucoma affects about $1-2 \%$ of the population, ranging from $0.2 \%$ in $40-50$ years old to $4.7 \%$ in individuals aged above 80 years. $^{8,10,12}$ The incidence rate is estimated to be $0.1 \%$ per year. ${ }^{13}$ 


\section{Risk factors}

Four important risk factors associated with glaucomatous optic neuropathy are the IOP, race (African or Hispanic/Latino descent), age, and family history of glaucoma. ${ }^{11}$ The association between POAG and other potential risk factors like low diastolic perfusion pressures, diabetes, myopia, and systemic hypertension has not been demonstrated consistently.

\section{Natural history}

Glaucoma is a chronic, slowly progressive, generally bilateral but often asymmetrical disease. ${ }^{14}$ In the end stages glaucoma produces tunnel vision and finally blindness. In many patients there are no noticeable symptoms until the later stages of the disease. Glaucoma is therefore sometimes called the "silent blinder". 15 In the Baltimore Eye Survey about $50 \%$ of people with glaucoma were unaware they had the disease. ${ }^{16}$ Blindness caused by glaucoma is irreversible. The incidence of blindness is estimated to be about $1 \%$ per year in treated glaucoma patients and about $10 \%$ in untreated. $^{17-20}$

\section{Treatment}

Glaucoma can not be cured. Treatment can stop or delay its progression to blindness. ${ }^{11}$ Therapy is directed towards lowering the intraocular pressure, which can be achieved by means of medication, laser or surgery. Patients are committed to regular medical check-ups. Glaucoma medication is applied topically and is required lifelong. It can cause ocular and systemic side-effects. The purpose of treatment is to preserve visual function while minimizing adverse effects of therapy, thereby enhancing the patient's health and quality of life, especially with regard to such issues as self-care, driving and working. ${ }^{11}$

Several types of IOP lowering drugs are now available. The most often used drugs are beta-adrenergic antagonists (timolol, betaxolol), carbonic anhydrase inhibitors (dorzolamide, brinzolamide and acetazolamide), alpha2-adrenergic agonists (brimonidine, apraclonidine) and hypotensive lipids (bimatoprost, latanoprost, travoprost). They have a different pharmacokinetic and pharmacodynamic profile. Moreover, they differ in IOP lowering effects and adverse events.

\section{Public health impact}

Glaucoma is the second leading cause of world-wide blindness. ${ }^{21}$ It has been estimated that there will be 60.5 million people with glaucoma in 2010 , increasing to 79.6 million by $2020,74 \%$ of whom will have POAG. Bilateral blindness will be present in 4.5 million people with POAG in 2010, rising to 5.9 million people in $2020 .^{21}$ Because of the health, social, and economic consequences of blindness, adequate glaucoma management is not only a concern of patients and their physicians, but of the entire society. ${ }^{15}$

\section{Early detection and treatment}

As stated above, glaucoma is a slowly progressive disease without symptoms during a long time period. Glaucoma is a good candidate for early detection and 
treatment. The disease can be diagnosed without much burden for the patient and effective treatment exists. Moreover, preventive treatment of ocular hypertension is an option to reduce glaucoma blindness.

\section{Methodology}

The goal of the study presented in this thesis is to explore the clinical effects and cost-effectiveness of current $\mathrm{OH}$ and POAG management and to provide relevant information for clinically and socially important decisions regarding early detection and treatment of $\mathrm{OH}$ and POAG. In the studies different methodology tools are used. A systematic review of literature of clinical trials with a meta-analysis is used to evaluate the effect on the risk of conversion to glaucoma of medical IOP lowering in $\mathrm{OH}$ patients. A case-referent study was designed to study the impact of early detection on the prevention of glaucoma blindness. Simulation models, in which the clinical experience of glaucoma specialists and the currently available scientific evidence are combined, estimate the long-term health-effectiveness. Finally, the principles of cost-effectiveness analysis are applied for an evaluation of different strategies for $\mathrm{OH}$ and POAG management. ${ }^{22}$ For this purpose the corresponding costs have been identified and assigned in the decision models.

In the field of ophthalmology the use of modeling techniques and the methods of cost-effectiveness evaluation are increasingly applied. It is common that an economic evaluation is formulated in terms of a choice between competing alternatives. The basic tasks of any economic evaluation are to identify, measure, value, and compare the costs and consequences of the alternatives being considered. ${ }^{22}$ In a health economic assessment it is of importance that all costs related to detection, treatment, and management of the disease, as well as the outcomes of treatment, are taken into account. ${ }^{23}$ When all relevant costs and all outcomes, including adverse events and treatment failures, are properly included in the evaluation, a seemingly expensive treatment strategy might ultimately turn out to be less costly than a seemingly less expensive alternative. Specific for the cost expenditure in glaucoma is that costs are being spent in advance, while health benefits predominantly occur in the long term. Long-term data are required to estimate therapy effects. Such data are, however, difficult to obtain. Clinical trials mostly have a limited follow-up and are guided by a strict protocol, so they do not give a true reflection of patient management in clinical practice. A combination of these data with observational clinical data might be a better approach to this problem. Modeling allows to combine data from different sources, such as data sets, the literature, systematic reviews or even expert opinion in a meaningful way. Models allow real life situations to be represented in a mathematical or statistical way. A wide range of diagnostic and treatment scenarios can be investigated by varying the influential factors. Moreover, real life situations can be simulated to avoid placing individuals at risk and long-term progression can be studied in limited time. Mathematical modeling is used widely in economic evaluation of pharmaceutical and health care technologies. ${ }^{24}$ Such models, often complex, deal with structural assumptions and parameter estimates. 
To provide modellers with scientific guidelines, the International Society for Pharmacoeconomics and Outcomes Research (ISPOR) has recommended criteria for assessing the quality of models, addressing model structure, the data used as input, and model validation. ${ }^{24}$ The models presented in this thesis comply with these criteria.

The decision analyses in this thesis are based on state-transition Markov models. A Markov model is a useful tool when a decision problem involves recurrent events and risk that is continuous over time. A Markov model is comprised of a set of mutually exclusive and collectively exhaustive health states. ${ }^{25}$ Health states may be defined according to disease stages, treatment status, or a combination of the two. The events are represented in the model as transitions from one state to another. The members of a hypothetical population are allocated and subsequently repeatedly reallocated into these health states. The reallocation happens at fixed time intervals, known as the Markov cycle length according to the defined transition probabilities. For instance, with a known yearly probability for patients to develop a disease, yearly transitions of patients from a health state 'well' to a health state 'ill' can be simulated. Likewise, progression from an early stage to an advanced stage of a disease can be modelled. These transitions may differ per strategy. Transition probabilities will often be different for untreated patients compared to patients under treatment. To each health state specific values can be assigned, such as costs, associated with the required health care related to the particular state. The transitions are repeatedly simulated over a chosen time period. The distribution of the population over the health states per cycle determines the quantity of the accumulated costs. The defined health outcomes and the total cost expenditure over the modelled time period can be identified per modelled strategy and compared.

In Figure 1 a hypothetical example of a Markov model is given. In this example a conversion to a disease and the disease progression over time are modelled. Transitions to a health state 'dead' are incorporated as well. The health state 'dead' is an absorbing state, from where no more transitions are possible, in contradiction to the other health states. From the state 'well' transitions to the states 'early stage of illness' and 'dead' are possible, which models healthy individuals becoming ill or dying. In the given example the mortality rate is illness dependent, but it is independent of age and gender. In contrast, in two models in this thesis the mortality rate does depend on age and gender, but it is not connected to glaucoma. In those models the mortality rate is increasing with each cycle as the simulated population is becoming older. 

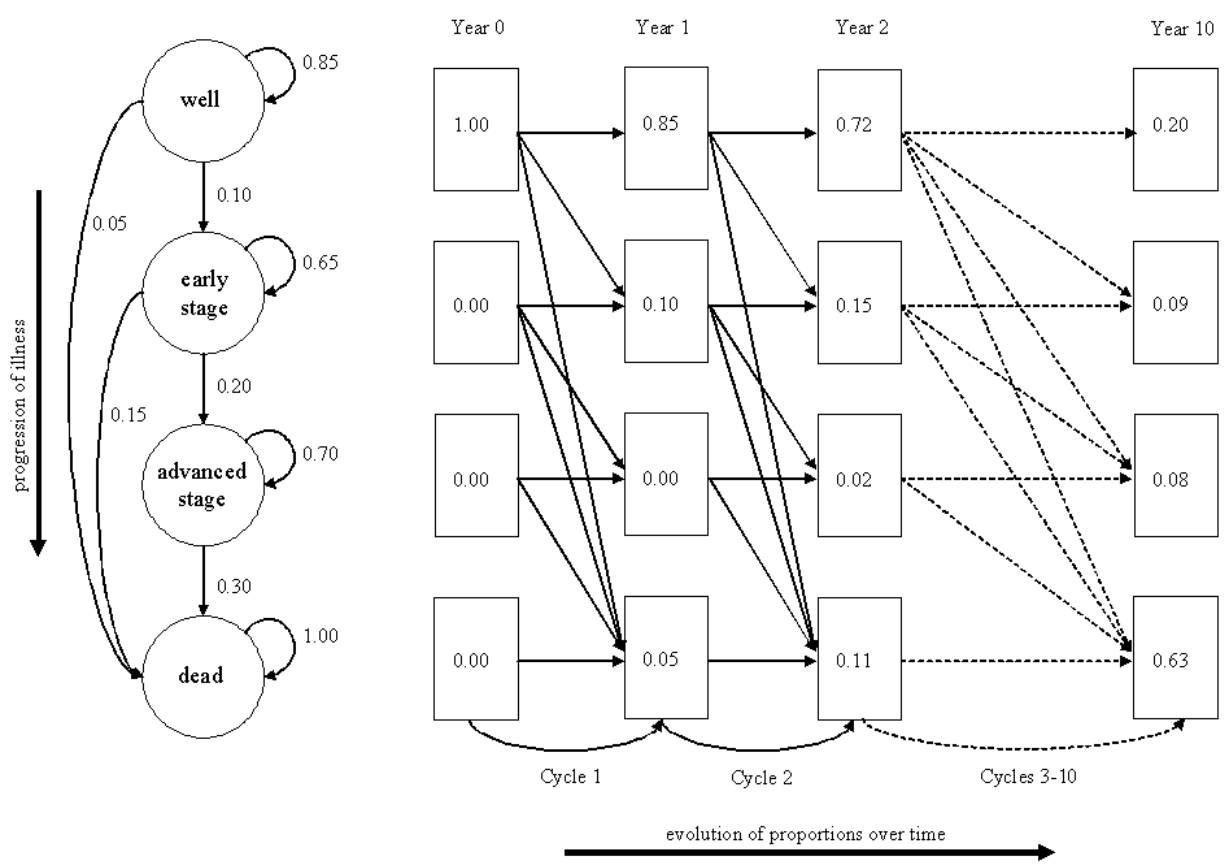

Figure 1: On the left: Representation of a Markov model, as a flowchart, with four health-states: 'well', 'early stage of illness', 'advanced stage of illness', and 'dead', shown as circles. Possible state transitions are indicated by arrows, labelled with yearly transition probabilities. On the right: The proportion of the population in each state at the beginning of a cycle and the change of this proportion over time is shown. Initially, the entire population is situated in the state 'well'. The distribution of patients among the health states in the subsequent cycles is determined by their distribution in the previous cycles and the transition probabilities between the states.

In the models presented in this thesis a decision tree structure is incorporated as well. This is used to model events which occur once only, like diagnosing of patients, or adjustments of medication after the initiation of therapy. In a decision tree the sequence of chance events and decisions over time is represented. ${ }^{26}$ Each chance event is assigned a probability. Each path in the decision tree represents one possible sequence of chance and decision events.

\section{Outline of the thesis}

The feasibility of screening for glaucoma is a subject of a currently ongoing debate among ophthalmologists and health decision makers. ${ }^{27}$ This is a complex problem and despite the recent advances in the diagnosis and treatment of glaucoma it is uncertain if glaucoma screening can be effectively and reliably achieved. ${ }^{28}$ This thesis is directed to investigate issues connected to the early detection and treatment of ocular hypertension and glaucoma. 
One of the puzzling controversies in glaucoma management is whether ocular hypertension should be treated or not, considering a different susceptibility of patients to tolerate high intraocular pressures and the uncertain rate of conversion to glaucoma and progression to blindness in treated and untreated patients. ${ }^{11}$ We have estimated the effect of treatment on the conversion to glaucoma in patients with ocular hypertension and its progression in patients with early glaucoma through a systematic review of randomized clinical trials. This is described in Chapter 2. The results of this study help to decide whether patients with $\mathrm{OH}$ or early POAG should be treated.

The impact of early detection and subsequent treatment of $\mathrm{OH}$ or POAG on the occurrence of blindness has not been explicitly assessed in the literature. If treatment initiated at an early stage of the disease can prevent the progression to blindness one would expect that patients who did become blind due to glaucoma have not been diagnosed in time. These issues are investigated in a case-referent study, described in Chapter 3. The results of this study help to decide whether tests to detect $\mathrm{OH}$ and POAG at an early stage should be applied by ophthalmologists.

A realistic alternative for screening to discover and treat $\mathrm{OH}$ and POAG at an early stage is case-finding among patients visiting an ophthalmologist. Even though casefinding strategies are currently being applied by most ophthalmologists, the effects of such strategies to prevent glaucoma blindness are unknown. In Chapter 4 a costeffectiveness evaluation of different case-finding strategies is given. A simulation model is used to compare the lifetime costs and effects of three different strategies. The results of this study help to decide which case-finding strategy should be applied by an ophthalmologist.

The emergence of new types of glaucoma drugs in the past years has offered better opportunities to medically treat patients but also caused a substantial rise of the therapy costs. ${ }^{29-31}$ A broad spectrum of available drugs, which differ in costs and effects, which may or may not cause side-effects, which may also be combined, allows for a large variety of possible treatment strategies. In practice such strategies involve the use of target pressures, which are different for POAG and $\mathrm{OH}$. In order to make progress in investigating optimal treatment strategies for $\mathrm{OH}$, we here study the question of which drug should be used as a first treatment choice. In Chapters 5 and 6 an evaluation of two different strategies for the initiation of $\mathrm{OH}$ therapy by means of a simulation model is given. Initiation of $\mathrm{OH}$ therapy with a new topical agent (latanoprost) is compared to initiation by a beta-blocker (timolol). The short and long-term clinical consequences of these two strategies are described in detail in Chapter 5. In Chapter 6 a cost-effectiveness analysis of these two strategies is presented. The results of these studies help ophthalmologists to decide which initial $\mathrm{OH}$ medication therapy to apply.

Finally, in Chapter 7 the findings of this thesis are discussed and recommendations for further research are given. 


\section{References}

1 Liesegang TJ, Skuta GL, Cantor LB, editors. Glaucoma. Basic and Clinical Science Course 2003-2004. San Francisco: American Academy of Ophthalmology; 2003.

2 Gordon MO, Beiser JA, Brandt JD, et al. The Ocular Hypertension Treatment Study: baseline factors that predict the onset of primary open-angle glaucoma. Archives of ophthalmology 2002; 120:714-20.

3 Kamal D, Garway Heath D, Ruben S, et al. Results of the betaxolol versus placebo treatment trial in ocular hypertension. Graefe's archive for clinical and experimental ophthalmology; Albrecht von Graefes Archiv fur klinische und experimentelle Ophthalmologie 2003; 241:196-203.

4 Kass MA, Gordon MO, Hoff MR, et al. Topical timolol administration reduces the incidence of glaucomatous damage in ocular hypertensive individuals. A randomized, double-masked, long-term clinical trial. Archives of ophthalmology 1989; 107:1590-8.

5 Schulzer M, Drance SM, Douglas GR. A comparison of treated and untreated glaucoma suspects. Ophthalmology 1991; 98:301-7.

6 Hovding G, Aasved H. Prognostic factors in the development of manifest open angle glaucoma. A longterm follow-up study of hypertensive and normotensive eyes. Acta ophthalmologica 1986; 64:601-8.

7 Kass MA, Heuer DK, Higginbotham EJ, et al. The Ocular Hypertension Treatment Study: a randomized trial determines that topical ocular hypotensive medication delays or prevents the onset of primary openangle glaucoma. Archives of ophthalmology 2002;120(6):701-13.

8 Dielemans I, Vingerling JR, Wolfs RC, et al. The prevalence of primary open-angle glaucoma in a population-based study in The Netherlands. The Rotterdam Study. Ophthalmology 1994;101(11):1851-5.

9 Bonomi L, Marchini G, Marraffa M, et al. Prevalence of glaucoma and intraocular pressure distribution in a defined population. The Egna-Neumarkt Study. Ophthalmology 1998;105(2):209-15.

10 Giuffre G, Giammanco R, Dardanoni G, Ponte F. Prevalence of glaucoma and distribution of intraocular pressure in a population. The Casteldaccia Eye Study. 1995;73(3):222-5.

11 American Academy of Ophthalmology Glaucoma Panel. Preferred Practice Pattern. Primary Open-Angle Glaucoma. San Francisco, CA: American Academy of Ophthalmology; 2005. Available at: www.aao.org/ppp.

12 Hollows FC, Graham PA. Intra-ocular pressure, glaucoma, and glaucoma suspects in a defined population. British journal of ophthalmology, The 1966;50(10):570-86.

13 Leske MC, Ederer F, Podgor M. Estimating incidence from age-specific prevalence in glaucoma. American Journal of Epidemiology 1981; 113: 606-613.

14 American Academy of Ophthalmology Glaucoma Panel. Preferred Practice Pattern. Primary Open-angle Glaucoma. San Francisco, CA: American Academy of Ophthalmology; 2000.

15 Coleman AL. Glaucoma. Lancet 1999;354(9192):1803-10.

16 Tielsch JM, Sommer A, Katz J, et al. Racial variations in the prevalence of primary open-angle glaucoma. The Baltimore Eye Survey. JAMA the journal of the American Medical Association 1991;266(3):369-74.

17 Kwon YH, Kim CS, Zimmerman MB, et al. Rate of visual field loss and long-term visual outcome in primary open-angle glaucoma. American journal of ophthalmology 2001;132(1):47-56.

18 Chen PP. Blindness in patients with treated open-angle glaucoma. Ophthalmology 2003;110(4):726-33.

19 Quigley HA. Proportion of those with open-angle glaucoma who become blind. Ophthalmology 1999;106(11):2039-41

20 Jay JL, Murdoch JR. The rate of visual field loss in untreated primary open angle glaucoma. The British journal of ophthalmology, 1993;77(3):176-8.

21 Quigley HA, Broman AT. The number of people with glaucoma worldwide in 2010 and 2020. British Journal of Ophthalmology 2006;90:262-267; doi:10.1136/bjo.2005.081224

22 Drummond MF, O'Brien BJ, Stoddart GL, Torrance GW. Methods for the Economic Evaluation of Health Care Programmes, 2nd ed. Oxford: Oxford University Press, 1997.

23 Kobelt G. Health economics, economic evaluation, and glaucoma. Journal of glaucoma 2002;11(6):531-9.

24 Weinstein MC, O'Brien B, Hornberger J, et al. Principles of Good Practice for Decision Analytic Modeling in Health-Care Evaluation: Report of the ISPOR Task Force on Good Research Practices Modeling Studies. Value in Health 2003; 6(1):9-17.

25 Drummond MF, McGuire AL. Economic evaluation in health care: merging theory with practice. Oxford University press;2001.

26 Gold MR, Siegel JE, Russel LB, et al. Cost-effectiveness in Health and Medicine. First press release. New York: Oxford University Press; 1996.

27 Nduaguba C, Lee RK. Glaucoma screening: current trends, economic issues, technology, and challenges. Current opinion in ophthalmology 2006;17(2):142-52. 


\section{Chapter 1}

28 Harasymowycz P, Kamdeu Fansi A, Papamatheakis D. Screening for primary open-angle glaucoma in the developed world: are we there yet? Canadian journal of ophthalmology; Journal canadien d'ophtalmologie 2005;40(4):477-86.

29 Knox FA, Barry M, McGowan B, O'Brien C. The rising cost of glaucoma drugs in Ireland 1996-2003. British journal of ophthalmology 2006;90(2):162-5.

30 Azuara Blanco A, Burr J. The rising cost of glaucoma drugs. British journal of ophthalmology 2006;90(2):130-1.

31 De Natale R, Draghi E, Dorigo MT. How prostaglandins have changed the medical approach to glaucoma and its costs: an observational study of 2228 patients treated with glaucoma medications. Acta ophthalmologica Scandinavica 2004;82(4):393-6. 


\section{2.}

\section{Quantifying the effect of the reduction of intraocular pressure on the occurrence and progression of glaucoma}

Andrea Peeters ${ }^{1}$

Jan S.A.G. Schouten ${ }^{1}$

Carroll A.B. Webers ${ }^{1}$

Maurice P. Zeegers ${ }^{2,3}$

Fred Hendrikse ${ }^{1}$

Martin H. Prins 4,5

1 Department of Ophthalmology, Maastricht University Hospital, Maastricht, The Netherlands 2 Unit of Genetic Epidemiology, Department of Public Health and Epidemiology, University of Birmingham, United Kingdom

3 Department of General Practice, Catholic University of Leuven, Belgium 4 Department of Epidemiology, Maastricht University, Maastricht, The Netherlands 5 Department of Clinical Epidemiology and Medical Technology Assessment, Maastricht University Hospital, Maastricht, The Netherlands

Submitted for publication 


\begin{abstract}
Objective: To estimate the effect of IOP lowering therapy on the incidence of primary open-angle glaucoma (POAG) in patients with ocular hypertension $(\mathrm{OH})$ and on the progression in patients with glaucoma.

Design: Meta-analysis of randomized controlled trials.

Participants: Nine articles which included $\mathrm{OH}$ patients and one article which included early glaucoma patients.

Methods: An electronic search of the databases Medline, Embase and the Cochrane Register of Controlled Trials was conducted to identify articles for inclusion. The inclusion criteria were: articles written in English, French, German or Dutch; trials in $\mathrm{OH}$ or POAG; a randomized comparison of intraocular pressure (IOP) lowering intervention versus placebo or no treatment; visual field loss or optic disc changes as outcome; follow-up longer than 6 months. The methodological quality of the selected studies was evaluated by criteria of the Delphi list and the Cochrane Collaboration. In a meta-analysis performed for $\mathrm{OH}$ trials a pooled relative risk was calculated using a 'random effects model'. A meta-regression analysis was performed to assess the magnitude of the glaucoma risk reduction in $\mathrm{OH}$ patients per $\mathrm{mm} \mathrm{Hg}$ of IOP reduction achieved through therapy.
\end{abstract}

Outcome measures: Conversion to glaucoma or its progression.

Results: The search resulted in nine $\mathrm{OH}$ trials and one POAG trial, which met the inclusion criteria. All individual $\mathrm{OH}$ studies show a positive effect of IOP lowering on a reduction of the incidence rate of glaucoma. The calculated pooled relative risk is 0.61 (95\% confidence interval $0.45-0.83)$. A meta-regression model shows a decrease of the relative risk of conversion to glaucoma by $14 \%$ with each $\mathrm{mm} \mathrm{Hg}$ of extra IOP reduction $(\mathrm{p}=0.045)$. The only trial, which included glaucoma patients, shows a protective effect of hypotensive therapy in early glaucoma.

Conclusions: There is sufficient evidence that IOP lowering therapy in patients with ocular hypertension reduces the risk of conversion to glaucoma. The relative risk decreases more with larger IOP reduction. The protective effect of IOP lowering on glaucoma progression is shown by one trial which included patients with early visual field loss. 


\section{Introduction}

An elevated intraocular pressure (IOP) is an important risk factor for a conversion to glaucoma in patients with ocular hypertension $(\mathrm{OH})$ and a prognostic factor in patients with primary open-angle glaucoma (POAG). ${ }^{1}$ Medication, laser and surgery are used to lower the IOP. The final goal of therapy is to prevent or delay damage to the optic nerve and thereby to prevent functional limitations and blindness.

In the past, trials have been carried out which show that lowering the IOP in patients with glaucoma is beneficial for the prevention of severe visual field loss and the usefulness of glaucoma treatment is not questioned. ${ }^{2-6}$ In these trials a comparison is made between different types of hypotensive treatment. The effect of treatment versus no treatment is particularly of interest for $\mathrm{OH}$ patients and patients with early glaucoma. The susceptibility of the optic nerve to IOP-related damage varies among individuals and for many patients treatment may not be considered necessary.

The efficacy of early detection and treatment in connection with prevention of advanced stages of glaucoma with severe visual loss or blindness is closely associated with the effectiveness of treatment of $\mathrm{OH}$ and early POAG. A level of IOP achieved by treatment plays a role in this as well. In the current glaucoma management an ophthalmologist strives to achieve for each patient an IOP level by which protection against optic nerve damage is achieved. The estimated upper limit of such IOP level is considered 'target pressure'. For $\mathrm{OH}$ patients a target pressure may be viewed as a threshold recommended for initiation of treatment. ${ }^{7}$ Therefore, it is of interest to investigate to what extent a larger IOP reduction in $\mathrm{OH}$ patients influences the risk of conversion to glaucoma.

In the present study the currently available scientific evidence concerning the benefit of treatment in $\mathrm{OH}$ and early glaucoma is systematically analysed. A quantification of the effect of IOP lowering in $\mathrm{OH}$ patients on the occurrence of glaucoma is performed by combining data of several comparable randomized controlled trials in a meta-analysis. Nine $\mathrm{OH}$ studies, including two so far largest trials, the Ocular Hypertension Treatment Study (OHTS) ${ }^{8}$ and the European Glaucoma Prevention Study (EGPS) ${ }^{9}$ are included in this meta-analysis. Meta-regression analysis based on the outcomes of these nine $\mathrm{OH}$ trials determines the magnitude of risk reduction of conversion of $\mathrm{OH}$ to glaucoma per each extra $\mathrm{mm} \mathrm{Hg}$ of IOP reduction achieved through therapy.

\section{Methods}

\section{Search strategy}

Articles describing randomized controlled trials (RCT's) on treatment of patients with ocular hypertension or primary open-angle glaucoma were identified through a systematic search in the databases Medline, Embase, and the Cochrane Register of 
Controlled Trials. For search in Medline the modified version, advised by the Cochrane Handbook, of the published search strategy of Dickersin was used. ${ }^{10}$ For search in Embase a strategy of Tulder et al was applied. ${ }^{11}$

Keywords in connection with the disease were: "glaucoma" and "ocular hypertension". Keywords in connection with the study outcome were: "visual field", "dB", "Humphreys", "Friedman" and "perimetr*". The 'thesaurus' of the databases and the 'explode' option were utilized. The original search of the databases was done until February 2004, but recently the search was updated. Subsequently the reference lists of the selected articles and of two meta-analysis articles ${ }^{12,13}$ were consulted until no further studies could be found. Also the result of a search conducted in connection with a meta-analysis performed earlier by the authors was checked. ${ }^{14}$

\section{Selection of the studies; inclusion criteria}

Two researches (JS and AP) selected independently potential articles to be included in the meta-analysis. By viewing the title, abstract and the medical subject heading $(\mathrm{MeSH})$ of the articles, a first judgement of the eligibility was done. The potentially eligible publications were printed or photocopied for further evaluation. All selected articles had to fulfil the following inclusion criteria: 1) language: English, French, German or Dutch; 2) disease in question: $\mathrm{OH}$ or POAG; 3) randomized comparison: IOP lowering intervention versus placebo or no treatment; 4) study outcomes: visual field loss or optic disc changes; 5) follow-up longer than 6 months.

\section{Quality Assessment and Data Abstraction}

Methodological quality of the selected studies was evaluated by the criteria for evaluation of RCT's recommended by the Delphi list, ${ }^{15}$ the Cochrane Collaboration and criteria added by the authors (see Table 1). The quality items used for the quality assessment are given in Table 1. Two researchers (JS and AP) assessed the quality, independently. In case of different opinion a discussion followed until consensus was reached. For each trial several quality items, as shown in Table 1, were noted. Based on these trial features the quality of each study was rated. If an article qualified for an item, one point was given. The maximum quality score was 16. Next, the following data were collected on a standardized record form: number of patients, nature of the disease, interventions, nature of the study outcomes, methods for evaluating the optic disc and the visual field, mean pre- and post treatment IOP per trial arm or the change in IOP from baseline, and the incidence of glaucoma or its progression. 
Table 1: Quality items included for the quality assessment, source of the quality item, and number of publications with a positive quality score per item in 10 trials identified in the systematic review

\begin{tabular}{|c|c|c|c|}
\hline $\begin{array}{l}\text { Item } \\
\text { code }\end{array}$ & Source & Quality item & $\begin{array}{c}\text { No. of } \\
\text { publications scored } \\
\text { 'yes'* }\end{array}$ \\
\hline$\overline{\mathrm{A}}$ & Delphi list ${ }^{15}$ & Was the randomization procedure concealed? & 5 \\
\hline B & Delphi list & Were eligibility criteria specified? & 9 \\
\hline $\mathrm{C}$ & Delphi list & Was the patient blinded? & 4 \\
\hline $\mathrm{D}$ & Delphi list & Was the care provider blinded? & 4 \\
\hline E & Delphi list & Was the outcome assessor blinded? & 8 \\
\hline $\mathrm{F}$ & Delphi list & $\begin{array}{l}\text { Were the groups similar at baseline regarding the } \\
\text { most important prognostic indicators? }\end{array}$ & 8 \\
\hline G & Cochrane Collaboration & Was there a selective loss to follow-up? & 3 \\
\hline $\mathrm{H}$ & Delphi list & $\begin{array}{l}\text { Did the analysis include an intention-to-treat analy- } \\
\text { sis? }\end{array}$ & 10 \\
\hline I & Cochrane Collaboration & Were other interventions comparable? & 4 \\
\hline $\mathrm{J}$ & Considered for Delphi list & $\begin{array}{l}\text { Is it unlikely that compliance may explain differences } \\
\text { between groups? }\end{array}$ & 0 \\
\hline K & Delphi list & $\begin{array}{l}\text { Were point estimates and measures of variability } \\
\text { presented for the primary outcome measures? }\end{array}$ & 9 \\
\hline $\mathrm{L}$ & Added by authors & Was the follow-up period comparable? & 9 \\
\hline M & Added by authors & Was there an explicit description of intervention? & 10 \\
\hline $\mathrm{N}$ & Added by authors & Was the outcome assessment properly described? & 8 \\
\hline $\mathrm{O}$ & Added by authors & Were side effects reported? & 7 \\
\hline $\mathrm{P}$ & Considered for Delphi list & $\begin{array}{l}\text { Was calculation of statistical power reported after } \\
\text { treatment allocation? }\end{array}$ & 6 \\
\hline
\end{tabular}

* complementary answers were 'unknown' or 'no'

\section{Data Analysis}

The outcome of interest was defined as the cumulative incidence of glaucoma or its progression. A relative risk per study was calculated: the incidence in the intervention group divided by the incidence in the control group, with its $95 \%$ confidence interval. The relative risks of the individual studies were combined in a metaanalysis and a pooled relative risk was calculated using a 'random effects model' ${ }^{16}$ Heterogeneity was assessed by judging the forest plot and by the Q-test and I2 statistic. ${ }^{17}$ To examine publication bias Egger's measure of publication bias was calculated. $^{18}$

The interpretation of data from one study needs further clarification. In the European Glaucoma Prevention Study (EGPS) there was a major loss to follow-up and patients who reached a safety point (IOP $>35 \mathrm{~mm} \mathrm{Hg}$ ) were excluded from the trial. We assumed that patients lost to follow-up developed glaucoma according to the incidence of the group without treatment. Furthermore, because high IOP is often associated with conversion to glaucoma we considered patients who reached a safety endpoint as having developed glaucoma.

A meta-regression analysis was used to determine the glaucoma risk reduction per $\mathrm{mm} \mathrm{Hg}$ of IOP reduction achieved through therapy. For this purpose the logarithm of the relative risk was modeled, weighted by the inverse of its variance, dependent on the difference in the end IOP. This was defined for each study as the end IOP in the control group minus end IOP in the intervention group $(\mathrm{mm} \mathrm{Hg})$. 
In a sensitivity analysis, the robustness of the findings to different assumptions was examined. Also the impact of an exclusion of trials of poorer quality on the outcome of the meta-analysis was examined. The overall effect was calculated for the studies with a quality score of 10 points or more. An impact of an addition of a study with no treatment effect on the outcome of the meta-analysis was assessed by including a hypothetical study with 4000 patients and a relative risk of 1 . Additionally, meta-analyses were performed with different relative risk values for the EGPS study (the calculations of these values are given in Table 2).

\section{Results}

4109 articles were identified. After screening the articles by title and abstract 1422 papers remained. From these finally, nine trials in $\mathrm{OH}$ patients and one trial in glaucoma patients met the inclusion criteria and were selected. ${ }^{8,9,19-26}$ (see Figure 1). Results from the $\mathrm{OH}$ trials were pooled in a meta-analysis. In Table 2 the basic characteristics of the selected studies and the quality score for each study are shown. Five $\mathrm{OH}$ trials and the glaucoma study had a score above 10 (maximum score was 16). These were also the largest and the most recent studies. There was no indication for significant heterogeneity between the studies $(\mathrm{Q}=15.19(\mathrm{P}=$ $0.085), \mathrm{I} 2=47 \%$ ). Nor was there an indication for presence of a publication bias, the P value of Eager's measure of publication bias was 0.31. Figure 2 gives the results of the meta-analysis. As seen in this figure, all individual studies in ocular hypertension showed a positive effect of IOP lowering by glaucoma medication on a reduction of the incidence rate of glaucoma. The calculated pooled relative risk is 0.61 (95\% CI $0.45-0.83)$. The $95 \%$ confidence intervals of the studies include the overall effect estimate.

According to the meta-regression model there is a relationship between the difference in end IOP in the control group and the intervention group and the risk of conversion to glaucoma (see Figure 3). The relative risk of conversion to glaucoma decreases with an increase in difference in the achieved IOP reduction between the control group and the intervention group. With each $\mathrm{mm} \mathrm{Hg}$ difference of the end IOP the relative risk of conversion to glaucoma decreases with $14 \%$.

The Early Manifest Glaucoma Trial (EMGT) showed that lowering the IOP is beneficial in slowing glaucoma progression. When the cumulative incidence was calculated after 48 months, the relative risk was 0.61 (95\% CI $0.45-0.84)$. When calculations were made after a median follow-up of 6 years, the relative risk was 0.73 (95\% CI 0.57-0.92). 
Figure 1: Flowchart of the selection of the studies

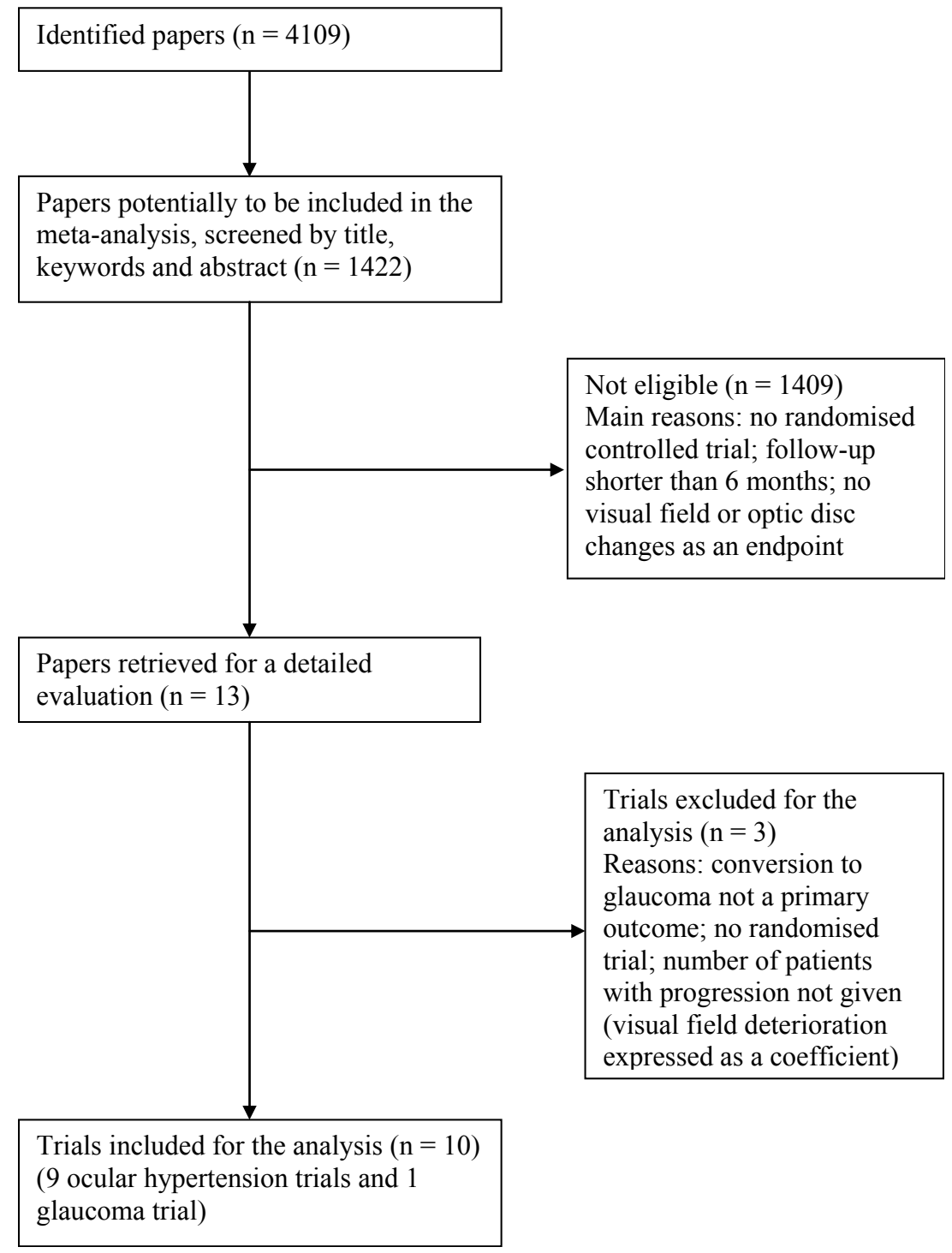

\section{Sensitivity analysis}

The calculations of the overall effect in the meta-analysis by the random and fixed effects models showed no substantial difference. The pooled relative risk calculated by the 'random effects model' was $0.61(95 \%$ CI $0.45-0.83)$ whereas by the 'fixed effects model' this was 0.65 (95\% CI $0.54-0.78)$. When only studies with a quality score higher than 10 (points) were included, the pooled relative risk was 0.63 (95\% 
CI 0.43-0.90). Inclusion of a hypothetical study, showing no treatment effect, in the meta-analysis did not change its conclusions. When a hypothetical study with 4000 patients, a relative risk 1 , and an assumed glaucoma incidence of $10 \%$ was added, the pooled relative risk remained below 1 , namely 0.80 (95\% CI 0.71-0.92). Calculations of the overall effect with the higher value for the relative risk of the EGPS study did not influence the conclusions of the meta-analysis. An analysis with a 0.93 value (see Table 2 ) gave a pooled relative risk of 0.62 (95\% CI $0.44-0.87)$. The value of 0.77 (see Table 2) gave a pooled relative risk of 0.60 (95\% CI 0.45-0.80).

Figure 2: Meta-analysis of the relative risks of the nine ocular hypertension trials

Forest plot

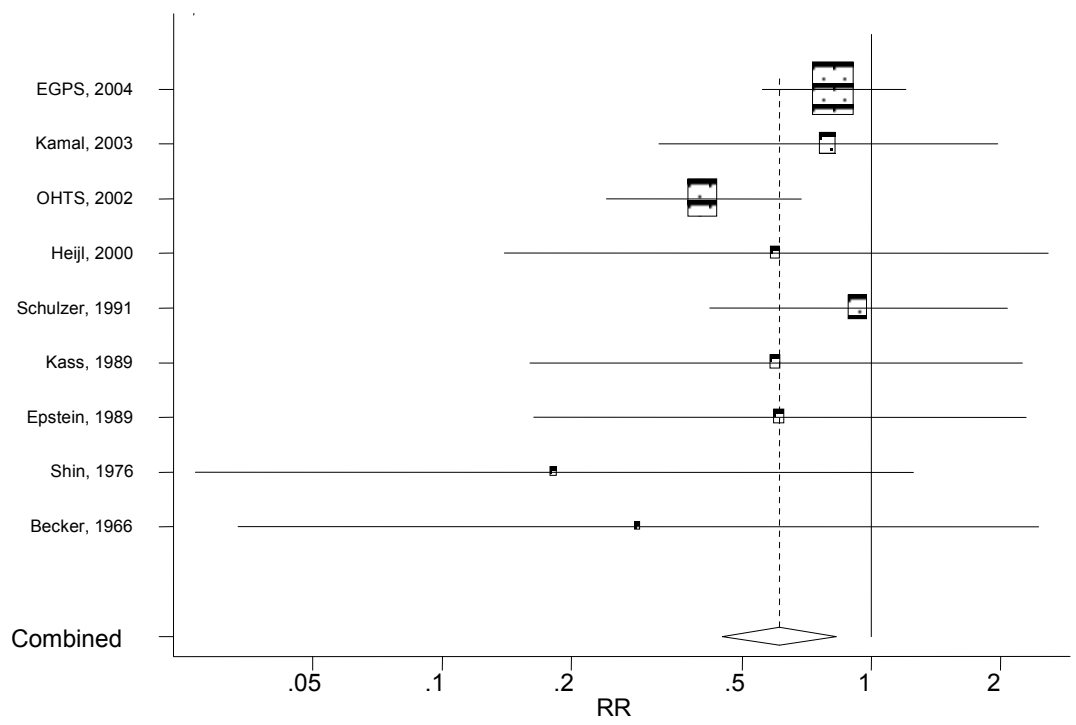

Pooled relative risk: $\mathrm{RR}=0.61(95 \% \mathrm{CI} 0.45-0.83) ; \mathrm{Q}=15.19, \mathrm{P}=0.085 ; \mathrm{I} 2=47 \%$; p-publication bias 0.313 The square and the horizontal line for each study correspond to the point estimate and a $95 \%$ confidence interval. The area of the square reflects the weight of the study in the meta-analysis. The solid vertical line through $\mathrm{RR}=1$ corresponds to no effect of treatment. The diamond represents the pooled relative risk with $95 \%$ confidence interval.

EGPS = European Glaucoma Prevention Study; OHTS = Ocular Hypertension Treatment Study 


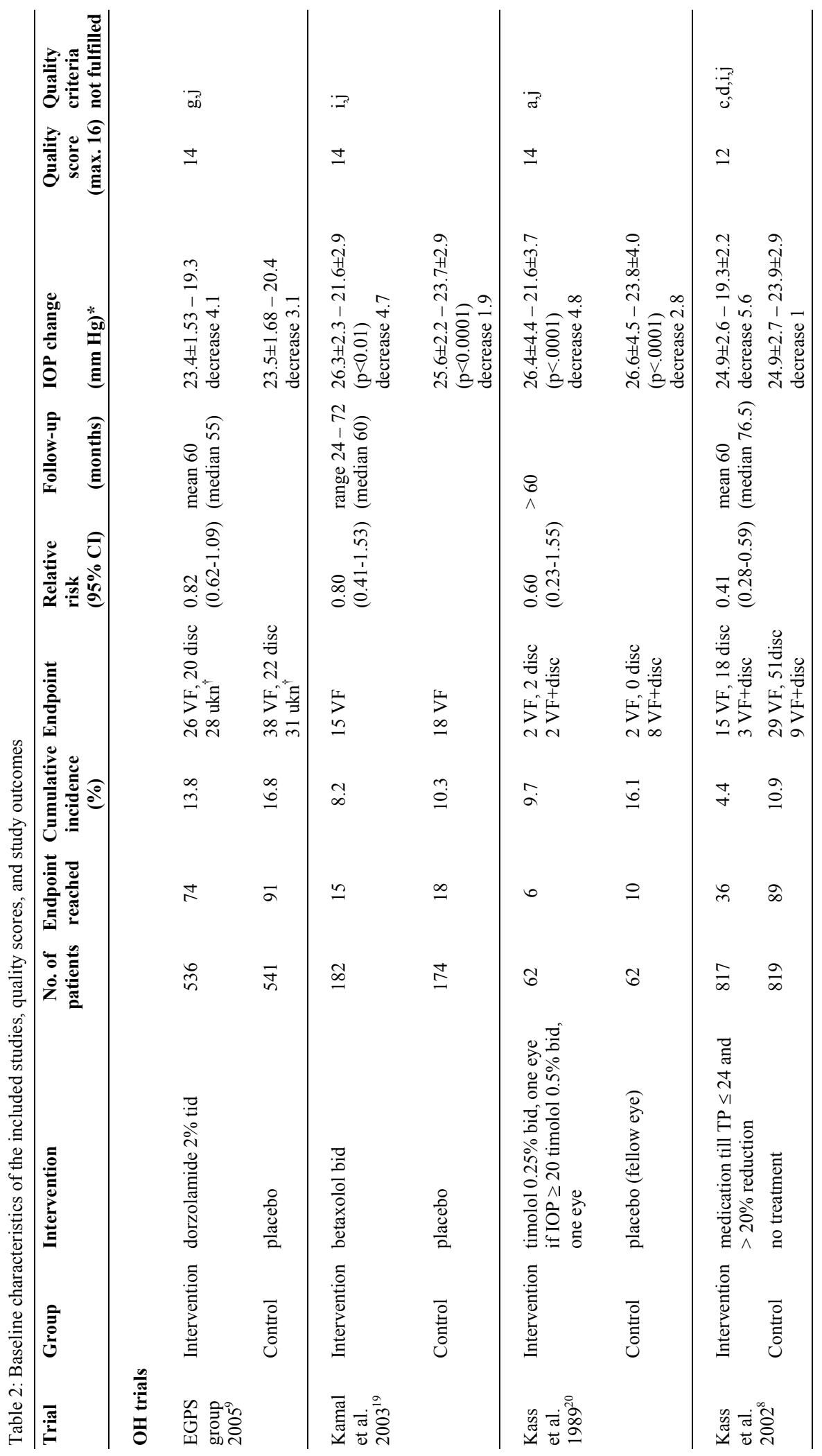




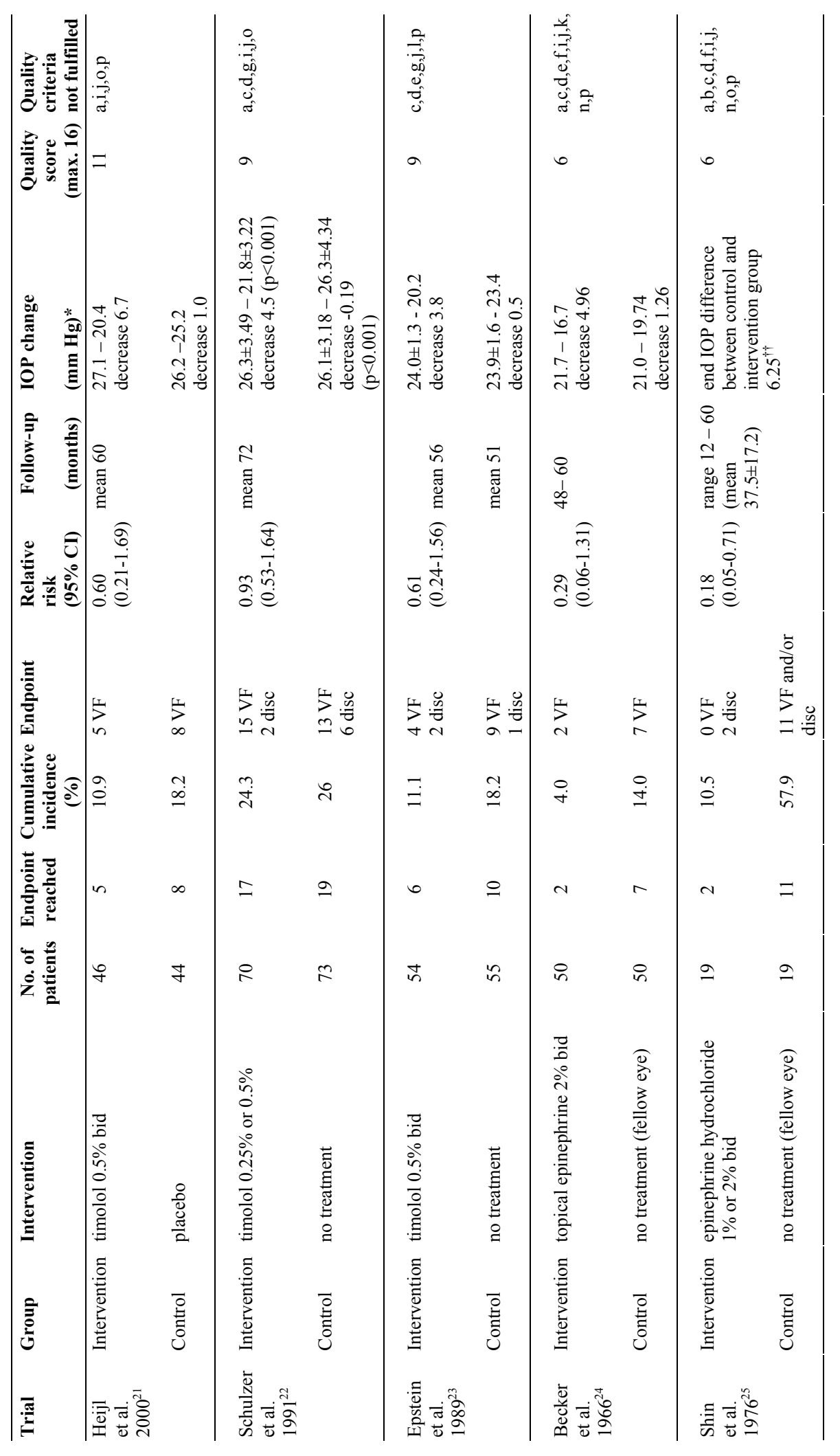




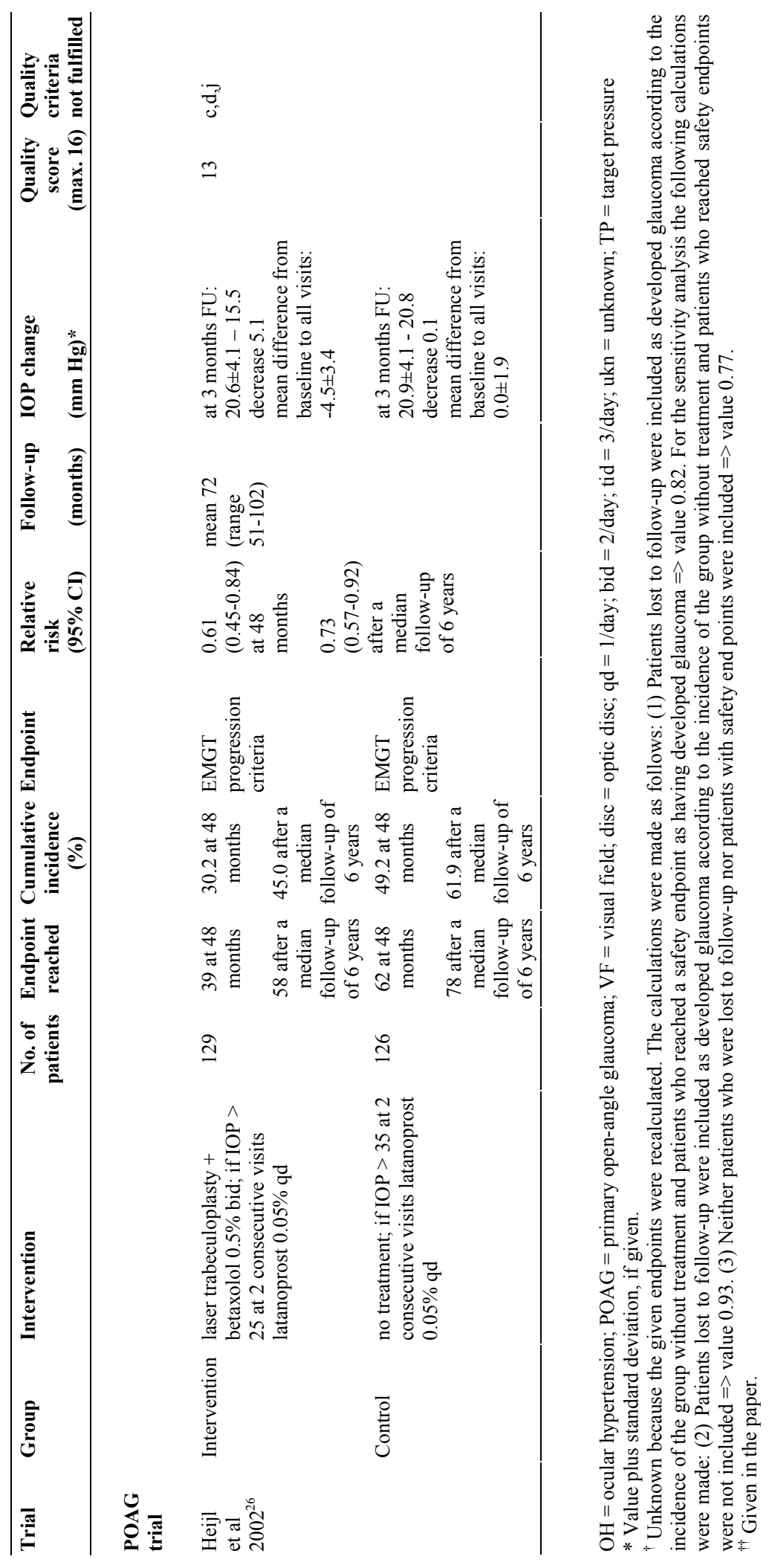


Figure 3: Meta-regression analysis of the relative risks of the nine ocular hypertension trials, carried out in the logarithmic domain, dependent on the end intraocular pressure (IOP) difference between the control and the intervention group

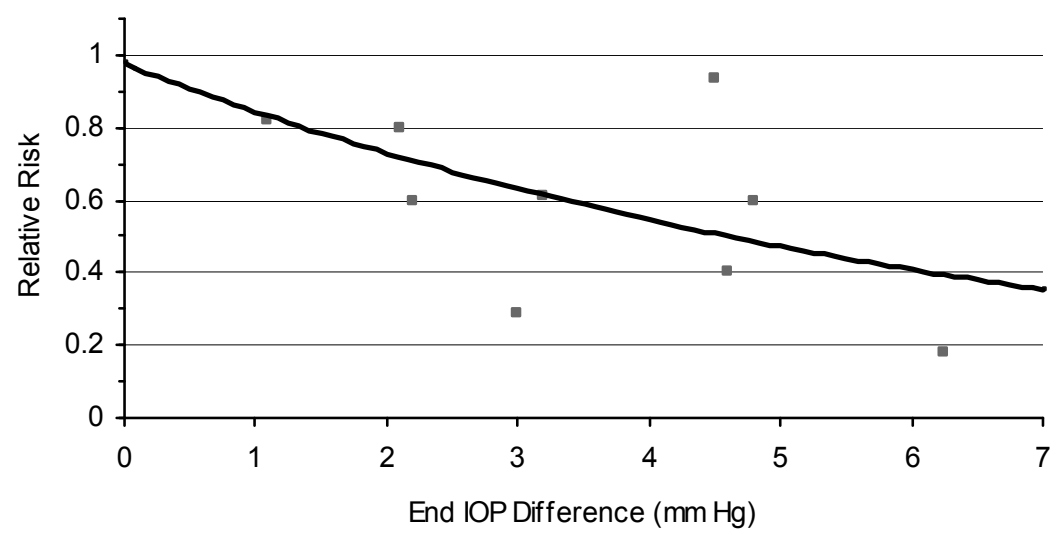

p-interaction: $0.045 ; \log R R=-0.025-0.15$ "End IOP Difference"

\section{Discussion}

Our analysis shows that IOP lowering reduces the risk of glaucoma and also that a larger lowering of IOP is associated with a greater reduction of this risk. All studies included in the meta-analysis showed a beneficial effect of an IOP lowering therapy. The computed pooled relative risk was 0.61 (95\% CI 0.45-0.83). The relative risks were calculated from the cumulative incidence. All studies had a follow-up up to 5-6 years. The meta-regression model showed that the relative risk of conversion to glaucoma decreases by $14 \%$ with each $\mathrm{mm} \mathrm{Hg}$ of IOP reduction achieved through therapy.

The protective effect of pressure lowering treatment is consistent with the outcomes of a recently published meta-analysis performed by Maier et al. ${ }^{27}$ The authors of this study performed a meta-analysis of time to event data and the computed hazard ratio in this study is 0.56 (95\% CI $0.39-0.81)$. However, Maier et al. included only five $\mathrm{OH}$ trials in their analysis. In the present meta-analysis four more $\mathrm{OH}$ studies were added including the second largest trial in ocular hypertension, the European Glaucoma Prevention Study, the results of which were only published in 2005. Three of the remaining four studies use fellow eye as a control. ${ }^{20,24,25}$ This was an exclusion criterion by Maier et al. In addition, in the present study the outcomes of the nine individual trials were used to carry out a meta-regression analysis to relate the size of IOP reduction to the effect on the conversion to glaucoma.

The present systematic review is based on search of articles in the three most relevant databases (Medline, Embase and Cochrane). The validity of the search is 
corroborated by the search results of Maier et al., who identified the same articles. The meta-analysis was performed for the $\mathrm{OH}$ trials. We have identified one trial only which included glaucoma patients, the Early Manifest Glaucoma Trial. We did not search for normal pressure glaucoma, considering the possible different pathogenesis of the normal- and high-pressure glaucoma, and a different therapy response. It must be noted that a proportion of patients in the EMGT study had normal pressure glaucoma, however, the subgroup analysis of the patients showed a protective effect of IOP lowering particularly for those patients with an increased intraocular pressure. $^{26}$

The trial interventions were limited to the use of topical medication in $\mathrm{OH}$ patients and a combination of topical medication with laser trabeculoplasty in glaucoma patients. As expected, surgery was not included in any of the trials, because it is not a primary treatment option for ocular hypertension or early glaucoma. We did not find any randomized controlled trials comparing treatment with no treatment conducted in patients with advanced glaucoma. This is to be expected, since avoiding treatment in such patients would be ethically inappropriate.

The $\mathrm{OH}$ studies with the most extreme positive outcomes, with the lowest relative risks, are the oldest studies with the lowest quality scores and with least weight in the meta-analysis. In three studies the relative risk was higher than the pooled estimate, but still lower than 1 . The study with a relative risk closest to 1 (done by Schulzer et al.) scored 9 quality points. It included 143 patients. The Ocular Hypertension Treatment Study (OHTS) and the European Glaucoma Prevention Study are the studies with most weight in the meta-analysis. These studies included 1636 and 1077 patients. The OHTS study is the largest study, which showed the effectiveness of reducing the IOP with topical medication in delaying or preventing the onset of POAG with statistical significance $(\mathrm{p}<0.0001)$. The EGPS study failed to do so. This study showed somewhat unexpected results. The difference in IOP reduction between the treatment and control group was only $1 \mathrm{~mm} \mathrm{Hg}$ during the course of the study and the IOP dropped substantially in the control group. As pointed out by Dr. Quigley, three significant differences with the OHTS study may explain the failure of the EGPS study to find a therapy benefit: (1) the use of dorzolamide therapy alone, regardless of IOP lowering with placebo control; (2) a major regression to the mean in IOP at 6 months; (3) selective loss to follow-up of persons with higher IOP. ${ }^{28}$ It should be noted, that the observed, even though non-significant risk reduction in this study, is consistent with the expected effect of a $1 \mathrm{~mm} \mathrm{Hg}$ difference in IOP, according to our meta-regression model.

By viewing the results of the individual studies, most striking are the outcomes of the trial done by Schulzer et al.. In this study, in spite of an end IOP difference of $4.5 \mathrm{~mm} \mathrm{Hg}$, the difference in the glaucoma development between the two trial arms was small $(\mathrm{RR}=0.93(95 \% \mathrm{CI} 0.53-1.64)$ ). It must be noted that glaucoma incidence was very high in this study (see Table 2 ). This could be explained by the fact that the population was at high risk of developing glaucoma. From the included patients $31 \%$ had a positive family history of glaucoma, $20 \%$ had a baseline entry 
pressure of $30 \mathrm{~mm} \mathrm{Hg}$ or greater, and $29 \%$ had a cup-to-disc ratio of 0.5 or greater at entry. The high-risk patients were represented equally in the intervention and control group. Moreover, the mean achieved IOP level in the treated group was 21.8 $\mathrm{mm} \mathrm{Hg}$, which is rather high for the high-risk patients. This study scored 9 quality points. When a separation of the studies into two groups with a quality score less than 10 points and 10 points or more was introduced in the regression model, this did not significantly change the outcomes of the meta-regression ( $p$-interaction = $0.770)$.

The Early Manifest Glaucoma Trial showed a protective effect of immediate treatment, compared with no initial treatment or later treatment, in patients with early glaucoma. This trial included newly diagnosed and previously untreated open-angle glaucoma patients with early visual field loss. When the cumulative incidence was calculated after 48 months, the relative risk was 0.61 (95\% CI $0.45-0.84)$. When calculations were made after a median follow-up of 6 years, the relative risk was 0.73 (95\% CI 0.57-0.92). The authors of the study calculated patient-based risk of progression using a Cox proportional hazard regression model. The calculated hazard ratio after 6 years was 0.50 (95\% CI $0.35-0.71)$. In the trial an initial randomization to treatment or no treatment was maintained only as long as progression did not occur. The study does not include long-term follow-up of untreated patients beyond EMGT progression. The EMGT multivariate analyses showed that the risk decreased about $10 \%$ with each millimeter mercury of IOP reduction from baseline, which seems consistent with the results of our meta-regression. ${ }^{29}$

\section{Conclusion}

There is sufficient scientific evidence that topical hypotensive therapy reduces the risk of conversion to glaucoma in ocular hypertension and a progression of visual field loss in early glaucoma. The evidence is provided by a number of wellconducted randomized controlled trials. Moreover, the risk of conversion to glaucoma in patients with ocular hypertension decreases with approximately $14 \%$ per each $\mathrm{mm} \mathrm{Hg}$ of extra IOP reduction.

\section{References}

1 American Academy of Ophthalmology Glaucoma Panel. Preferred Practice Pattern. Primary Open-Angle Glaucoma. San Francisco, CA: American Academy of Ophthalmology; 2005. Available at: www.aao.org/ppp.

2 Jay JL, Allan D. The benefit of early trabeculectomy versus conventional management in primary open angle glaucoma relative to severity of disease. Eye London, England 1989;3(Pt 5):528-35.

3 Migdal C, Gregory W, Hitchings R. Long-term functional outcome after early surgery compared with laser and medicine in open-angle glaucoma. Ophthalmology 1994;101(10):1651-6.

4 The Glaucoma Laser Trial Research Group. The Glaucoma Laser Trial (GLT). 2. Results of argon laser trabeculoplasty versus topical medicines. Ophthalmology 1990;97(11):1403-13.

5 GLT Research Group. The Glaucoma Laser Trial: 4. Contralateral effects of timolol on the intraocular pressure of eyes treated with ALT. Ophthalmic surgery 1991;22(6):324-9. 
6 The AGIS Investigators. The Advanced Glaucoma Intervention Study (AGIS): 7. The relationship between control of intraocular pressure and visual field deterioration. American journal of ophthalmology 2000;130(4):429-40.

7 American Academy of Ophthalmology Glaucoma Panel. Preferred Practice Pattern. Primary Open-Angle Glaucoma Suspect. San Francisco, CA: American Academy of Ophthalmology; 2005. Available at: www.aao.org/ppp.

8 Kass MA, Heuer DK, Higginbotham EJ, et al. The Ocular Hypertension Treatment Study: a randomized trial determines that topical ocular hypotensive medication delays or prevents the onset of primary openangle glaucoma. Archives of ophthalmology 2002;120(6):701-13.

9 Miglior S, Zeyen T, Pfeiffer N, et al. Results of the European Glaucoma Prevention Study. Ophthalmology ISE: 15494713 2005;112(3):366-75.

10 Dickersin K, Scherer R, Lefebvre C. Identifying relevant studies for systematic reviews. Br Med J 1994;309:1286-1291.

11 Tulder MW van, Assendelft WJ, Koes BW, et al. Method guidelines for systematic reviews in the Cochrane Collaboration Back Review Group for Spinal Disorders. Spine 1997;22(20):2323-2330.

12 Rossetti, L., et al., Randomized clinical trials on medical treatment of glaucoma. Are they appropriate to guide clinical practice? Archives of ophthalmology, 1993. 111(1): p. 96-103.

13 Aguinaga Ontoso, I., et al., Does medical treatment of mild intraocular hypertension prevent glaucoma? European journal of epidemiology, 1997. 13(1): p. 19-23.

14 Van der Valk R, Webers CAB, Schouten JSAG, Zeegers MP, Hendrikse F, Prins MH. Intraocular Pressure-Lowering Effects of All Commonly Used Glaucoma Drugs: A Meta-analysis of Randomized Clinical Trials. Ophthalmology 2005;112:1177-85.

15 Verhagen AP, de Vet HCW, de Bier RA, et al. The Delphi list; a criteria list for quality assessment of Randomized Clinical Trials for conducting systematic reviews developed by Delphi consensus. J Clin Epidemiol 1998;51:1235-1241.

16 Egger M, Smith GD, Phillips AN. Meta-analysis: principles and procedures. BMJ Clinical research 1997;315(7121):1533-7.

17 Higgins JPT, Thompson SG. Quantifying heterogeneity in a meta-analysis. Statistics in Medicine 2002; 21:1539-1558

18 Egger M, Smith GD, Schneider M, Minder C. Bias in meta-analysis detected by a simple, graphical test. BMJ 1997;315:629-634.

19 Kamal D, Garway Heath D, Ruben S, et al. Results of the betaxolol versus placebo treatment trial in ocular hypertension. Graefe's archive for clinical and experimental ophthalmology; Albrecht von Graefes Archiv fur klinische und experimentelle Ophthalmologie 2003;241(3):196-203.

20 Kass MA, Gordon MO, Hoff MR, et al. Topical timolol administration reduces the incidence of glaucomatous damage in ocular hypertensive individuals. A randomized, double-masked, long-term clinical trial. Archives of ophthalmology 1989;107(11):1590-8.

21 Heijl A, Bengtsson B. Long-term effects of timolol therapy in ocular hypertension: a double-masked, randomised trial. Graefe's archive for clinical and experimental ophthalmology 2000;238(11):877-83.

22 Schulzer M, Drance SM, Douglas GR. A comparison of treated and untreated glaucoma suspects. Ophthalmology 1991;98(3):301-7.

23 Epstein DL, Krug JH, Jr., Hertzmark E, et al. A long-term clinical trial of timolol therapy versus no treatment in the management of glaucoma suspects. Ophthalmology 1989;96(10):1460-7.

24 Becker B, Morton WR. Topical epinephrine in glaucoma suspects. American journal of ophthalmology 1966;62(2):272-7.

25 Shin DH, Kolker AE, Kass MA, et al. Long-term epinephrine therapy of ocular hypertension. Archives of ophthalmology 1976;94(12):2059-60.

26 Heijl A, Leske MC, Bengtsson B, et al. Reduction of intraocular pressure and glaucoma progression: results from the Early Manifest Glaucoma Trial. Archives of ophthalmology 2002;120(10):1268-79.

27 Maier PC, Funk J, Schwarzer G, et al. Treatment of ocular hypertension and open angle glaucoma: metaanalysis of randomised controlled trials. BMJ Clinical research ed ISE: 14685833 2005;331(7509):134.

28 Quigley HA. European Glaucoma Prevention Study. Ophthalmology 2005;112(9):1642-3.

29 Leske MC, Heijl A, Hussein M, et al. Factors for glaucoma progression and the effect of treatment: the early manifest glaucoma trial. Archives of ophthalmology 2003;121(1):48-56. 



\title{
The effect of early detection of ocular hypertension and primary open-angle glaucoma on the occurrence of blindness A case-referent study
}

\author{
Andrea Peeters ${ }^{1}$ \\ Benjamin J. Pij1 ${ }^{2}$ \\ Carroll A.B. Webers ${ }^{1}$ \\ Henny J.M. Beckers ${ }^{1}$ \\ Pieter Leffers ${ }^{3}$ \\ Fred Hendrikse ${ }^{1}$ \\ Martin H. Prins ${ }^{3,4}$ \\ Jan S.A.G. Schouten ${ }^{1}$
}

1 Department of Ophthalmology, Maastricht University Hospital, The Netherlands

2 Department of Ophthalmology, University Hospital St Radboud Nijmegen, The Netherlands

3 Department of Epidemiology, Maastricht University, The Netherlands

4 Department of Clinical Epidemiology and Medical Technology Assessment, Maastricht University Hospital, Maastricht, The Netherlands

Submitted for publication 


\section{Abstract}

Objective: To establish the effectiveness of early detection and treatment of ocular hypertension $(\mathrm{OH})$ and primary open-angle glaucoma (POAG) in the ophthalmic practice on the prevention of glaucoma blindness.

Design: A case-referent study.

Methods: Cases are patients who became blind due to glaucoma in at least one eye. Referents are patients with an exudative form of age-related macular degeneration (AMD) and a Snellen visual acuity $<0.3$ in at least one eye. An exposure to tests by which $\mathrm{OH}$ and glaucoma can be detected (tonometry and ophthalmoscopy) prior to the diagnosis was retrieved from the medical charts of the cases and referents. Two glaucoma specialists did the retrieval of data from the medical records, independent of each other and unaware whether the record was of a case or a referent. They were asked to give the amount of certainty with which they judged whether an examination could be considered a 'screening' moment and thus not based on patients symptoms on a six point scale from 'certainly' to 'certainly not'. If early detection and treatment is effective in preventing glaucoma blindness it is to be expected that the frequency of these examinations is lower among cases compared to referents that represent the frequency of such testing in the general population. The relative risk, expressing the effect of early detection on glaucoma-related blindness, adjusted for potential confounders was estimated in a logistic regression analysis. Diabetes mellitus, hypertension, myopia, family history of glaucoma, year of the diagnosis and age were taken as potential confounders.

Results: Fewer cases than referents were screened by ophthalmologists for ocular hypertension and early glaucoma within 20 years prior to their diagnosis. The crude relative risk (RR) is 0.57 (90\% confidence interval $0.31-1.05)$, when adjusted for potential confounders the RR is 0.46 (90\% confidence interval $0.22-1.00)$.

Conclusion: The application of tonometry and ophthalmoscopy as screening tests for early detection of ocular hypertension and glaucoma by ophthalmologists is likely to lead to a reduction of glaucoma blindness. 


\section{Introduction}

Primary open-angle glaucoma (POAG) is a chronic optic neuropathy in which the progressive loss of the retinal ganglion cells leads to characteristic structural changes at the head of the optic nerve and to functional loss to the visual field. ${ }^{1}$ This process is insidious and takes place over a relatively long time period. In many patients there are no noticeable symptoms until patients lose their central vision. An elevated intraocular pressure (IOP) defines ocular hypertension $(\mathrm{OH})$ and is a major risk factor for a conversion to glaucoma and a prognostic factor for the occurrence of visual field loss. Treatment is aimed to lower the IOP.

In spite of the fact that glaucoma is an important public health problem there is no screening programme for $\mathrm{OH}$ and $\mathrm{POAG}{ }^{2}$ However, early detection in the form of case-finding takes place in ophthalmologic practice. The efficacy of early detection by case-finding and consequent treatment to prevent glaucoma blindness has not yet been investigated. Due to the need of a large sample size, long follow-up and ethical considerations, a randomized clinical trial or a prospective cohort study are not well suited for this purpose. Another type of epidemiological study, a casereferent study, can give an estimation of the effect of screening or case-finding if the number of screening examinations received prior to the date of diagnosis for cases and referents are assessed. ${ }^{3}$ This type of study allows a direct estimation of the effect size. ${ }^{4}$ A case-referent study is relatively easy to conduct with fewer costs since fewer patients need to be included and there is no need for a follow-up since cases already have reached the outcome that one wishes to prevent with screening or case-finding. In other fields of medicine case-referent studies have been used to evaluate the efficacy of screening programmes on the occurrence of death.,

Glaucoma meets many criteria for screening. ${ }^{2}$ One of the criteria is that the targeted disease has a pre-clinical stage which is detectable by suitable screening tests. A further prerequisite is that there are effective treatments that reduce the progression to the end stage of the disease. An elevated IOP can be detected by tonometry. ${ }^{7}$ The early glaucomatous structural changes of the optic nerve head can be detected by ophthalmoscopy before significant visual field loss occurs. ${ }^{8}$ There are effective treatments to lower the intra-ocular pressure that prevent a conversion to glaucoma or its progression. ${ }^{9-11}$

If early detection and a subsequent application of an efficacious therapy can reduce the conversion or progression rate of the disease, then it is likely that testing for early detection is beneficial for the prevention of glaucoma-related blindness. In this paper a case-referent study is presented in which the effect of early detection of $\mathrm{OH}$ and POAG by case-finding in ophthalmologic practice on the occurrence of glaucoma blindness is estimated. 


\section{Methods}

\section{Study setting}

Cases and referents were ophthalmic patients treated at the University Hospital Maastricht. The hospital research ethics board (REB) approved the conduct of this study. All patients were informed about the study and consented to their enrolment. The study adhered to the tenets of the Declaration of Helsinki.

\section{Identification of cases and referents}

For identifying potential cases first all consecutive patients who underwent a 10-2 Humphrey visual field testing (Humphrey perimetry, Carl Zeiss Meditec, Dublin CA) during two years, from 01-01-2000 until 19-02-2002, at the University Hospital Maastricht were selected. The print-outs of the visual field and basic patient information were abstracted directly from the Humphrey hardware by the use of a software program PeriData (PeriData Software $\mathrm{GmbH}$ ). Next, patients were selected who met the inclusion criteria. Cases had to meet the following criteria: (1) diagnosis primary open-angle glaucoma (2) functioning visual field in at least one eye restricted to 10 degrees (3) resident of the chosen region (4) born between 1920-1940 (5) treated for glaucoma at the University Hospital Maastricht. The final selection of the study participants was based on patients' approval with the participation in the study and on the availability of the data. First, the medical charts of all potential participants were collected. If patients were referred from another hospital, a copy of their medical record was requested. If a record could not be found, if the notes were incomplete, or if the diagnosis preceded the first date on the medical chart patients were not included.

Referents had to meet the following criteria: (1) a diagnosis exudative form of age related macular degeneration (AMD) (2) visual acuity $<0.3$ due to MD in at least one eye (3) resident of the chosen region (4) born between 1920-1940 (5) treated for macular degeneration at the University Hospital Maastricht. First, all consecutive patients who underwent fluorescein angiography (FAG) at the University Hospital Maastricht from 01-01-1997 until 31-12-2002 were identified. Thereafter, the same procedure as described by the cases was used for the final selection of referents.

Patients were initially approached by mail. The letters, printed in large print, in which the nature of the study was explained, were signed by the treating ophthalmologist. Patients were asked to sign their approval of enrollment in the study. Patients who did not respond received a reminder. Patients who did not respond to the reminder were approached by phone.

\section{Data collection}

An exposure to tests for early detection prior to the diagnosis POAG or AMD was ascertained by reviewing the medical records of the study participants. The tests for detection were defined as tonometry and ophthalmoscopy. A diagnosis $\mathrm{OH}$ was considered detection for POAG patients. If an IOP of $22 \mathrm{~mm} \mathrm{Hg}$ or more was found 
the date of this finding was taken as the date of the diagnosis. Testing had to be performed in a time period when progression in glaucoma patients could have been stopped or slowed down by treatment. Testing had to take place within 20 years preceding the date of the diagnosis. For the cases testing was not considered a 'screening' moment if the tests were performed due to complaints associated with glaucoma or if it took place within one year before the occurrence of blindness. For the referents testing was not considered a 'screening' moment if the tests were performed due to complaints of AMD. For each participant the information on medical history and notes made during the outpatients visits were photocopied from the charts. Two glaucoma specialists (CW and $\mathrm{HB}$ ) were asked to review the photocopies and state whether an examination could be considered as screening or was based on patient's symptoms. The judgment was scored on a six point ordinal scale: 'certainly'; 'very probably'; 'probably'; 'probably not'; 'very probably not'; 'certainly not'. They were kept unaware of whether a participant was a case or a referent.

Further patient data that were retrieved from the medical charts were: age, sex, year of the diagnosis (POAG or AMD) and myopia (spherical equivalent $<-4.0 \mathrm{D}$ ). In addition, presence of diabetes mellitus, hypertension, and a positive family history of glaucoma were assessed by means of a questionnaire. This questionnaire was sent by mail, printed in large letters.

\section{Data analysis}

The effect of early detection of $\mathrm{OH}$ and POAG on glaucoma blindness was expressed as a relative risk (RR). The ratio of the frequency of testing for $\mathrm{OH}$ and POAG prior to the diagnosis POAG among the cases was divided by the ratio of the frequency of such testing prior to the diagnosis AMD among the referents. A RR below 1 would then indicate that the testing for early detection of $\mathrm{OH}$ and POAG is less likely among the cases. Next, the calculated RR was adjusted for potential confounders in a logistic regression model. The following variables were taken as potential confounders: diabetes mellitus, hypertension, myopia, family history of glaucoma, year of the diagnosis and age. For the analyses the judgement of the ophthalmologist, whether the performed testing could be considered as screening, which was more conservative (leading to a RR closest to 1 ) was chosen. The analyses were performed for two different cut-off points on the ordinal scale. First the options 'certainly', 'very probably', and 'probably' were considered positive and then only the options 'certainly' and 'very probably'. 
Table 1: Number of potential cases and referents, reasons for exclusion and the final number of the study participants

\begin{tabular}{lcc}
\hline $\begin{array}{l}\text { Patients considered for the study } \\
\text { (based on visual field or fluorescein angiography) }\end{array}$ & Cases & 252 \\
Patients who met the inclusion criteria & 151 & 186 \\
Reasons for no participation in the study: & 83 & 41 \\
$\quad$ - no informed consent & & 9 \\
- no additional information from a referring hospital & 17 & 4 \\
- incomplete additional information from a referring hospital & 3 & 5 \\
- untraceable medical chart & - & 3 \\
- diagnosis before the history of the medical chart & 4 & 14 \\
- diagnosis of glaucoma prior to the diagnosis of MD & - & 110 \\
\hline
\end{tabular}

Table 2: Baseline characteristics of cases and referents

\begin{tabular}{lcc}
\hline & $\begin{array}{c}\text { Cases } \\
(\mathrm{n}=41)\end{array}$ & $\begin{array}{c}\text { Referents } \\
(\mathrm{n}=110)\end{array}$ \\
\hline Mean age at diagnosis (years \pm SD) $)$ & $63.5( \pm 5.9)$ & $70.0( \pm 5.0)$ \\
Men & $17(41 \%)$ & $57(46 \%)$ \\
Myopia & $26(63 \%)$ & $48(44 \%)$ \\
Family history of glaucoma & $7(17 \%)$ & $14(13 \%)$ \\
Diabetes mellitus & $7(17 \%)$ & $15(14 \%)$ \\
Hypertension & $7(17 \%)$ & $21(19 \%)$ \\
\hline
\end{tabular}

\section{The results}

In Table 1 an overview is given of number of patients initially considered for the study, the reasons for non-inclusion and the final number of patients who were enrolled. Finally, 41 cases and 110 referents were included. The baseline characteristics of these patients are given in Table 2. Cases were younger when diagnosed, with a mean age of 63 years, compared to 70 years in referents. The mean year of the diagnosis was $1992(\mathrm{SD} \pm 6.2$ ), among the cases and $1997(\mathrm{SD} \pm 3.8)$ among the referents. A history of tests for early detection by tonometry and/or ophthalmoscopy was less common among cases, namely $16(39 \%)$, than among referents, $58(53 \%)$ $(\mathrm{p}=0.13)$. The results of the analysis are given in Table 3 . The crude effect measure (not adjusted for possible confounding) was 0.57 (90\% confidence interval 0.31-1.05). After adjustment for all listed potential confounders in a logistic regression model the RR became 0.46 (90\% confidence interval $0.22-1.00)$. When in the analysis the cut-off point for the judgement whether testing could be considered a 'screening' moment was shifted and only the options 'certainly' and 'very probably' were taken as positive, then the unadjusted RR became 0.40 (90\% confidence interval $0.21-0.74$ ), and the RR adjusted for all potential confounders was 0.34 (90\% confidence interval 0.16-0.72). 
Table 3: Results of the case-referent study - relative risk of the application of the examinations for early detection of glaucoma among the cases and referents, unadjusted and adjusted for potential confounders, for two different cut-off points of the certainty that the performed examinations were applied as an early detection

\begin{tabular}{lcl}
\hline & Relative risk (RR) & Relative risk (RR) \\
Crude effect & cut-off point $1 * *$ & cut-off point $2 * * *$ \\
\hline
\end{tabular}

Unadjusted for confounding $\quad 0.57(90 \%$ CI $0.31-1.05) \quad 0.40$ (90\% CI 0.21-0.74)

Adjusted for the listed potential confounders* $\quad 0.46(90 \%$ CI $0.22-1.00) \quad 0.34(90 \%$ CI $0.16-0.72)$

* potential confounders: diabetes mellitus, systemic hypertension, myopia, family history of glaucoma, year of the diagnosis, age

** options 'certainly', 'very probably', and 'probably' taken for the confirmation that testing was applied as an early detection

*** options 'certainly' and 'very probably' taken for the confirmation that testing was applied as an early detection

\section{Discussion}

In this paper a case-referent study is presented which was designed to investigate if early detection of $\mathrm{OH}$ and $\mathrm{POAG}$ by means of case-finding by the ophthalmologist is beneficial for the prevention of glaucoma-related blindness. The relative risk adjusted for possible confounding is 0.46 ( $90 \%$ confidence interval $0.22-1.00$ ). When for more certainty was chosen in whether testing could be considered a 'screening moment', the relative risk, after adjustments for confounding, became $0.34(90 \%$ confidence interval $0.16-0.72)$. This suggests that early detection of $\mathrm{OH}$ and POAG by means of case-finding by the ophthalmologist reduces the risk of glaucoma blindness to about one half or more of the risk when no case-finding is done.

The calculation of the relative risk is based on a proportion of individuals who underwent testing by tonometry and/or ophthalmoscopy prior to their diagnosis, not based on patient's symptoms. The argumentation why this should have an impact on the occurrence of blindness is that when a performance of these tests by which $\mathrm{OH}$ and early POAG can be detected is not based on the disease symptoms, one can assume that the disease is diagnosed and treated in an early stage. If treatment of $\mathrm{OH}$ and early glaucoma is effective in blindness prevention then patients diagnosed in time will not progress to blindness. To obtain a reasonable estimate of the true effect it is essential that the proportion of individuals who underwent tonometry and ophthalmoscopy among the referents is a valid estimate of the proportion of individuals with these examinations in the general population from which the blind glaucoma patients come.

The choice of the referents is fundamental and has to fulfill two criteria. ${ }^{12}$ Firstly, the referents must come from the same general population as the cases. For this reason referents were chosen from the same hospital and the same region as the cases. It is plausible that if a referent would have become a glaucoma patient he would have been included in the study as a case because he would have been treated 
in the same hospital. Secondly, the referents' disease and disease stage should not be related to the examinations under study. Blindness due to exudative macular degeneration is not associated with the tests for early detection of glaucoma. Although AMD can be detected by ophthalmoscopy, this does not influence the course of the disease and the occurrence of blindness since there is, or until recently there was not, an effective treatment for it. To prevent bias the testing was only considered a 'screening' moment if the tests were not related to the symptoms of AMD that may have led these patients to visit an ophthalmologist.

Another precaution taken to minimize bias was blinding of the ophthalmologists (who had to indicate whether testing was done on indication or not) to whether a patient was a case or a referent.

The confounders for which the crude effect has been adjusted, i.e. diabetes mellitus, hypertension, myopia, family history of glaucoma and age are (potential) risk factors for glaucoma. Additonally, year of the diagnosis and also age may be related to the aspect of time. Cases have been diagnosed earlier than referents. This is to be expected because the rate of blindness is slower in patients with glaucoma than in patients with AMD. The time period may be associated with detection, because in the past people used to visit an ophthalmologist more often than nowadays e.g. for a prescription of spectacles. Age may be associated with detection because older people visit an ophthalmologist more often than younger persons.

\section{Conclusions}

The results of the case-referent study show that fewer blind glaucoma patients underwent tests for early detection of ocular hypertension and glaucoma than referents, which represent such testing in the general population. This supports the hypothesis that early detection and treatment has a positive effect on the prevention of glaucoma blindness. The outcomes of the present study emphasize the need for the assessment of IOP and an optic nerve examination in each patient visiting an ophthalmologist.

\section{References}

1 Liesegang TJ, Skuta GL, Cantor LB. Glaucoma. Basic and Clinical Science Course. American Academy of Ophthalmology 2003.

2 Harasymowycz P, Kamdeu Fansi A, Papamatheakis D. Screening for primary open-angle glaucoma in the developed world: are we there yet? Canadian journal of ophthalmology; Journal canadien d'ophtalmologie 2005;40(4):477-86.

3 Hosek RS, Flanders WD, Sasco AJ. Bias in case-control studies of screening effectiveness. American journal of epidemiology 1996;143(2):193-201.

4 Miettinen OS. Estimability and estimation in case-referent studies. American journal of epidemiology 1976;103(2):226-235.

5 Sasco AJ, Day NE, Walter SD. Case-control studies for the evaluation of screening. Journal of chronic diseases 1986;39(5):399-405. 
6 Weiss NS, McKnight B, Stevens NG. Approaches to the analysis of case-control studies of the efficacy of screening for cancer. American journal of epidemiology 1992;135(7):817-23.

7 American Academy of Ophthalmology Glaucoma Panel. Preferred Practice Pattern. Primary Open-Angle Glaucoma. San Francisco, CA: American Academy of Ophthalmology; 2005. Available at: www.aao.org/ppp.

8 Zeyen G, Caprioli J. Progression of Disc and Field Damage in Early Glaucoma. Archives of Ophthalmology. 1993;111: 62-65.

9 Kass MA, Heuer DK, Higginbotham EJ, et al. The Ocular Hypertension Treatment Study: a randomized trial determines that topical ocular hypotensive medication delays or prevents the onset of primary openangle glaucoma. Archives of ophthalmology 2002; 120: 701-713.

10 Heijl A, Leske MC, Bengtsson B, Hyman L, Hussein M. Reduction of intraocular pressure and glaucoma progression: results from the Early Manifest Glaucoma Trial. Archives of ophthalmology 2002; 120: $1268-1279$

11 Kamal D, Garway-Heath D, Ruben S, et al. Results of the betaxolol versus placebo treatment trial in ocular hypertension. Graefe's archive for clinical and experimental ophthalmology 2003; 241: 196-203.

12 Miettinen OS. The "case-control" study: valid selection of subjects. Journal of chronic diseases 1985;38(7):543-48. 



\title{
4
}

\section{Cost-effectiveness of early detection and treatment of ocular hypertension and primary open-angle glaucoma by the ophthalmologist}

\author{
Andrea Peeters ${ }^{1}$ \\ Jan S.A.G. Schouten ${ }^{1}$ \\ Carroll A.B. Webers ${ }^{1}$ \\ Martin H. Prins ${ }^{2,3}$ \\ Fred Hendrikse ${ }^{1}$ \\ Hans L. Severens ${ }^{3,4}$
}

1 Department of Ophthalmology, Maastricht University Hospital, Maastricht, The Netherlands 2 Department of Epidemiology, Maastricht University, Maastricht, The Netherlands

3 Department of Clinical Epidemiology and Medical Technology Assessment, Maastricht University Hospital, Maastricht, The Netherlands

4 Department of Health Organisation, Policy and Economics, Maastricht University, The Netherlands

Eye advance online publication, 24 November 2006; doi:10.1038/sj.eye.6702637 


\begin{abstract}
Purpose: To determine the most cost-effective case-finding strategy for the ophthalmologist to detect and treat ocular hypertension $(\mathrm{OH})$ and primary open-angle glaucoma (POAG) at an early stage to prevent blindness.

Design: A Markov cost-effectiveness simulation model.

Methods: Three case-finding strategies are analyzed and compared. The simulated cohort consists of all initial patients of at least 40 years old visiting an ophthalmic practice. All patients undergo ophthalmoscopy, but tonometry is routinely performed to: (1) all initial patients, (2) high-risk patients only, or (3) no one. The population characteristics are based on data of 1000 initial patients. Transition probabilities are taken from the literature. The (direct) costs of diagnosis and treatment represent those for The Netherlands. The time-horizon of the model is 20 years. An annual discount rate of $4 \%$ is used.
\end{abstract}

Main outcome measures: Costs, proportion of patients becoming blind, years of blindness.

Results: The costliest strategy (1) leads to least blindness. The incremental costeffectiveness ratio, which shows extra costs per year of vision saved in comparison to the cheapest strategy (3), is lower for strategy (1) than for strategy (2). It amounts to $€ 1707$, not including extra costs due to blindness (e.g. associated with the use of disability facilities). When such costs exceed $€ 1707$ per patient per year, which is most likely, then strategy (1) becomes cost saving.

Conclusions: It is most cost-effective to routinely perform tonometry to all initial ophthalmic patients to prevent blindness due to glaucoma. 


\section{Introduction}

Primary open angle glaucoma (POAG) is an important public health problem, being the second leading cause of bilateral blindness worldwide. ${ }^{1}$ It is characterized by progressive optic nerve atrophy leading to visual field damage and possibly blindness. The natural history of POAG is though variable; some people develop significant visual problems, while others do not. ${ }^{2}$ An elevated intraocular pressure (IOP) defines ocular hypertension $(\mathrm{OH})$ and is a major risk factor for POAG. Through IOP lowering treatment the risk of glaucoma and its progression can be reduced. 3,4

In the past it has often been suggested that a screening program should be set up, but because of high costs and unknown effectiveness it has never been systematically introduced. ${ }^{5}$ In the last two decades new technologies have been introduced that permit earlier detection of structural and functional damage due to glaucoma. New treatments, such as hypotensive lipids and selective laser trabeculoplasty, allow for safer and more effective IOP reduction. Several well conducted clinical trials showed the effectiveness of treatment. ${ }^{3,4}$ These new developments, and a possibly increasing prevalence of POAG due to aging, bring along the necessity to re-evaluate screening. ${ }^{6}$ However, the feasibility and efficacy of a screening program still can be questioned. Only recently the US Preventive Services Task Force concluded that there is still insufficient evidence to recommend for or against a screening program for glaucoma. ${ }^{7,8}$

An alternative for screening to discover and treat $\mathrm{OH}$ and POAG at an early stage is case-finding among patients visiting an ophthalmologist. The advantages compared to screening in the general population are the use of an existing infrastructure, the high probability for discovery by means of a complete ophthalmic examination and the direct initiation of treatment without loss to follow-up. Moreover, the prevalence of $\mathrm{OH}, \mathrm{POAG}$, and risk factors for glaucoma, is higher among patients visiting an ophthalmologist than in the general population.

In many countries ophthalmologists routinely apply strategies to detect $\mathrm{OH}$ and POAG. However, the effect of these strategies to prevent glaucoma blindness is unknown. The cost-effectiveness is unknown as well. This study aims to investigate the effects, costs, and cost-effectiveness of different case-finding strategies that can be applied by an ophthalmologist in daily practice to detect and treat $\mathrm{OH}$ and POAG at an early stage to prevent glaucoma blindness.

\section{Method}

Three case-finding strategies, which differ with respect to the group of patients routinely receiving tonometry, are analyzed and compared using a Markov costeffectiveness simulation model. In the model all initial ophthalmic patients undergo ophthalmoscopy to detect a glaucomatous optic nerve, but the three strategies differ by whether tonometry is routinely performed to: (1) all initial patients, (2) high-risk 
patients only, or (3) no one. In case of positive results of testing with ophthalmoscopy and/or tonometry, perimetry is performed to complete the assessment of the correct diagnosis. These different diagnostic strategies lead to different proportions of patients being diagnosed and treated for $\mathrm{OH}$ or POAG. The long-term consequences of these three strategies are then evaluated.

The population characteristics are based on data gathered from the charts of 1000 initial patients visiting an ophthalmic practice. The transition probabilities are taken from the literature. The (direct) costs of diagnosis and treatment represent those for The Netherlands. The time-horizon of the model is 20 years and an annual discount rate of $4 \%$ is used. The analysis is performed from a societal perspective.

\section{The Model}

It is modeled that a cohort of initial patients visiting an ophthalmologist, having a certain prevalence of $\mathrm{OH}$ and $\mathrm{POAG}$, undergoes testing to detect these disorders. The use of the diagnostic tests is strategy dependent, as described above, and so per strategy different proportions of patients are specified for observation, treatment, or discharge. Subsequently a 20 -year follow-up is modeled, while the progression of patients returning for regular visits, but also that of the discharged patients is being tracked. Per strategy blindness due to glaucoma is determined and the corresponding costs are computed.

The cohort simulated in the model corresponds to initial patients of at least 40 years old visiting an ophthalmic practice. In the Netherlands the general practitioner refers the majority of such patients. The age and sex distribution, and the prevalence of $\mathrm{OH}$ and POAG are jointly taken into account. In the model the high-risk group is defined to consist of patients reporting a positive family history of glaucoma. Such patients have an increased risk of having glaucoma. ${ }^{9,10}$

The model consists of two parts. Part one models the diagnostic process; part two models the disease progression over time. In part one, the known sensitivity and specificity of ophthalmoscopy and tonometry are used to calculate proportions of patients receiving the diagnosis $\mathrm{OH}$ or POAG for each strategy. This leads to a strategy dependent distribution of the patient cohort over the set of health states. These health states are defined by the true condition of a patient, by the obtained diagnosis and by the assigned therapy (see Figure 1). The therapy assignment corresponds to the clinical practice, where IOP level, the presence of risk factors, and severity of the disease play a role. Patients diagnosed as $\mathrm{OH}$ are either put under observation or given medical treatment with monotherapy. In the strategy 'tonometry all' $50 \%$ of the $\mathrm{OH}$ patients starts medication directly after the diagnosis is made. The rest is kept under observation and receives treatment only if conversion to POAG occurs. In the strategy 'tonometry high-risk group' all patients diagnosed as $\mathrm{OH}$ are at risk and therefore require medication. POAG patients start 
therapy with monotherapy in all strategies; a small proportion undergoes laser or surgery directly. Missed $\mathrm{OH}$ and POAG patients are discharged.

In part two of the model transitions between health states can take place. Here the development of $\mathrm{OH}$ in normotensives, the development of $\mathrm{POAG}$ from $\mathrm{OH}$, and the progression of POAG to blindness is modeled. Also, undiagnosed patients are tracked and can be rediscovered. A distinction is made between patients completely discharged and patients still visiting the ophthalmologist regularly for some other ophthalmic condition. The latter group of patients has a higher chance of $\mathrm{OH} / \mathrm{POAG}$ detection. For patients under therapy every 6 months an outpatient visit is modeled to take place and the proportion of patients showing progression is modeled to undergo a therapy switch. The therapy sequence is based on recommendations of the American Academy of Ophthalmology; its chronological order is monotherapy, combination therapy, laser, and surgery. ${ }^{11}$ The end stage of the disease is blindness. Patients under treatment develop blindness only after surgery, when there are no further treatment possibilities. Discharged patients can also eventually develop blindness without treatment. Patients who become blind continue to use combination therapy and to visit an ophthalmologist once in two years. The false positives, patients unjustly positively diagnosed, continue to use monotherapy medication.

The model is built and analyzed using the software package 'Decision Analysis by TreeAge' (Data), version 3.5. It has the structure of a Markov model and it has a time horizon of 20 years, consisting of 40 cycles of 6 months each. This choice of cycle length reflects the common time between the consecutive outpatient visits of the glaucoma patients. The diagnostic process is implemented as the first cycle only, the disease progression over time involves the other cycles. At the end of each cycle transitions between the health states take place. These transitions include age and sex dependent survival probabilities, probabilities concerning the discovery of undiagnosed patients, and the probabilities related to the development or progression of $\mathrm{OH}$ and POAG. These probabilities are independent of the three strategies being evaluated. 
Figure 1: Part two of the simulation model: transitions among the health states

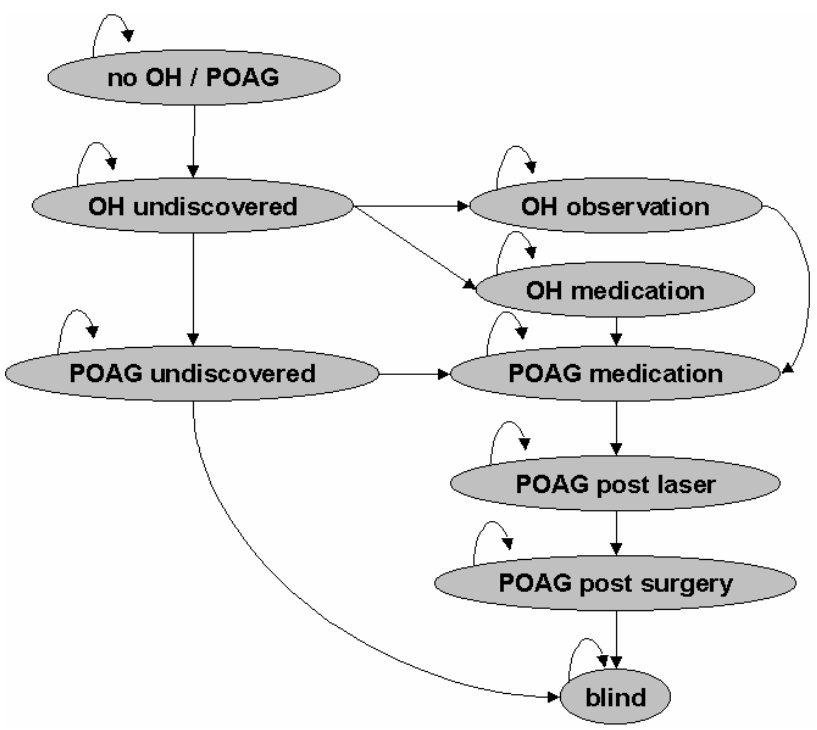

The health state 'dead' (not shown) can be entered from all other states. After the diagnosis was made, in part one of the model, all health states except 'blind' and 'dead' can be entered. The shown scheme is a simplified reproduction of the model. In the model a distinction is namely made between undiscovered patients completely discharged and patients still visiting the ophthalmologist regularly for some other ophthalmic condition. A distinction is also made in the form of medication, namely monotherapy or combination therapy. Another health state, not shown, is 'false positives on monotherapy'.

\section{Cost assignment}

The direct medical costs are assigned as once-only costs and state dependent costs. The once-only costs are the costs of the diagnostic process and the costs for laser treatment and surgery. The state dependent costs are the costs of outpatient visits and medication. These costs are assigned to the health states and reflect the treatment requirements related to 6 months of treatment of a particular state. The costs for diagnosis apply to all patients. The costs for treatment apply to diagnosed patients only.

\section{Outcomes}

The outcomes of the analysis concern: 1) costs, 2) proportion of patients becoming blind, 3) years of blindness. 


\section{The Data}

The data and their sources are presented in Tables 1-3. The age distribution and the $\mathrm{OH} / \mathrm{POAG}$ prevalence for the population have been determined from the charts of 1000 initial patients, consecutively visiting a general ophthalmic practice in Maastricht (Medisch Centrum Maastricht Annadal - MCMA), starting from January 1999. ${ }^{12}$ The global characteristics of the data are consistent with the indications from the literature. ${ }^{13-15}$ The values for sensitivity and specificity of the diagnostic tests were taken from the literature. The starting therapy assignment for discovered patients is consistent with the opinion of the glaucoma specialists, the recommendations of the American Academy of Ophthalmology and the European Glaucoma Society. ${ }^{11,16}$ In part two of the model the 6 months transition probabilities are calculated from the yearly transition probabilities, which are obtained as follows. The age and sex dependent survival probabilities are taken from data provided by the Dutch Central Bureau for Statistics (CBS). ${ }^{17}$ The modeled disease progression is based on the literature, mainly on the long-term follow-up studies and on therapy trials. $^{3,18-37}$ The unit prices related to the outpatient visits, laser trabeculoplasty and surgery are as determined at the University Hospital Maastricht. This was done according to the micro costing method. ${ }^{38}$ The prices of medical drugs represent the prices in the Netherlands (incl. VAT). The prices of monotherapy and combination therapy are based on the average use of the individual drugs in the Netherlands, combining up to three drugs in the combination therapy. The frequency of the health care use is modeled in accordance with the specialists' opinion and the recommendations of the American Academy of Ophthalmology. The costs due to blindness in connection with the usage of disability facilities in the Netherlands could not be retrieved. 
Table 1: Parameters used in the simulation model

\begin{tabular}{|c|c|c|c|c|}
\hline Parameter & Lower bound & Baseline & Upper bound & Source \\
\hline \multicolumn{5}{|l|}{ A. Proportions } \\
\hline Se tonometry ${ }^{\mathrm{a}}$ & 0.90 & 1 & - & $54-56$ \\
\hline Se ophthalmoscopy & 0.60 & 0.80 & 1 & $5,57-61$ \\
\hline Sp tonometry & 0.90 & 1 & - & $54-56$ \\
\hline Sp ophthalmoscopy & 0.80 & 0.90 & 1 & $5,57-61$ \\
\hline Screen positive $\mathrm{OH}^{\mathrm{b}}$ & & & & $5,57-61$ \\
\hline strategy (1) & 0.91 & 1 & - & \\
\hline strategy (2) & 0.20 & 0.28 & 0.36 & \\
\hline strategy (3) & 0 & 0.10 & 0.20 & \\
\hline Screen positive $P^{\prime} O A G^{b}$ & & & & $5,57-61$ \\
\hline strategy (1) & 0.96 & 1 & - & \\
\hline strategy (2) & 0.67 & 0.84 & 1 & \\
\hline strategy (3) & 0.60 & 0.80 & 1 & \\
\hline Screen positive 'normal'b & & & & $5,57-61$ \\
\hline strategy (1) & - & 0 & 0.05 & \\
\hline strategy (2) & - & 0 & 0.012 & \\
\hline strategy (3) & - & 0 & 0.01 & \\
\hline Discovered $\mathrm{OH}$ patients with check-up only & & & & Estimate \\
\hline strategy (1) & 0.40 & 0.50 & 0.60 & \\
\hline strategy (2) & - & 0 & - & \\
\hline strategy (3) & 0.40 & 0.50 & 0.60 & \\
\hline Patients with regular visits due to other condition & 0.4 & 0.5 & 0.7 & 14 , clinical data \\
\hline POAG patients with direct laser assignment & 0 & 0.02 & 0.05 & 39 , estimate \\
\hline POAG patients with direct surgery assignment & 0 & 0.02 & 0.05 & 39 , estimate \\
\hline
\end{tabular}

B. Yearly probability estimates

Discovery of $\mathrm{OH}$ in 'visitors'

strategy (1)

strategy (2)

strategy (3)

Discovery of $\mathrm{OH}$ in 'discharged"

strategy (1)

strategy (2)

strategy (3)

Discovery of POAG in 'discharged"

strategy (1)

strategy (2)

strategy (3)

0.02

39 , estimate

OH development in discharged 'normals'

POAG development in discharged $\mathrm{OH}$ patients

Blindness development in untreated POAG patients

POAG development in $\mathrm{OH}$ patients with check-up only

Switch to combination therapy in $\mathrm{OH}$ patients on monotherapy

Switch to combination therapy in POAG patients on monotherapy

POAG development in $\mathrm{OH}$ patients on combination therapy

Switch to laser in POAG patients on combination therapy

Success laser 0-1 years after the intervention ${ }^{\mathrm{d}}$

Success laser $>1$ year after the intervention ${ }^{d}$

Success surgery 0-5 years after the intervention ${ }^{\mathrm{e}}$

Success surgery 5-10 years after the intervention ${ }^{\mathrm{e}}$

Success surgery $>10$ years after the intervention ${ }^{\text {e }}$

Discovery of POAG in 'visitors'

0.95

0.10

0.10

0.01

0.0028

0.001

0.05

0.014

0.005

0.01

0.0084

0.008

0.002

0.02

0.05

0.015

0.08

0.20

0.037

0.32

0.65

0.85

-
5,57-61

62, clinical data

0.10

0.028

0.01

$\begin{array}{cc}0.05 & 0.10 \\ 0.042 & 0.084\end{array}$

$0.04 \quad 0.08$

$0.003 \quad 0.006$

$0.05 \quad 0.10$

18,19

$3,18,20-24$

$0.25,63,64$

$0.07 \quad 3,23$

$0.113,25,26$

$0.25 \quad 25-27$

$0.089 \quad 3,24,28$

$0.74 \quad 25,39$

$0.75 \quad 29-33$

$0.90 \quad 29-33$

34-37

34-37

34-37 
a Values reflect IOP measurement by the Goldmann applanation tonometer (golden standard) to diagnose patients with IOP $>21 \mathrm{~mm} \mathrm{Hg}$.

b Per strategy the proportions of the correct diagnoses have been calculated, using the following assumption. In case of a positive outcome of at least one of the performed tests a patient undergoes further examinations and will be correctly diagnosed within the first 6 months. Values for perimetry were not required for the calculations, even if perimetry contributes to the achievement of a correct diagnosis. Perimetry is performed in case of positive results of testing with ophthalmoscopy and/or tonometry.

c The probability of visiting an ophthalmologist has been multiplied by the probability of being diagnosed. d The complementary probability to 'success laser' is the probability to switch to surgery.

e The complementary probability to 'success surgery' is the probability to become blind.

Strategy (1) = 'tonometry all'; Strategy (2) = 'tonometry high-risk group' (the values shown are valid if $20 \%$ of $\mathrm{OH}$ and $\mathrm{POAG}$ and $5 \%$ of the rest of the patients report a positive family history of glaucoma); Strategy (3) = 'tonometry no one'; Discovery = probability of discovering undiagnosed patients in part two of the model; Visitors = patients visiting the ophthalmologist regularly due to other ophthalmic condition than $\mathrm{OH}$ or POAG; Discharged = patients being discharged after the diagnostic process (part one of the model) is completed; Monotherapy $=$ receiving 1 medication; Combination therapy $=$ receiving more than 1 medication; Normal $=$ has neither OH nor POAG

Table 2: $\mathrm{OH}$ and POAG prevalence among initial ophthalmic patients ${ }^{12}$

\begin{tabular}{lccc}
\hline Age category & $\mathrm{OH}$ & POAG & Normal $^{\mathrm{a}}$ \\
\hline 40 - 49 years & $16.7 \%$ & $0 \%$ & $83.3 \%$ \\
50 - 59 years & $2.2 \%$ & $1 \%$ & $96.8 \%$ \\
60 - 69 years & $5.3 \%$ & $1 \%$ & $93.7 \%$ \\
70 - 79 years & $7.9 \%$ & $4 \%$ & $88.1 \%$ \\
$80+$ years & $5.2 \%$ & $6.9 \%$ & $87.9 \%$ \\
All age-categories & $6.7 \%$ & $2.4 \%$ & $90.9 \%$ \\
\hline
\end{tabular}

a normal $=$ has neither $\mathrm{OH}$ nor POAG 
Table 3: Prices (2001) and frequency of the health care use

\begin{tabular}{|c|c|c|c|}
\hline Resource & Patient type & Frequency & Unit price $(€)$ \\
\hline \multirow[t]{9}{*}{ Outpatient visit $^{\mathrm{a}}$} & & & 23 \\
\hline & $\mathrm{OH}$ patients with check-up only & $1 /$ year & \\
\hline & $\mathrm{OH}$ patients on monotherapy & $1 /$ year & \\
\hline & $\mathrm{OH}$ patients on combination therapy & $1 /$ year & \\
\hline & POAG patients on monotherapy & 2 / year & \\
\hline & POAG patients on combination therapy & $2 /$ year & \\
\hline & POAG patients post laser ${ }^{\mathrm{b}}$ & $2 /$ year & \\
\hline & POAG patients post surgery ${ }^{c}$ & $2 /$ year & \\
\hline & blind & $0.5 /$ year & \\
\hline \multirow[t]{7}{*}{ Perimetry } & & & 77 \\
\hline & $\mathrm{OH}$ patients on monotherapy & $0.2 /$ year & \\
\hline & $\mathrm{OH}$ patients on combination therapy & $0.33 /$ year & \\
\hline & POAG patients on monotherapy & $1 /$ year & \\
\hline & POAG patients on combination therapy & $1 /$ year & \\
\hline & POAG patients post laser & $1 /$ year & \\
\hline & POAG patients post surgery & $1 /$ year & \\
\hline Argon laser therapy & POAG patients (by indication) & 1 & 267 \\
\hline Surgery & POAG patients (by indication) & 1 & 1282 \\
\hline Monotherapy & patients on monotherapy & daily & $158 /$ year $^{65}$ \\
\hline Combination therapy & patients on combination therapy & daily & $358 /$ year $^{65}$ \\
\hline Transportation & all patients & per visit & 3 \\
\hline
\end{tabular}

a 10 minutes consult: included are visus control, tonometry, ophthalmoscopy (the first consult costs $26 €$ if tonometry is included, and $24 €$ without tonometry)

b plus 1 extra consult after the intervention

c plus 10 extra consults after the intervention

\section{Results}

Table 4 gives the expected costs and outcomes per initial ophthalmic patient due to $\mathrm{OH}$ and POAG within a period of 20 years. Not surprisingly, both strategies 'tonometry all' and 'tonometry high risk group' cost more than 'tonometry no one' but also avert more blindness. The strategy 'tonometry all' is the most expensive one, with least blindness. For this strategy the incremental costs to prevent blindness in comparison with 'tonometry no one' are $€ 7778$ to prevent one person from becoming blind and $€ 1707$ per year of vision saved. For strategy 'tonometry high risk group' the incremental costs to prevent blindness are higher. These outcomes do not include extra costs due to blindness, e.g. in connection with the usage of disability facilities. Since such costs are likely to exceed $€ 1707$ per year, inclusion of such costs makes the strategy 'tonometry all' cheapest and most effective. 
The sensitivity analysis shows that in strategy 'tonometry all' the occurrence of blindness is always lowest and in strategy 'tonometry no one' always highest. The incremental costs to prevent blindness are always lower for the strategy 'tonometry all' than 'tonometry high-risk group'. These results show the robustness of the conclusions.

In a one-way sensitivity analysis the lower and upper bound values of all parameters for which ranges are given were used. Alteration of glaucoma incidence among undiscovered $\mathrm{OH}$ patients has the largest impact on the results of the costeffectiveness analysis. The incremental costs per year of vision saved for strategy 'tonometry all' are $€ 4670$, when glaucoma incidence among discharged $\mathrm{OH}$ patients is lowest and $€ 564$ when it is highest. Alteration of blindness incidence among untreated glaucoma patients gives incremental costs per year of vision saved $€ 3900$, when it is lowest, and $€ 1240$, when it is highest. A two-way sensitivity analysis, which uses the lower values of both above-mentioned parameters, gives the incremental costs $€ 12250$ per year of vision saved. Alteration of the health care costs, with all unit prices raised by $10 \%$ and $30 \%$, has no substantial effect on the outcomes of the cost-effectiveness analysis (data not shown). Neither does an alteration of the cohort characteristics and of the sensitivity and specificity of the diagnostic tests (data not shown).

Table 4: Results of the cost-effectiveness analysis of three different strategies for early detection and treatment of $\mathrm{OH}$ and POAG among initial ophthalmic patients

\begin{tabular}{lccc}
\hline & $\begin{array}{c}\text { Strategy } \\
\text { 'tonometry all' }\end{array}$ & $\begin{array}{c}\text { Strategy } \\
\text { 'tonometry high- } \\
\text { risk group' }\end{array}$ & $\begin{array}{c}\text { Strategy } \\
\text { 'tonometry no } \\
\text { one' }\end{array}$ \\
\hline Costs $^{\mathrm{a}}(€)$ & 295 & 265 & 225 \\
Proportion of patients not becoming blind $^{\mathrm{a}}$ & 0.993 & 0.986 & 0.984 \\
Years of blindness $^{\mathrm{a}}$ & 0.021 & 0.053 & 0.062 \\
Incremental cost-effectiveness ratio $^{\mathrm{b}}$ & 7778 & 20000 & - \\
(extra costs to prevent 1 person from becoming blind) $_{\text {Incremental cost-effectiveness ratio }}^{\mathrm{b}}$ & & & - \\
(extra costs per year of vision saved) & 1707 & 4444 & - \\
\hline
\end{tabular}

a expected costs and effects per initial ophthalmic patient due to ocular hypertension or glaucoma within 20 years (costs and years in blindness have been discounted by $4 \%$ )

b the incremental cost-effectiveness ratio shows extra costs per effect in comparison with the strategy 'tonometry no one' (ratio between the difference in costs and the difference in effects)

\section{Discussion}

This study evaluates the long-term consequences of three case-finding strategies, which differ with respect to the group of patients receiving tonometry. For this purpose a simulation model was used. Although a randomized clinical trial would be of interest, it is almost impossible to conduct. Beside the ethical objections such trial would inevitably give large expenses because of the low prevalence of glaucoma and its slow progression to blindness. An advantage of modeling is the possibility to simulate and compare several strategies. Another advantage is the possibil- 
ity to integrate current research results and examine the influence of alteration of different parameters.

The figures incorporated in the model are based on information from different sources. This could give uncertainty about the exact value of the figures. A sensitivity analysis was performed to assess the impact of variation of the uncertain quantities in the model on the outcomes of the cost-effectiveness analysis. The conclusions were robust to these uncertainties.

To validate the simulation model strategy 'tonometry all', which represents more or less the current practice, was studied in more detail. The model shows that on average over a period of 20 years, each year $5.2 \%$ of glaucoma patients undergoes laser therapy and $2.7 \%$ surgery. A questionnaire, distributed among glaucoma patients in randomly chosen practices in the Netherlands, showed comparable results. ${ }^{39}$ Per year $4.8 \%$ of patients had laser therapy and $2 \%$ surgery. The model was further validated by comparing the incidence of glaucoma blindness to those reported in the literature. Two longitudinal studies were conducted in patients from a clinic. ${ }^{40,41}$ The incidence rate of blindness in these studies was $1.05 \%$ and $0.95 \%$ per year, respectively. The model shows an incidence rate of blindness $0.90 \%$ per year.

The costs seem to be comparable to those reported in the literature. One study assessed the annual resource use and costs of patients in the Netherlands. ${ }^{42}$ The mean costs per glaucoma patient were $€ 469$ (converted and using the retail price index). In the simulation model this is $€ 454$. Another study calculated the direct treatment costs for newly diagnosed $\mathrm{OH}$ or POAG patients in Germany. ${ }^{43}$ The mean costs per $\mathrm{OH} / \mathrm{POAG}$ patient for one year of treatment were about $€ 324$ (converted and using the retail price index). The same authors calculated the costs for France and the United Kingdom. ${ }^{44}$ This was $€ 387$ and $€ 560$, respectively. Other published glaucoma cost studies show comparable estimates for yearly costs in Europe and Canada. ${ }^{45-47}$ In the U.S. the published yearly costs ranged from $€ 486$ for early stage of the disease to $€ 1960$ for patients with end-stage disease. ${ }^{48}$ Differences in unit costs, in medication prices, in the assignment of laser therapy and surgery, can explain some variations in the costs. However, raising the costs in our study did not affect its conclusions.

The outcomes show that strategy 'tonometry all' is the most preferable in relation to blindness prevention. This strategy is most costly, but prevents most blindness. The incremental costs to prevent blindness when compared to 'tonometry no one' are small. For strategy 'tonometry high risk group' the incremental costs are higher. Even if the financing would be limited, it would be more preferable to perform tonometry in all patients, and not in high-risk group only, because strategy 'tonometry all' dominates strategy 'tonometry high risk group' in the extended sense. ${ }^{38}$ The costs due to blindness from glaucoma could not be retrieved. If such yearly costs exceed $€ 1707$, then performing tonometry in all patients becomes cost saving. This is likely the case because blindness is accompanied by the utilization of disability 
facilities. In the Netherlands a common help in the household for disabled people (12 hours a week) has a yearly cost of $€ 5$ 300. The costs of blindness may vary per country depending on the care and support given. A study conducted in the United Kingdom, which took the societal perspective, estimated the costs of blindness for people with age related macular degeneration. ${ }^{49}$ The costs of blindness in this study were $€ 10134$ ( $€ 2$ 159- $€ 26$ 847) in the first year and $€ 9883$ (€ 2 080-€ 26 376) in the second and subsequent years (converted and using the retail price index). The same paper gives an overview of the estimates of the cost of blindness for UK, Scotland, Australia, USA and Switzerland. The yearly costs due to blindness in these countries probably exceed $€ 1707$.

At first glance it is not obvious why strategy 'tonometry all' is the most costeffective because in general, approaching a high-risk group would give a higher yield of case-finding. However, in strategy 'tonometry all' not every detected $\mathrm{OH}$ patient is treated, as current guidelines advice only treatment in case of a presence of a risk factor. Those who are not treated at once are followed for the occurrence of glaucoma. Those who develop glaucoma are treated at an early stage; thereby blindness can still be prevented, and the costly treatment of those $\mathrm{OH}$ patients who never develop POAG can be avoided. When the proportion of high-risk patients receiving treatment was made similar to that in strategy 'tonometry all', the results became more alike, confirming that monitoring of $\mathrm{OH}$ patients without direct treatment contributes to a favorable cost-effectiveness ratio of strategy 'tonometry all'.

The impact of not using the ophthalmoscope to detect POAG has not been addressed. In daily practice ophthalmoscopy cannot be left out of the first ophthalmic examination. Its use is needed for the diagnosis of many diseases. Tonometry could be left out more easily since there is often no indication for it, except for the early detection of $\mathrm{OH}$ or POAG. The use of perimetry, costly and time consuming, is unlikely an option for case-finding. In the model patients undergo perimetry on indication, to confirm the diagnosis.

A positive family history of glaucoma was appointed as an indication for being at risk of having glaucoma. It is an established risk factor and it is easy to assess in daily practice. ${ }^{11}$ It has been estimated that about $20 \%$ of the $\mathrm{OH}$ and POAG patients and $5 \%$ of others in the ophthalmic patients population report a positive family history of glaucoma. ${ }^{10,50}$ The simulations show that even if these proportions are much higher strategy 'tonometry all' remains the most cost-effective (data not shown).

Note that normal tension glaucoma (NTG) is not included in this study. The role of IOP in its pathogenesis and the response to therapeutic lowering of IOP is different in comparison with high-tension glaucoma. Moreover, this disorder cannot be primarily detected by tonometry. As a consequence, inclusion of NTG in the study has no impact on the outcomes of the cost-effectiveness analysis, because the incremental costs and the incremental effects do not change. When NTG is in- 
cluded, the proportion of patients prevented from blindness due to glaucoma is slightly lower than calculated.

The indirect costs have not been used in the presented analysis, because glaucoma effects mainly elderly and the consequences in terms of potential loss of production are limited. ${ }^{51}$ No cost-utility analysis has been performed. An estimate for the utility for blindness is $0.6^{52}$ The estimated incremental costs per quality-adjusted life-year (QALY) for strategy 'tonometry all' are then approximately $€ 2850$. According to the guidelines in the Netherlands a $4 \%$ discount rate is used. Because of the current international recommendation of $3 \%$, an extra analysis was performed. ${ }^{38,53}$ If using a $3 \%$ discount rate, the incremental costs per year of vision saved for 'tonometry all' are $€ 1550$.

\section{Conclusion}

The strategy 'tonometry all' is the most preferable strategy for blindness prevention, with $€ 1707$ extra costs per year of vision saved when compared to strategy 'tonometry no one'. When costs associated with the use of disability facilities due to blindness exceed $€ 1707$ per patient per year, which is most likely, then strategy 'tonometry all' becomes cost saving. We conclude that it is most cost-effective to routinely perform tonometry to all initial ophthalmic patients to prevent blindness due to glaucoma.

\section{References}

1 Quigley HA. Number of people with glaucoma worldwide. British journal of ophthalmology 1996; 80: 389-393.

2 Harris R. Screening for glaucoma. BMJ 2005; 331: 376-377.

3 Kass MA, Heuer DK, Higginbotham EJ, et al. The Ocular Hypertension Treatment Study: a randomized trial determines that topical ocular hypotensive medication delays or prevents the onset of primary openangle glaucoma. Archives of ophthalmology 2002; 120: 701-713.

4 Heijl A, Leske MC, Bengtsson B, Hyman L, Hussein M. Reduction of intraocular pressure and glaucoma progression: results from the Early Manifest Glaucoma Trial. Archives of ophthalmology 2002; 120: 1268-1279.

5 Gottlieb LK, Schwartz B, Pauker SG. Glaucoma screening. A cost-effectiveness analysis. Survey of ophthalmology 1983; 28: 206-226.

6 Harasymowycz P, Kamdeu Fansi A, Papamatheakis D. Screening for primary open-angle glaucoma in the developed world: are we there yet? Canadian journal of ophthalmology; Journal canadien d'ophtalmologie 2005; 40: 477-486.

7 Fleming C, Whitlock EP, Beil T, et al. Screening for primary open-angle glaucoma in the primary care setting: an update for the US preventive services task force. Annals of family medicine 2005; 3: 167-170.

8 Screening for glaucoma: recommendation statement. Annals of family medicine 2005; 3: 171-172.

9 Wolfs RC, Klaver CC, Ramrattan RS, van Duijn CM, Hofman A, de Jong PT. Genetic risk of primary open-angle glaucoma. Population-based familial aggregation study. Archives of ophthalmology 1998; 116: 1640-1645.

10 Tielsch JM, Katz J, Sommer A, Quigley HA, Javitt JC. Family history and risk of primary open angle glaucoma. The Baltimore Eye Survey. Archives of ophthalmology 1994; 112: 69-73.

11 American Academy of Ophthalmology. Preferred Practice Patterns: primary open-angle glaucoma. San Francisco (CA): American Academy of Ophthalmology; 2000. 
12 Van der Horst FG, Webers CAB, Bours SJM. Transmuraal model oogzorg [Transmural Model Eyecare]. Maastricht: Datawyse; 2003.

13 Koch H. Practice Patterns of the Office-Based Ophthalmologist, National Ambulatory Medical Care Survey, 1985. Advance data 1989: 1-12.

14 Schappert SM. Office visits for glaucoma: United States, 1991-92. Advance data 1995: 1-14.

15 Ellwein LB, Urato CJ. Use of eye care and associated charges among the Medicare population: 19911998. Archives of ophthalmology 2002; 120: 804-811.

16 European Glaucoma Society. Terminology and Guidelines for Glaucoma. Editrice Dogma; 2003.

17 Centraal Bureau voor de Statistiek (CBS). Statline. Available at: http://statline.cbs.nl. Accessed September 8, 2003.

18 Jensen JE. Glaucoma screening: a 16-year follow-up of ocular normotensives. Acta ophthalmologica 1984; 62: 203-209.

19 Perkins SE. Bedford Glaucoma Survey II. Rescreening of the normal population. British journal of ophthalmology 1973; 57: 186-192.

20 Bengtsson B. Manifest glaucoma in the aged I: occurrence nine years after a population survey. Acta ophthalmologica 1981; 59: 321-331.

21 Sorensen PN, Nielsen NV, Norskov K. Ocular hypertension. A 15-year follow-up. Acta ophthalmologica 1978; 56: 363-372.

22 Lundberg L, Wettrell K, Linner E. Ocular hypertension. A prospective twenty-year follow-up study. Acta ophthalmologica 1987; 65: 705-708.

23 Epstein DL, Krug JH, Jr., Hertzmark E, Remis LL, Edelstein DJ. A long-term clinical trial of timolol therapy versus no treatment in the management of glaucoma suspects. Ophthalmology 1989; 96: 14601467.

24 Kamal D, Garway-Heath D, Ruben S, et al. Results of the betaxolol versus placebo treatment trial in ocular hypertension. Graefe's archive for clinical and experimental ophthalmology 2003; 241: 196-203.

25 Uusitalo RJ, Palkama A. Long-term evaluation of timolol. Acta ophthalmologica 1989; 67: 573-581.

26 Airaksinen PJ, Valle O, Takki KK, Klemetti A. Timolol treatment of chronic open-angle glaucoma and ocular hypertension. A 2.5-year multicenter study. Graefe's archive for clinical and experimental ophthalmology 1982; 219: 68-71.

27 Maclure GM. Chronic open angle glaucoma treated with Timolol. A four year study. Transactions of the ophthalmological societies of the United Kingdom 1983; 103: 78-83.

28 Heijl A, Bengtsson B. Long-term effects of timolol therapy in ocular hypertension: a double-masked, randomised trial. Graefe's archive for clinical and experimental ophthalmology 2000; 238: 877-883.

29 Shingleton BJ, Richter CU, Bellows AR, Hutchinson BT, Glynn RJ. Long-term efficacy of argon laser trabeculoplasty. Ophthalmology 1987; 94: 1513-1518.

30 Ticho U, Nesher R. Laser trabeculoplasty in glaucoma. Ten-year evaluation. Archives of ophthalmology 1989; 107: 844-846.

31 Vogel M, Ecker S, Cieplik G, Bernhardt G. Laser trabeculoplasty in glaucoma chronicum simplex. Results of a prospective, clinical study [in German]. Klinische Monatsblatter fur Augenheilkunde 1988; 193: 8-15.

32 Ustundag C, Diestelhorst M. Efficacy of argon laser trabeculoplasty: 3-year preliminary results of a prospective placebo-controlled study. Graefe's archive for clinical and experimental ophthalmology 1997; 235: 354-358.

33 Spiegel D, Wegscheider E, Lund OE. Argon laser trabeculoplasty: long-term follow-up of at least 5 years. German journal of ophthalmology 1992; 1: 156-158.

34 Parc CE, Johnson DH, Oliver JE, Hattenhauer MG, Hodge DO. The long-term outcome of glaucoma filtration surgery. Am J Ophthalmol 2001; 132: 27-35.

35 Molteno AC, Bosma NJ, Kittelson JM. Otago glaucoma surgery outcome study: long-term results of trabeculectomy - 1976 to 1995 . Ophthalmology 1999; 106: 1742-1750.

36 Lamping KA, Bellows AR, Hutchinson BT, Afran SI. Long-term evaluation of initial filtration surgery. Ophthalmology 1986; 93: 91-101.

37 Popovic V, Sjostrand J. Long-term outcome following trabeculectomy: II Visual field survival. Acta ophthalmologica 1991; 69: 305-309.

38 Gold MR, Siegel JE, Russel LB, et al. Cost-effectiveness in Health and Medicine. First press release. New York: Oxford University Press; 1996.

39 Voorlichting aan glaucoompatienten [Education for glaucoma patients]. Rapport, 2002; nr 143. Amstelveen, The Netherlands: College voor zorgverzekeringen; 2002.

40 Chen PP. Blindness in patients with treated open-angle glaucoma. Ophthalmology 2003; 110: 726-733.

41 Kwon YH, Kim CS, Zimmerman MB, Alward WL, Hayreh SS. Rate of visual field loss and long-term visual outcome in primary open-angle glaucoma. Am J Ophthalmol 2001; 132: 47-56. 
42 Oostenbrink JB, Rutten van Molken MP, Sluyter Opdenoordt TS. Resource use and costs of patients with glaucoma or ocular hypertension: a one-year study based on retrospective chart review in the Netherlands. Journal of glaucoma 2001; 10: 184-191.

43 Kobelt G, Jonsson L, Gerdtham U, Krieglstein GK. Direct costs of glaucoma management following initiation of medical therapy. A simulation model based on an observational study of glaucoma treatment in Germany. Graefe's archive for clinical and experimental ophthalmology 1998; 236: 811-821.

44 Kobelt G, Jonsson L. Modeling cost of treatment with new topical treatments for glaucoma. Results from France and the United Kingdom. International journal of technology assessment in health care 1999; 15: 207-219.

45 Traverso CE, Walt JG, Kelly SP, et al. Direct costs of glaucoma and severity of the disease: a multinational long term study of resource utilisation in Europe. British journal of ophthalmology 2005; 89: 12451249.

46 Lindblom B, Nordmann JP, Sellem E, et al. A multicentre, retrospective study of resource utilization and costs associated with glaucoma management in France and Sweden. Acta ophthalmologica Scandinavica 2006; 84: 74-83.

47 Iskedjian M, Walker J, Vicente C, et al. Cost of glaucoma in Canada: analyses based on visual field and physician's assessment. Journal of glaucoma 2003; 12: 456-462.

48 Lee PP, Walt JG, Doyle JJ, et al. A multicenter, retrospective pilot study of resource use and costs associated with severity of disease in glaucoma. Archives of ophthalmology 2006; 124: 12-19.

49 Meads C, Hyde C. What is the cost of blindness? British journal of ophthalmology 2003; 87(10): 12011204.

50 Weih LM, Nanjan M, McCarty CA, Taylor HR. Prevalence and predictors of open-angle glaucoma: results from the visual impairment project. Ophthalmology 2001; 108: 1966-1972.

51 Kobelt G. Health economics, economic evaluation, and glaucoma. Journal of glaucoma 2002; 11: 531539.

52 Brown MM, Brown GC, Sharma S, Busbee B. Quality of life associated with visual loss: a time tradeoff utility analysis comparison with medical health states. Ophthalmology 2003; 110: 1076-1081.

53 Hunink MG, Glasziou P, et al. Decision making in health and medicine: integrating evidence and values. Cambridge: Cambridge University Press; 2001.

54 Dielemans I, Vingerling JR, Hofman A, Grobbee DE, de Jong PT. Reliability of intraocular pressure measurement with the Goldmann applanation tonometer in epidemiological studies. Graefe's archive for clinical and experimental ophthalmology 1994; 232: 141-144.

55 Grolman B, Myers KJ, Lalle P. How reliable is the Goldmann tonometer as a standard? Journal of the American Optometric Association 1990; 61: 857-862.

56 Whitacre MM, Stein R. Sources of error with use of Goldmann-type tonometers. Survey of ophthalmology $1993 ; 38: 1-30$.

57 Tielsch JM, Katz J, Singh K, et al. A population-based evaluation of glaucoma screening: the Baltimore Eye Survey. American journal of epidemiology 1991; 134: 1102-1110.

58 Tuck MW, Crick RP. The cost-effectiveness of various modes of screening for primary open angle glaucoma. 1997; 4: 3-17.

59 Quigley HA. Open-angle glaucoma. New England journal of medicine 1993; 328: 1097-1106.

60 Harper R, Reeves B. The sensitivity and specificity of direct ophthalmoscopic optic disc assessment in screening for glaucoma: a multivariate analysis. Graefe's archive for clinical and experimental ophthalmology 2000; 238: 949-955.

61 Ivers RQ, Macaskill P, Cumming RG, Mitchell P. Sensitivity and specificity of tests to detect eye disease in an older population. Ophthalmology 2001; 108: 968-975.

62 RIVM Nationaal Kompas Volksgezondheid - Gezichtsstoornissen [Visual Impairments], RIVM: Volksgezondheid Toekomst Verkenning; 1977: ISBN 903521868 X NUGI.

63 Quigley HA. Proportion of those with open-angle glaucoma who become blind. Ophthalmology 1999; 106: 2039-2041.

64 Jay JL, Murdoch JR. The rate of visual field loss in untreated primary open angle glaucoma. British journal of ophthalmology, 1993; 77: 176-178.

65 Commissie Farmaceutische hulp $(\mathrm{CFH})$ van het College voor zorgverzekeringen [Health Care Insurance Board]. Farmacotherapeutisch Kompas [Pharmacotherapeutic Compass] 2004; ISBN 90-70918-35-8. 


\section{The clinical impact of two different strategies for initiating therapy in patients with ocular hypertension}

Andrea Peeters ${ }^{1}$

Carroll A.B. Webers ${ }^{1}$

Martin H. Prins ${ }^{2,3}$

Fred Hendrikse ${ }^{1}$

Jan S.A.G. Schouten ${ }^{1}$

1 Department of Ophthalmology, Maastricht University Hospital, The Netherlands

2 Department of Epidemiology, Maastricht University, The Netherlands

3 Department of Clinical Epidemiology and Medical Technology Assessment, Maastricht University Hospital, Maastricht, The Netherlands

Submitted for publication 


\begin{abstract}
Objective: To assess the impact of two strategies for initiating therapy in ocular hypertension on intraocular pressure, drug use, and eventual blindness due to glaucoma.

Design: A simulation model.

Methods: Two strategies are modelled. In strategy (1) therapy is started with timolol, in strategy (2) with latanoprost. By Monte Carlo simulation the IOP lowering effect of the specific drugs is applied to a hypothetical cohort of $\mathrm{OH}$ patients, characterized by an initial IOP distribution. Depending on the achieved IOP and occurrence of side effects, the prescribed therapy can be maintained or therapy switches occur, at most four times. The adjustment of therapy to reach the target pressure involves consecutively monotherapy, combination therapy, and laser. Switches to different types of monotherapy and combination therapy are included. Four drugs are used: latanoprost, timolol, brimonidine, and dorzolamide. After 15 months of therapy adjustments a lifelong follow-up with possible conversion to glaucoma and to blindness is modeled (Markov model). Conversion rates depend on the achieved IOP. The parameters in the model are based on the literature, the cohort characteristics on the data of 1000 patients. The analyses were performed for a cohort with a sampled and fixed initial IOP (25 and $30 \mathrm{~mm} \mathrm{Hg}$ ).
\end{abstract}

Outcome measures: 1) drug distribution after 15 months 2) IOP after 15 months 3) blindness through glaucoma within a lifelong follow-up.

Results: Treatment goal was achieved in both strategies in $90 \%$ by monotherapy. For a cohort with an initial IOP $30 \mathrm{~mm} \mathrm{Hg}$ this was $60 \%$. The originally prescribed medication was maintained in $66 \%$ in strategy (1) and in $77 \%$ in strategy (2). IOP decreased with approximately $34 \%$, from $25.4 \mathrm{~mm} \mathrm{Hg}$ (sampled mean) to $16.7 \mathrm{~mm}$ $\mathrm{Hg}$ in strategy (1) and to $16.5 \mathrm{~mm} \mathrm{Hg}$ in strategy (2). The computed blindness per person within 18.7 years of life expectancy was 0.0923 years in strategy (1) and 0.0870 years in strategy (2), which corresponds to approximately 1 month. The difference between strategies corresponds to 2 days spent in blindness per patient.

Conclusion: Concerning the clinical effects of the two strategies, the differences are quite small. This is largely caused by the key concept of a target pressure, which underlies both strategies. 


\section{Introduction}

The introduction of new IOP lowering drugs in the last decades has contributed to a change of the drug prescription pattern for ocular hypertension $(\mathrm{OH})$ and glaucoma. ${ }^{1-3}$ An ophthalmologist can choose from a broad spectrum of hypotensive drugs. The IOP lowering effect, the ease of application, the occurrence of sideeffects, contraindications, and costs, are all important factors in drug choice. For many years, non-selective beta-blockers such as timolol have been the first choice in treatment. However, the use of beta-blockers is decreasing and hypotensive lipids, such as latanoprost, are becoming the most commonly prescribed drugs. One may question whether latanoprost should be the first choice in $\mathrm{OH}$ therapy instead of timolol. Latanoprost gives only a slightly better IOP lowering effect than timolol. ${ }^{4}$ The cost price of latanoprost is, however, considerably higher than that of timolol. In the literature mostly a head-to-head comparison can be found between treatment with hypotensive lipids and treatment with timolol, based on the achieved IOP level. One study compared the effectiveness of treatment on the glaucoma progression as well, however, based on IOP reduction through timolol only and hypotensive lipids only. ${ }^{5}$ Such a comparison does not take into account essential aspects of patient management. In daily practice, therapies often get adjusted, even repeatedly. For each patient a target pressure is defined and a best fitting therapy is searched for, a therapy that achieves an optimal IOP reduction with minimal adverse events. The goal of each treatment strategy is to reach the same target pressure. Therefore, one may expect that such strategies will give similar clinical results. In this paper a simulation model is presented, which was used to quantitatively assess the clinical effects of initiating $\mathrm{OH}$ therapy with timolol or with latanoprost. The details of therapy adjustments have been taken into account. The model is set up to compare the two strategies with respect to their impact on the IOP, drug use, and blindness due to glaucoma. Our analysis is focused on the difference in the clinical effects due to a different first therapy choice, followed by similar steps for therapy adjustments, for a cohort of $\mathrm{OH}$ patients as they enter an ophthalmic practice.

\section{Methods}

\section{General design}

Two strategies for the initiation and adjustment of $\mathrm{OH}$ medication are modelled and compared. In strategy (1) therapy is started with timolol and in strategy (2) with latanoprost. By using a Monte Carlo simulation the IOP lowering effect of the specific drugs is applied to a hypothetical cohort of $\mathrm{OH}$ patients. This cohort is characterized by the initial IOP and age distributions. The adjustment of therapy in order to reach the target pressure is modelled as in the ophthalmic practice. Patients start therapy with a topical agent and return for evaluation. In case of adverse events, or unsatisfactory IOP decrease, therapy is adjusted and a new evaluation follows. Therapy switches are modelled at most four times. Therapies involve monotherapy, combination therapy and laser. Four drugs, representatives of four 
major generic classes, are used: timolol (beta-blockers), latanoprost (hypotensive lipids), brimonidine ( $\alpha 2$-adrenergic agonists), and dorzolamide (topical carbonic anhydrase inhibitors). The modelled IOP lowering effects are specific for each drug and for each drug combination. Effects correspond to timolol $0.5 \%$, latanoprost $0.005 \%$, dorzolamide $2 \%$, brimonidine $0.2 \%$. Contraindication to timolol is taken into account. Once the therapy adjustments are completed, which covers at most 15 months of therapy, per strategy the achieved new IOP distribution and the drug distribution within the cohort are determined. Subsequently by using a Markov model also a lifelong follow-up of the cohort and the disease progression over time are modelled. A conversion to glaucoma and to blindness can take place. Yearly conversion rates are dependent on the achieved IOP level. Per strategy the eventual years of blindness are determined. The time horizon of the model is based on the life expectancy of patients. The parameters used in the model are based on the literature. The IOP lowering effect of the specific drugs is based on a meta-analysis of randomized clinical trials. ${ }^{4}$ The estimates of other parameters are based on clinical trials and long-term follow-up studies. Glaucoma specialists were consulted to decide which medication should be used in case of a therapy switch. The characteristics of the simulated cohort are based on the data of 1000 ophthalmic patients.

\section{The model}

The model is built by use of software package 'Decision Analysis by TreeAge' (Data), version 3.5. Input data and their sources are shown in Tables 1-3 and Figure 1. In addition, the survival probabilities are taken from data provided by the Dutch Central Bureau for Statistics (CBS) ${ }^{33}$ Conversion to blindness is based on an assumption that $1 \%$ of glaucoma patients per year become blind. ${ }^{34,35}$ The simulated cohort consists of initial $\mathrm{OH}$ patients (without glaucomatous changes of the optic nerve head or visual field loss) of at least 40 years old. Mean age is 64.5 years. Initial IOP within this population includes values from 22 to $35 \mathrm{~mm} \mathrm{Hg}$. Mean initial IOP value is $25.36 \mathrm{~mm} \mathrm{Hg}$.

Figure 1: The IOP dependent yearly incidence of POAG in $\mathrm{OH}$ patients under treatment ${ }^{21-32}$

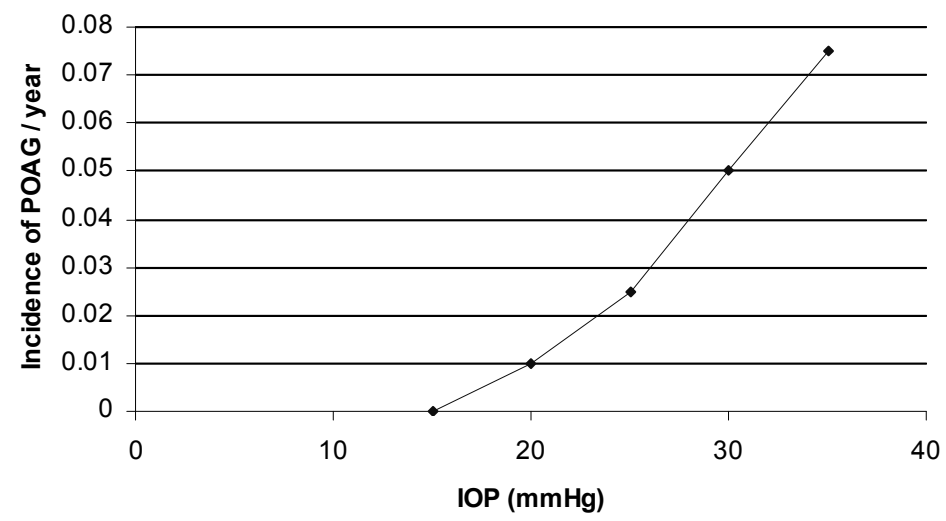


Table 1: The initial IOP distribution of the simulated cohort ${ }^{6}$

\begin{tabular}{cc}
\hline IOP $(\mathrm{mm} \mathrm{Hg})$ & Proportion \\
\hline 22 & 0.17 \\
23 & 0.16 \\
24 & 0.15 \\
25 & 0.13 \\
26 & 0.11 \\
27 & 0.08 \\
28 & 0.05 \\
29 & 0.04 \\
30 & 0.03 \\
31 & 0.02 \\
32 & 0.02 \\
33 & 0.02 \\
34 & 0.01 \\
35 & 0.01 \\
\hline
\end{tabular}

Two treatment strategies are set up as follows. In strategy 'start with timolol' patients start therapy with timolol unless contraindicated, in which case latanoprost is used. In strategy 'start with latanoprost' all patients start therapy with latanoprost. Both latanoprost and timolol are used in each strategy. A switch from latanoprost to timolol and vice versa is possible. In case of a therapy switch first latanoprost and timolol are used, brimonidine, and dorzolamide afterwards. Laser treatment follows only if there are no more treatment options through medication. Contraindication to timolol is taken into account at all places in the model where this drug is applied. The corresponding proportion of patients receives another medication.

Table 2: IOP reduction through therapy used in the simulation model ${ }^{4,7-11}$

\begin{tabular}{lc}
\hline Intervention & $\begin{array}{c}\text { IOP reduction }(\%) \\
(\text { mean } \pm \mathrm{SD})\end{array}$ \\
\hline Timolol $(0.5 \%)$ & $26.5 \pm 14$ \\
Latanoprost $(0.005 \%)$ & $29.5 \pm 13.4$ \\
Dorzolamide $(2 \%)$ & $19.5 \pm 13.5$ \\
Brimonidine $(0.2 \%)$ & $21 \pm 13.1$ \\
Timolol + latanoprost (add on) & $20.5 \pm 13.9$ \\
Timolol + dorzolamide (add on) & $18 \pm 12$ \\
1 drug + 1 drug or laser (add on) & $18 \pm 12$ \\
2 drugs + 1 drug or laser (add on) & $10 \pm 5$ \\
3 drugs + laser (add on) & $8 \pm 4$ \\
Laser & $30 \pm 12$ \\
\hline
\end{tabular}

Table 3: Parameters used in the simulation model ${ }^{12-20}$

\begin{tabular}{lccc}
\hline Parameter & $\begin{array}{c}\text { Proportion } \\
\text { (lower bound) }\end{array}$ & $\begin{array}{c}\text { Proportion } \\
\text { (baseline) }\end{array}$ & $\begin{array}{c}\text { Proportion } \\
\text { (upper bound) }\end{array}$ \\
\hline Contraindication timolol & 0.1 & 0.2 & 0.3 \\
Side effect* timolol & 0.05 & 0.1 & 0.3 \\
Side effect* latanoprost & 0.01 & 0.03 & 0.1 \\
Side effect* dorzolamide & 0.05 & 0.15 & 0.25 \\
Side effect* brimonidine & 0.05 & 0.15 & 0.25 \\
\hline
\end{tabular}

* any side effects of medication that cause a therapy change

Therapy adjustment is modelled within the structure of a decision tree. A simplified impression of the tree is given in Figure 2. Always three months after a prescription 
of a medication an evaluation is modelled to take place. For each simulated patient a new IOP, achieved by the IOP lowering effect of the prescribed drug, and an occurrence of side effects are modelled probabilistically. A patient then either maintains the prescribed medication, or a therapy change follows with a subsequent new evaluation. Criteria for treatment adjustments are as follows. 1) If serious side effects occur, the drug is replaced with another one, regardless of the achieved IOP level. 2) In the absence of side effects the treatment assignment depends on the achieved IOP level as follows: a) If the achieved IOP is less than or equal to $21 \mathrm{~mm}$ $\mathrm{Hg}$, medication is not changed. b) If the achieved IOP is higher than $21 \mathrm{~mm} \mathrm{Hg}$ and the IOP reduction is more than $20 \%$ of the original IOP level another drug is added. c) If the achieved IOP is higher than $21 \mathrm{~mm} \mathrm{Hg}$ and the IOP reduction is less than $20 \%$ of the original IOP level, the currently used medication is substituted by another one. Laser treatment is assigned in the same way as a new drug, as an addition to the medication or as a replacement of it. Occurrence of side effects is independent of age or IOP.

Figure 2: Visual representation of the therapy adjustments applied during the first 15 months of treatment

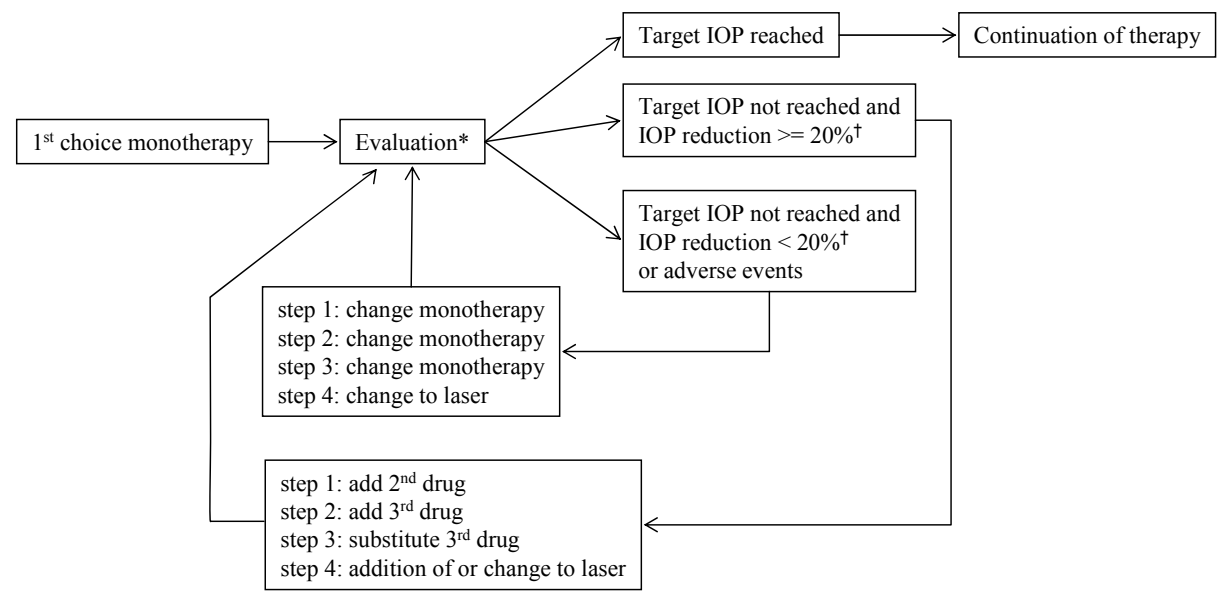

* if target IOP reached or if all 4 steps have been evaluated, then continuation therapy
${ }^{\dagger}$ with respect to baseline IOP

Subsequent lifelong follow-up is implemented as a Markov model. In a Markov model a set of independent states is defined and patients switch from one state to another at a regular interval (cycle) according to the transition probabilities. The following health states can be entered: 'glaucoma', 'blindness' and 'death'. Age and sex dependent survival probabilities, an IOP dependent (per $\mathrm{mm} \mathrm{Hg}$ ) glaucoma incidence rate, and a yearly probability of becoming blind from glaucoma are included. In the model sex has been distributed equally. Transitions to the health states can take place always at the end of a 6 months cycle. The choice of the cycle length reflects the common time between consecutive outpatient visits. 


\section{Analysis}

The analyses were performed for an initial IOP sampled from the distribution and additionally for the fixed values of the initial IOP: 25 and $30 \mathrm{~mm} \mathrm{Hg}$. The following outcomes were determined: 1) drug distribution after 15 months after initiation of therapy 2) IOP distribution and mean IOP within the cohort after 15 months after initiation of therapy 3) blindness through glaucoma within a lifetime follow-up. A sensitivity analysis was conducted for the outcomes of mean IOP and blindness. For this purpose the parameters for contraindication to timolol, the occurrence of sideeffects, and the IOP lowering effect of timolol and latanoprost were varied. Also analyses were conducted after an elimination of the IOP lowering effect of brimonidine, dorzolamide, and laser. In addition, for the outcome of blindness, a comparison was made with a simulated 'no-treatment' option.

\section{Results}

Drug use after 15 months after initiation of therapy

The drug distribution within the cohort after the therapy adjustment is given in Table 4 . In both strategies approximately $90 \%$ of the simulated patients use monotherapy. In a cohort of patients with an initial IOP of $30 \mathrm{~mm} \mathrm{Hg}$ this is about $60 \%$. The proportion of patients using initially prescribed medication is different per strategy. In strategy 'start with timolol' $53 \%$ of patients use monotherapy timolol and $32 \%$ monotherapy latanoprost. It must be noted that in this strategy it is modeled that $20 \%$ of patients start therapy with latanoprost because of contraindication to timolol. Thus about $66 \%$ maintain the originally prescribed timolol. In strategy 'start with latanoprost' $77.1 \%$ maintains the prescribed monotherapy latanoprost. The proportion of patients receiving combination therapy and/or laser treatment is similar for both strategies, even in the cohort of patients with IOP of $30 \mathrm{~mm} \mathrm{Hg}$.

Table 4: Drug use 15 months after the initiation of $\mathrm{OH}$ therapy with timolol or with latanoprost, per strategy, for different values of the initial IOP

\begin{tabular}{|c|c|c|c|c|c|c|}
\hline & \multicolumn{3}{|c|}{ Strategy 'start with timolol' } & \multicolumn{3}{|c|}{ Strategy 'start with latanoprost' } \\
\hline & IOP & IOP & IOP & IOP & IOP & IOP \\
\hline & sample & $25 \mathrm{~mm} \mathrm{Hg}$ & $30 \mathrm{~mm} \mathrm{Hg}$ & sample & $25 \mathrm{~mm} \mathrm{H}$ & $30 \mathrm{~mm} \mathrm{Hg}$ \\
\hline \multicolumn{7}{|l|}{ Monotherapy } \\
\hline timolol & $53.0 \%$ & $55.8 \%$ & $28.8 \%$ & $8.0 \%$ & $10.2 \%$ & $7.6 \%$ \\
\hline latanoprost & $32.0 \%$ & $35.8 \%$ & $23.8 \%$ & $77.1 \%$ & $81.8 \%$ & $47.5 \%$ \\
\hline brimonidine or dorzolamide & $5.8 \%$ & $7.1 \%$ & $7.8 \%$ & $5.8 \%$ & $6.9 \%$ & $7.9 \%$ \\
\hline \multicolumn{7}{|l|}{ Combination of 2 drugs } \\
\hline timolol+latanoprost & $2.0 \%$ & $0.0 \%$ & $9.3 \%$ & $3.4 \%$ & $0.0 \%$ & $16.1 \%$ \\
\hline timolol+dorzolamide & $1.5 \%$ & $0.0 \%$ & $7.3 \%$ & - & - & - \\
\hline dorzolamide + brimonidine & $0.4 \%$ & $0.0 \%$ & $1.7 \%$ & $0.4 \%$ & $0.0 \%$ & $1.6 \%$ \\
\hline timolol $+($ dorzolamide or brimonidine $)$ & $0.0 \%$ & $0.0 \%$ & $0.1 \%$ & $1.2 \%$ & $0.0 \%$ & $5.1 \%$ \\
\hline $\begin{array}{l}\text { latanoprost }+(\text { dorzolamide or } \\
\text { brimonidine) }\end{array}$ & $3.0 \%$ & $0.0 \%$ & $12.8 \%$ & $1.4 \%$ & $0.0 \%$ & $6.6 \%$ \\
\hline \multicolumn{7}{|l|}{ Combination of 3 drugs } \\
\hline $\begin{array}{l}\text { various combinations of timolol, } \\
\text { latanoprost, dorzolamide, brimonidine }\end{array}$ & $1.2 \%$ & $0.0 \%$ & $4.3 \%$ & $1.2 \%$ & $0.0 \%$ & $4.1 \%$ \\
\hline Laser treatment & $1.9 \%$ & $1.2 \%$ & $5.8 \%$ & $2.1 \%$ & $1.2 \%$ & $5.7 \%$ \\
\hline
\end{tabular}




\section{IOP after 15 months of treatment}

In Figure 3, for the cohort with sampled IOP, an IOP distribution after therapy adjustment is given for both strategies. The patterns of distribution seem superimposible. Nevertheless, values of $19 \mathrm{~mm} \mathrm{Hg}$ and higher are more frequent in strategy 'start with timolol', 30\% against 27\%, and complementary values of $18 \mathrm{~mm} \mathrm{Hg}$ and lower are more frequent in strategy 'start with latanoprost', 73\% against $70 \%$. The mean IOP values are shown in Table 5. The initial IOP decreased with approximately $34 \%$ from $25.4 \mathrm{~mm} \mathrm{Hg}$ (sampled mean) to 16.7 ( \pm 0.017$) \mathrm{mm} \mathrm{Hg}$ in strategy 'start with timolol' and to $16.5( \pm 0.013) \mathrm{mm} \mathrm{Hg}$ in strategy 'start with latanoprost'. In a cohort of patients with an initial IOP of $30 \mathrm{~mm} \mathrm{Hg}$ the IOP decrease in both strategies was about $69 \%$, to $17.5 \mathrm{~mm} \mathrm{Hg}$.

Figure 3: IOP distribution after 15 months of treatment per strategy, for a cohort with a sampled initial IOP

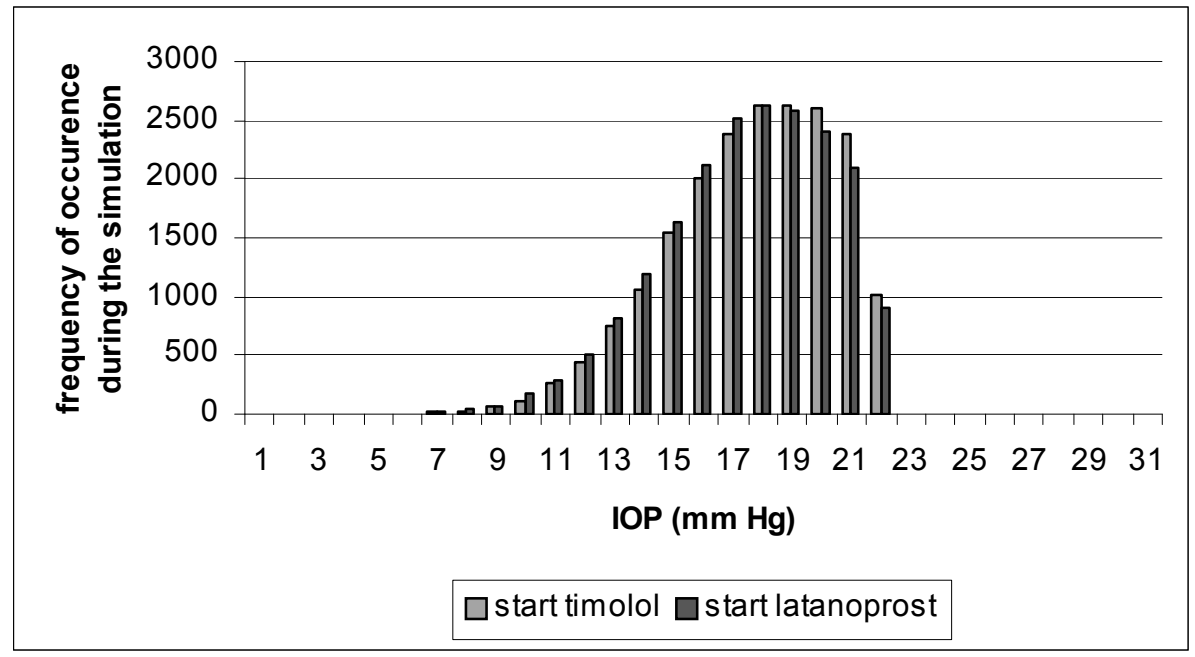

Years of blindness due to glaucoma

In Table 5 for each strategy the expected years of blindness due to glaucoma per patient are given. The computed time with blindness per patient is 0.0923 (33.7 days) years in strategy 'start with timolol' and 0.0870 (31.8 days) years in strategy 'start with latanoprost'. This corresponds to approximately 1 month of blindness per patient, over a period of 18.7 years, which is the computed mean life expectancy in the cohort. The difference between the strategies is 2 days of blindness, a difference of about $6 \%$. For reference, a 'no treatment' simulation $(0 \%$ IOP reduction through medication and laser) shows 0.492 expected years of blindness per patient, which corresponds to approximately 6 months of blindness. 


\section{Sensitivity analysis}

In a one-way sensitivity analysis the parameters for contraindication to timolol and occurrence of side-effects have been varied within the given ranges, as given in Table 3. This had however, minimal impact on the mean IOP or blindness (data not shown). In Table 5 other results of the sensitivity analysis are shown. The IOP lowering effects of timolol and latanoprost were varied within the range of a $95 \%$ confidence interval around the given value, in which the lower and upper bounds for both drugs represent about $2 \%$ more or less IOP reduction. ${ }^{4} \mathrm{~A}$ two-way sensitivity analysis with $2 \%$ less IOP reduction through timolol and $2 \%$ more IOP reduction through latanoprost shows a difference in blindness, which corresponds to 5 days per patient, in favor of strategy 'start with latanoprost'.

Table 5: Treatment effects of two different strategies for initiating $\mathrm{OH}$ therapy, (1) 'start with timolol' or (2) 'start with latanoprost', for different values of the initial IOP

\begin{tabular}{|c|c|c|c|c|c|c|}
\hline & \multicolumn{2}{|c|}{ Initial IOP = sample } & \multicolumn{2}{|c|}{ Initial IOP $=25 \mathrm{~mm} \mathrm{Hg}$} & \multicolumn{2}{|c|}{ Initial IOP $=30 \mathrm{~mm} \mathrm{Hg}$} \\
\hline & $\begin{array}{l}\text { Strategy (1) } \\
\text { (timolol) }\end{array}$ & $\begin{array}{l}\text { Strategy (2) } \\
\text { (latanoprost) }\end{array}$ & $\begin{array}{l}\text { Strategy (1) } \\
\text { (timolol) }\end{array}$ & $\begin{array}{l}\text { Strategy (2) } \\
\text { (latanoprost) }\end{array}$ & $\begin{array}{l}\text { Strategy (1) } \\
\text { (timolol) }\end{array}$ & $\begin{array}{l}\text { Strategy (2) } \\
\text { (latanoprost) }\end{array}$ \\
\hline & \multicolumn{6}{|c|}{$\begin{array}{l}\text { IOP change through medication after } 15 \text { months of therapy } \\
\qquad(\mathrm{mm} \mathrm{Hg})\end{array}$} \\
\hline Basic analysis & $\begin{aligned} & 16.66 \\
\pm & 0.017^{*}\end{aligned}$ & $\begin{array}{c}16.52 \\
\pm 0.013\end{array}$ & $\begin{aligned} & 16.88 \\
\pm & 0.016\end{aligned}$ & $\begin{array}{c}16.74 \\
\pm 0.014\end{array}$ & $\begin{array}{l}17.49 \\
\pm 0.008\end{array}$ & $\begin{array}{c}17.49 \\
\pm 0.011\end{array}$ \\
\hline \multicolumn{7}{|l|}{ Sensitivity analysis } \\
\hline $\begin{array}{l}0 \% \text { IOP reduction through } \\
\text { laser }\end{array}$ & $\begin{array}{l}16.73 \\
\pm 0.005\end{array}$ & $\begin{aligned} & 16.57 \\
\pm & 0.016\end{aligned}$ & $\begin{array}{l}16.92 \\
\pm 0.020\end{array}$ & $\begin{aligned} & 16.77 \\
\pm & 0.018\end{aligned}$ & $\begin{array}{l}17.67 \\
\pm 0.014\end{array}$ & $\begin{aligned} & 17.67 \\
\pm & 0.010\end{aligned}$ \\
\hline $\begin{array}{l}0 \% \text { IOP reduction through } \\
\text { laser, dorzolamide en } \\
\text { brimonidine }\end{array}$ & $\begin{array}{r}17.02 \\
\pm 0.014\end{array}$ & $\begin{array}{l}16.84 \\
\pm 0.024\end{array}$ & $\begin{aligned} & 17.17 \\
\pm & 0.019\end{aligned}$ & $\begin{array}{r}17.00 \\
\pm 0.019\end{array}$ & $\begin{array}{l}18.35 \\
\pm 0.014\end{array}$ & $\begin{array}{r}18.27 \\
\pm 0.018\end{array}$ \\
\hline $\begin{array}{l}2 \% \text { less IOP reduction through } \\
\text { timolol and } 2 \% \text { more IOP } \\
\text { reduction through latanoprost }\end{array}$ & $\begin{array}{l}16.66 \\
\pm 0.019\end{array}$ & $\begin{array}{l}16.22 \\
\pm 0.022\end{array}$ & $\begin{array}{l}16.85 \\
\pm 0.011\end{array}$ & $\begin{array}{l}16.42 \\
\pm 0.011\end{array}$ & $\begin{aligned} & 17.36 \\
\pm & 0.008\end{aligned}$ & $\begin{array}{l}17.29 \\
\pm 0.001\end{array}$ \\
\hline \multicolumn{7}{|c|}{$\begin{array}{l}\text { Blindness through glaucoma } \\
\text { (years of blindness) }\end{array}$} \\
\hline Basic analysis & $\begin{array}{c}0.0923 \\
\pm 0.0012\end{array}$ & $\begin{array}{l}0.0870 \\
\pm 0.0010\end{array}$ & $\begin{array}{c}0.0977 \\
\pm 0.0011\end{array}$ & $\begin{array}{c}0.0924 \\
\pm 0.0011\end{array}$ & $\begin{array}{c}0.1175 \\
\pm 0.0008\end{array}$ & $\begin{array}{c}0.1173 \\
\pm 0.0012\end{array}$ \\
\hline Sensitivity analysis & & & & & & \\
\hline $\begin{array}{l}0 \% \text { IOP reduction through all } \\
\text { medication and laser (no } \\
\text { treatment) }\end{array}$ & $\begin{array}{c}0.4924 \\
\pm 0.0031\end{array}$ & $\begin{array}{c}0.4924 \\
\pm 0.0031\end{array}$ & $\begin{array}{l}0.4555 \\
\pm 0.0038\end{array}$ & $\begin{array}{l}0.4555 \\
\pm 0.0038\end{array}$ & $\begin{array}{c}0.7741 \\
\pm 0.0059\end{array}$ & $\begin{array}{c}0.7741 \\
\pm 0.0059\end{array}$ \\
\hline $\begin{array}{l}0 \% \text { IOP reduction through } \\
\text { laser }\end{array}$ & $\begin{array}{c}0.0969 \\
\pm 0.0013\end{array}$ & $\begin{array}{c}0.0923 \\
\pm 0.0022\end{array}$ & $\begin{array}{l}0.1003 \\
\pm 0.0007\end{array}$ & $\begin{array}{l}0.0953 \\
\pm 0.0013\end{array}$ & $\begin{array}{c}0.1301 \\
\pm 0.0013\end{array}$ & $\begin{array}{c}0.1299 \\
\pm 0.0009\end{array}$ \\
\hline $\begin{array}{l}0 \% \text { IOP reduction through } \\
\text { laser, dorzolamide en } \\
\text { brimonidine }\end{array}$ & $\begin{array}{l}0.1092 \\
\pm 0.0021\end{array}$ & $\begin{array}{c}0.1040 \\
\pm 0.0020\end{array}$ & $\begin{array}{c}0.1107 \\
\pm 0.0004\end{array}$ & $\begin{array}{c}0.1047 \\
\pm 0.0002\end{array}$ & $\begin{array}{c}0.1546 \\
\pm 0.0023\end{array}$ & $\begin{array}{l}0.1535 \\
\pm 0.0024\end{array}$ \\
\hline $\begin{array}{l}2 \% \text { less IOP reduction through } \\
\text { timolol and } 2 \% \text { more IOP } \\
\text { reduction through latanoprost }\end{array}$ & $\begin{array}{c}0.0934 \\
\pm 0.0015\end{array}$ & $\begin{array}{r}0.0807 \\
\pm 0.0017\end{array}$ & $\begin{array}{c}0.0982 \\
\pm 0.0007\end{array}$ & $\begin{array}{c}0.0854 \\
\pm 0.0007\end{array}$ & $\begin{array}{c}0.1160 \\
\pm 0.0012\end{array}$ & $\begin{array}{c}0.1130 \\
\pm 0.0012\end{array}$ \\
\hline
\end{tabular}

\footnotetext{
* standard deviation for the average, computed from 5 Monte Carlo simulations of size 20000 each

${ }^{\dagger}$ mean expected time spent in blindness per person within 18.7 years of life expectancy
} 


\section{Discussion}

The difference in impact on IOP or blindness of the two analyzed treatment strategies was minimal. The model shows that from the clinical point of view it does not matter by which medication therapy should be initiated. Many $\mathrm{OH}$ patients can reach their target pressure with any first choice medication, whether timolol or latanoprost. For them, glaucoma development and blindness will be acceptably small; only slight differences will apply. For patients with a high initial IOP a similar situation arises, since treatment adjustments are also aimed to reach the target pressure. If the target pressure is achieved, clinical effects of the different strategies will again be very similar. Otherwise more therapy adjustments will occur to achieve a best possible treatment and the effect of the initial choice largely cancels out.

The choice for a simulation model requires some attention. The alternative of a clinical trial would inevitably be associated with large expenses, particularly due to a long follow-up. One of the advantages of modeling is the ability to predict events in the long-term. A simulation of a lifetime follow-up of a cohort of patients can be performed. Hence, in a short time period long-term results can be assessed. Another advantage is that different scenarios can be constructed by changing the influential factors. A model also allows a real life simulation, such as no treatment strategy, without placing patients at risk. Moreover, by applying a Monte Carlo simulation, which is run 100000 times, a reliable estimate of the clinical result of a strategy given the underlying variation is obtained (see the calculated standard deviations given in Table 5).

The parameters used in the model are taken from different sources and do not represent an exact value. We have attempted to use the best available data from the literature. A range of values was tested to determine the robustness of the qualitative conclusions drawn from the analysis. The outcomes of the sensitivity analysis did not alter the conclusions of the study.

To validate the model a process known as "debugging" the tree was applied, to avoid modeling or programming errors. ${ }^{36}$ Also, a comparison was made with clinical outcomes of $\mathrm{OH}$ treatment, as known from the literature. The design of the Ocular Hypertension Treatment Study (OHTS) corresponds well with the modelled therapy approach. ${ }^{37}$ In the OHTS study therapy was initiated with a topical agent and medication was subsequently changed and/or added, if required, until the treatment goals were met or the participant was receiving the maximum tolerated topical medical therapy. In the OHTS study the baseline pressure was $24.9 \pm 2.7 \mathrm{~mm}$ $\mathrm{Hg}$. In the modelled cohort this was $25.4 \pm 3.0 \mathrm{~mm} \mathrm{Hg}$. The model showed approximately $34 \%$ IOP reduction through medication. In the OHTS study the IOP reduction in the medication group was smaller, namely $22.5 \pm 9.9 \%$. There are several explanations for this. Firstly, the treatment goals of the studies differ in the target pressure criterion, this being $24 \mathrm{~mm} \mathrm{Hg}$ in the OHTS study and $21 \mathrm{~mm} \mathrm{Hg}$ in the model. Secondly, in the OHTS study the average IOP across follow-up visits is 
given, whereas the model outcomes show a mean IOP value after the therapy adjustments are completed. Thirdly, when treatment of the OHTS study participants started, the treatment choice was limited, as some of the hypotensive drugs, were not available yet.

In the model no difference is made between beginning and advanced glaucoma. The yearly estimate for blindness applies to all glaucoma patients. This might be slightly overestimated. The IOP reduction through various medications is taken from a meta analysis of randomized clinical trials. ${ }^{4}$ The age and IOP distributions within the cohort of initial $\mathrm{OH}$ patients were selected from the charts of 1000 initial patients, consecutively visiting a regional non-referral ophthalmic practice in Maastricht (Medisch Centrum Maastricht Annadal - MCMA), starting from January 1999. The global characteristics of these distributions have been verified to be consistent with the literature. ${ }^{38-40}$

In summary, we believe that our model approaches the clinical practice closely, uses the optimal current data, and produces results that are reliable.

\section{Conclusions}

Concerning the clinical effects of the two strategies of initiating $\mathrm{OH}$ therapy with latanoprost or with timolol, the differences are quite small. This is largely caused by the key concept of a target pressure, which underlies both treatment strategies. As it turns out, this target pressure can be achieved fairly easily by both strategies for many patients.

\section{References}

1 De Natale R, Draghi E, Dorigo MT. How prostaglandins have changed the medical approach to glaucoma and its costs: an observational study of 2228 patients treated with glaucoma medications. Acta ophthalmologica Scandinavica 2004;82(4):393-6.

2 Azuara Blanco A, Burr J. The rising cost of glaucoma drugs. British journal of ophthalmology 2006;90(2):130-1.

3 Knox FA, Barry M, McGowan B, O'Brien C. The rising cost of glaucoma drugs in Ireland 1996-2003. British journal of ophthalmology 2006;90(2):162-5.

4 Van der Valk R, Webers CAB, Schouten JSAG, Zeegers MP, Hendrikse F, Prins MH. Intraocular Pressure-Lowering Effects of All Commonly Used Glaucoma Drugs: A Meta-analysis of Randomized Clinical Trials. Ophthalmology 2005;112:1177-85.

5 Halpern MT, Covert DW, Robin AL. Projected impact of travoprost versus both timolol and latanoprost on visual field deficit progression and costs among black glaucoma subjects. Transactions of the American Ophthalmological Society 2002;100:109-17; discussion 17-8.

6 Van der Horst FG, Webers CAB, Bours SJM. Transmuraal model oogzorg [Transmural Model Eyecare]. Maastricht: Datawyse; 2003;ISBN 90-74474-08-X.

7 Tuulonen A, Niva AK, Alanko HI. A controlled five-year follow-up study of laser trabeculoplasty as primary therapy for open-angle glaucoma. American journal of ophthalmology 1987;104:334-8.

8 Ticho U, Nesher R. Laser trabeculoplasty in glaucoma. Ten-year evaluation. Archives of ophthalmology 1989;107:844-6.

9 Odberg T, Sandvik L. The medium and long-term efficacy of primary argon laser trabeculoplasty in avoiding topical medication in open angle glaucoma. 1999;77:176-81. 
10 Ustundag C, Diestelhorst M. Efficacy of argon laser trabeculoplasty: 3-year preliminary results of a prospective placebo-controlled study. Graefe's archive for clinical and experimental ophthalmology; Albrecht von Graefes Archiv fur klinische und experimentelle Ophthalmologie 1997;235:354-8.

11 Shingleton BJ, Richter CU, Bellows AR, Hutchinson BT, Glynn RJ. Long-term efficacy of argon laser trabeculoplasty. Ophthalmology 1987;94:1513.

12 Volksgezondheid Toekomst Verkenning 1997. De som der delen. Rijksinstituut voor Volksgezondheid en milieu. Elsevier/De Tijdstroom, Utrecht, 1997.

13 Zhang WY, Po AL, Dua HS, Azuara Blanco A. Meta-analysis of randomised controlled trials comparing latanoprost with timolol in the treatment of patients with open angle glaucoma or ocular hypertension. British journal of ophthalmology 2001;85:983-90.

14 Stewart WC, Garrison PM. Beta-blocker-induced complications and the patient with glaucoma. Newer treatments to help reduce systemic adverse events. Archives of internal medicine 1998;158:221-6.

15 Hoyng PF, van Beek LM. Pharmacological therapy for glaucoma: a review. Drugs 2000;59:411-34.

16 van Beek LM, de Keizer RJ, Polak BC, Elzenaar PR, van Haeringen NJ, Kijlstra A. Incidence of ocular side effects of topical beta blockers in the Netherlands. British journal of ophthalmology 2000;84:856-9.

17 McMahon CD, Shaffer RN, Hoskins HD, Jr., Hetherington J, Jr. Adverse effects experienced by patients taking timolol. American journal of ophthalmology 1979;88:736-8.

18 Perry CM, McGavin JK, Culy CR, Ibbotson T. Latanoprost : an update of its use in glaucoma and ocular hypertension. Drugs and aging 2003;20:597-630.

19 Camras CB, Alm A, Watson P, Stjernschantz J. Latanoprost, a prostaglandin analog, for glaucoma therapy. Efficacy and safety after 1 year of treatment in 198 patients. Latanoprost Study Groups. Ophthalmology 1996;103:1916-24.

20 Oostenbrink JB, Rutten van Molken MP, Sluyter Opdenoordt TS. Resource use and costs of patients with glaucoma or ocular hypertension: a one-year study based on retrospective chart review in the Netherlands. Journal of glaucoma 2001;10:184-91.

21 Gordon MO, Beiser JA, Brandt JD, et al. The Ocular Hypertension Treatment Study: baseline factors that predict the onset of primary open-angle glaucoma. Archives of ophthalmology 2002; 120:714-20.

22 Kass MA, Heuer DK, Higginbotham EJ, et al. The Ocular Hypertension Treatment Study: a randomized trial determines that topical ocular hypotensive medication delays or prevents the onset of primary openangle glaucoma. Archives of ophthalmology 2002; 120:701-13.

23 Kamal D, Garway Heath D, Ruben S, et al. Results of the betaxolol versus placebo treatment trial in ocular hypertension. Graefe's archive for clinical and experimental ophthalmology; Albrecht von Graefes Archiv fur klinische und experimentelle Ophthalmologie 2003; 241:196-203.

24 Kass MA, Gordon MO, Hoff MR, et al. Topical timolol administration reduces the incidence of glaucomatous damage in ocular hypertensive individuals. A randomized, double-masked, long-term clinical trial. Archives of ophthalmology 1989; 107:1590-8.

25 Schulzer M, Drance SM, Douglas GR. A comparison of treated and untreated glaucoma suspects. Ophthalmology 1991; 98:301-7.

26 David R, Livingston DG, Luntz MH. Ocular hypertension - a long-term follow-up of treated and untreated patients. British journal of ophthalmology, The 1977; 61:668-74.

27 Hovding G, Aasved H. Prognostic factors in the development of manifest open angle glaucoma. A longterm follow-up study of hypertensive and normotensive eyes. Acta ophthalmologica 1986; 64:601-8.

28 Kitazawa Y, Horie T, Aoki S, Suzuki M, Nishioka K. Untreated ocular hypertension. A long-term prospective study. Archives of ophthalmology 1977; 95:1180-4.

29 Heijl A, Bengtsson B. Long-term effects of timolol therapy in ocular hypertension: a double-masked, randomised trial. Graefe's archive for clinical and experimental ophthalmology; Albrecht von Graefes Archiv fur klinische und experimentelle Ophthalmologie 2000; 238:877-83.

30 Epstein DL, Krug JH, Jr., Hertzmark E, Remis LL, Edelstein DJ. A long-term clinical trial of timolol therapy versus no treatment in the management of glaucoma suspects. Ophthalmology 1989; 96:1460-7.

31 Tanito M, Itai N, Dong J, Ohira A, Chihara E. Correlation between intraocular pressure level and optic disc changes in high-tension glaucoma suspects. Ophthalmology 2003; 110:915-21.

32 Lundberg L, Wettrell K, Linner E. Ocular hypertension. A prospective twenty-year follow-up study. Acta ophthalmologica 1987; 65:705-8.

33 survival probabilities: Centraal Bureau voor de Statistiek (CBS). Statline. Available at: http://statline.cbs.nl. Accessed September 8, 2003.

34 Chen PP. Blindness in patients with treated open-angle glaucoma. Ophthalmology 2003;110:726-33.

35 Kwon YH, Kim CS, Zimmerman MB, Alward WL, Hayreh SS. Rate of visual field loss and long-term visual outcome in primary open-angle glaucoma. American journal of ophthalmology 2001;132:47-56. 
36 Detsky AS, Naglie G, Krahn MD, et al. Primer on medical decision analysis: Part 2-Building a tree. Medical decision making an international journal of the Society for Medical Decision Making 1997;17(2):126-35.

37 Kass MA, Heuer DK, Higginbotham EJ, et al. The Ocular Hypertension Treatment Study: a randomized trial determines that topical ocular hypotensive medication delays or prevents the onset of primary openangle glaucoma. Archives of ophthalmology 2002;120(6):701-13.

38 Koch H. Practice Patterns of the Office-Based Ophthalmologist, National Ambulatory Medical Care Survey, 1985. Advance data 1989:1-12.

39 Schappert SM. Office visits for glaucoma: United States, 1991-92. Advance data 1995:1-14.

40 Ellwein LB, Urato CJ. Use of eye care and associated charges among the Medicare population: 19911998. Archives of ophthalmology 2002;120:804-11. 



\section{Latanoprost versus timolol as first choice therapy in patients with ocular hypertension A cost-effectiveness analysis}

Andrea Peeters ${ }^{1}$

Jan S.A.G. Schouten ${ }^{1}$

Hans L. Severens ${ }^{2,3}$

Fred Hendrikse ${ }^{1}$

Martin H. Prins ${ }^{2,4}$

Carroll A.B. Webers ${ }^{1}$

1 Department of Ophthalmology, Maastricht University Hospital, The Netherlands

2 Department of Clinical Epidemiology and Medical Technology Assessment, Maastricht University Hospital, Maastricht, The Netherlands

3 Department of Health Organisation, Policy and Economics, Maastricht University, The Netherlands

4 Department of Epidemiology, Maastricht University, The Netherlands

Submitted for publication 


\section{Abstract}

Objective: To determine the long term cost-effectiveness of treatment of ocular hypertension $(\mathrm{OH})$ with latanoprost compared to timolol.

Design: A cost-effectiveness simulation model.

Methods: Two strategies are modelled. In strategy (1) therapy is started with timolol, in strategy (2) with latanoprost. By Monte Carlo simulation the IOP lowering effect of the specific drugs is applied to a hypothetical cohort of $\mathrm{OH}$ patients, characterized by an initial IOP distribution. Depending on the achieved IOP and occurrence of side effects the prescribed therapy can be maintained or changed, at most four times. In a short term decision analytic model the adjustment of therapy to reach the target pressure involves consecutively monotherapy, combination therapy, and laser. Switches to different types of monotherapy and combination therapy are included. Four drugs are used: latanoprost, timolol, brimonidine, and dorzolamide. After 15 months of therapy adjustments a lifelong follow-up with possible conversion to glaucoma and to blindness is modeled (Markov model). Conversion rates depend on the achieved IOP. The direct medical costs are assigned. The parameters in the model are based on the literature and on the data of 1000 patients. The analyses were performed with a sampled initial IOP and with fixed values of 25 and $30 \mathrm{~mm} \mathrm{Hg}$.

Outcome measures: 1) mean IOP after 15 months of therapy 2) mean expected costs after 15 months of therapy 3) blindness through glaucoma within a lifetime follow-up 4) mean expected lifetime costs.

Results: The IOP decreased from $25.4 \mathrm{~mm} \mathrm{Hg}$ (sampled mean) to $16.7 \mathrm{~mm} \mathrm{Hg}$ in strategy (1) and to $16.5 \mathrm{~mm} \mathrm{Hg}$ in strategy (2). In strategy (1) the mean expected time spent in blindness per patient within 18.7 years of life expectancy is 0.0334 years and the lifetime costs are $€ 3514$ and in strategy (2) 0.0318 years and $€ 4397$, respectively (4\% discount used). The computed extra costs per year of vision saved for strategy (2) in comparison with strategy (1) amount to $€ 537000$. For patients with an initial IOP of $30 \mathrm{~mm} \mathrm{Hg}$ this is $€ 7068000$. These cost-effectiveness ratios are increasing with age, from $€ 222632$ for the 40 -years old to $€ 1057025$ for the 70 -years old.

Conclusion: It is computed, with the current cost price of latanoprost, that for saving one year of vision about $€ 537000$ extra is needed when therapy in $\mathrm{OH}$ patients is initiated with this drug compared to initiation with timolol. 


\section{Introduction}

The approach towards treatment of ocular hypertension $(\mathrm{OH})$ and primary openangle glaucoma (POAG) has changed in recent years. This is partly due to the introduction of new hypotensive agents, but also because of publication of the results of several randomized trials, which show the benefit of treatment in $\mathrm{OH}$ patients or in patients with early glaucoma. ${ }^{1-3}$ Recent research in various European countries indicates an increased number of treated patients, more aggressive treatment, and a change in therapy prescription pattern. ${ }^{4-7}$ The rising costs in glaucoma treatment can only be justified if associated with an adequate reduction in visual disability. The aim of therapy is to reduce increased intraocular pressure (IOP), a major risk factor in the development of glaucoma, and so prevent future visual deterioration and thus blindness.

Nowadays, hypotensive lipids are becoming the most commonly prescribed class of glaucoma drugs. ${ }^{6}$ Of these, latanoprost reduces IOP most and is currently often used as the drug of first choice instead of the beta-blocker timolol. However, its hypotensive effect is only slightly better than that of timolol, ${ }^{8}$ whereas the costs are much higher. Considering the costs and effects of these agents one may question whether it is cost-effective to change the initiation of therapy with timolol to latanoprost in $\mathrm{OH}$ patients. In the clinical trials an evaluation of the effectiveness of a specific glaucoma drug is based on its IOP lowering effect as monotherapy. However, it is important to realize, that patient management in the clinical practice often involves therapy switches and even combined therapies, in order to reach a target pressure for each patient.

In the present study, two strategies of initiating therapy in patients with ocular hypertension, starting with latanoprost or starting with timolol are modelled and evaluated for effects and costs. The two strategies are modelled as in the ophthalmic practice, including therapy adjustments, to reach a target pressure. Considering that this is the aim of both treatment strategies, one may expect small difference in the achieved IOP reduction. Which strategy is more cost-effective, may thus depend on whether the achieved difference in IOP will translate, in the long-term, in a reduction of glaucoma development and blindness that will outweigh the cost expenditure for $\mathrm{OH}$ medication. This study is performed from the societal perspective.

\section{Methods}

\section{General design}

Two strategies for the initiation and adjustment of $\mathrm{OH}$ medication are modelled and compared. In a previous study we have already assessed the short and long-term clinical effects of these strategies. In the present study we have assigned direct medical costs of treatment and calculated the incremental costs and effects of the two strategies, according to the standards of a cost-effectiveness analysis. ${ }^{9,10} \mathrm{We}$ use the same model as described earlier (paper submitted for publication). 
In strategy (1) therapy is started with timolol and in strategy (2) with latanoprost. By using a Monte Carlo simulation the IOP lowering effect of the specific drugs is applied to a hypothetical cohort of $\mathrm{OH}$ patients. This cohort is characterized by the initial IOP and age distributions. First the adjustment of therapy is modelled. Patients start therapy with a topical agent and return for evaluation. In case of adverse events, or unsatisfactory IOP decrease, therapy is adjusted and a new evaluation follows. Therapy switches are modelled at most four times. Therapies involve different types of monotherapy, combination therapy, and laser. Four drugs are used, representing four major generic classes: timolol (beta-blockers), latanoprost (hypotensive lipids), brimonidine ( $\alpha 2$-adrenergic agonists), and dorzolamide (topical carbonic anhydrase inhibitors). The modelled IOP lowering effects are specific for each drug and for each drug combination. Effects correspond to timolol $0.5 \%$, latanoprost $0.005 \%$, dorzolamide $2 \%$, brimonidine $0.2 \%$. Contraindication to timolol is taken into account. Once the therapy adjustments are completed, which covers at most 15 months of therapy, the achieved new IOP distribution and the drug distribution within the cohort are determined per strategy. Subsequently by using a Markov model a lifelong follow-up and the disease progression over time are modelled. A conversion to glaucoma and to blindness can take place. Yearly conversion is dependent on the IOP achieved after 15 months of treatment. Per strategy the eventual years of blindness are determined. The time horizon of the model is based on the life expectancy of patients. The IOP reductions through therapy, side-effects and contraindication of medication, glaucoma incidence and blindness development are based on the literature. The age and initial IOP distributions are based on the data of 1000 ophthalmic patients. Glaucoma specialists were consulted to decide which medication should be used in case of a therapy switch.

The hypothetical cohort consists of initial $\mathrm{OH}$ patients (without glaucomatous changes of the optic nerve head or visual field loss) of at least 40 years old. Mean age is 64.5 years. Initial IOP within this population includes values from 22 to 35 $\mathrm{mm} \mathrm{Hg}$. Mean initial IOP value is $25.4 \mathrm{~mm} \mathrm{Hg}$.

\section{The therapy adjustments (decision model)}

Therapy adjustment is modelled within the structure of a decision tree. The output of this decision model forms the input for the Markov model, which covers the lifelong follow-up. A simplified impression of the models is given in Figure 1. Two treatment strategies are set up as follows. In strategy 'start with timolol' patients start therapy with timolol unless contraindicated, in which case latanoprost is used. In strategy 'start with latanoprost' all patients start therapy with latanoprost. Both latanoprost and timolol are used in each strategy. A switch from latanoprost to timolol and vice versa is possible. In case of a therapy switch first latanoprost and timolol are used, followed by brimonidine, and dorzolamide. Laser treatment follows only if there are no more treatment options through medication. Contraindication to timolol is taken into account at all places in the model where this drug is applied. The corresponding proportion of patients with contraindication receives different medication. 
Every three months after a prescription of a medication an evaluation is modelled to take place. For each simulated patient a new IOP, achieved by the IOP lowering effect of the prescribed drug, and an occurrence of side effects are modelled probabilistically. A patient then either maintains the prescribed medication, or a therapy change follows with a subsequent new evaluation. Criteria for treatment adjustments are as follows. 1) If serious side effects occur, the drug is replaced with another one, regardless of the achieved IOP level. 2) In the absence of side effects the treatment assignment depends on the achieved IOP level as follows: a) If the achieved IOP is less than or equal to $21 \mathrm{~mm} \mathrm{Hg}$, medication is not changed. b) If the achieved IOP is higher than $21 \mathrm{~mm} \mathrm{Hg}$ and the IOP reduction is more than $20 \%$ of the original IOP level another drug is added. c) If the achieved IOP is higher than $21 \mathrm{~mm} \mathrm{Hg}$ and the IOP reduction is less than $20 \%$ of the original IOP level, the currently used medication is substituted by another one. Laser treatment is assigned in the same way as a new drug, as an addition to the medication or as a replacement of it. Occurrence of side effects is independent of age or IOP.

\section{The lifelong follow-up (Markov model)}

The lifelong follow-up is implemented within the structure of a Markov model. In a Markov model a set of independent states is defined and patients switch from one state to another at a regular interval (cycle) according to the transition probabilities. For all possible outcomes of medication assignment health states are defined, which can be entered. This takes place after the therapy adjustments are finished. At the end of the first 15 months period each simulated patient has his specific IOP achieved through therapy and a specific medication prescription. The initial health states are entered according to this specific medication. Subsequently during the follow-up the following health states can be entered: 'death', 'glaucoma', and 'blindness'. Age and sex dependent survival probabilities, an IOP dependent (per $\mathrm{mm} \mathrm{Hg}$ ) glaucoma incidence rate, and a yearly probability of becoming blind from glaucoma are included. In the model sex has been distributed equally. Transitions to the health states can take place always at the end of a 6 months cycle. The cycle length reflects the common time between consecutive outpatient visits. 


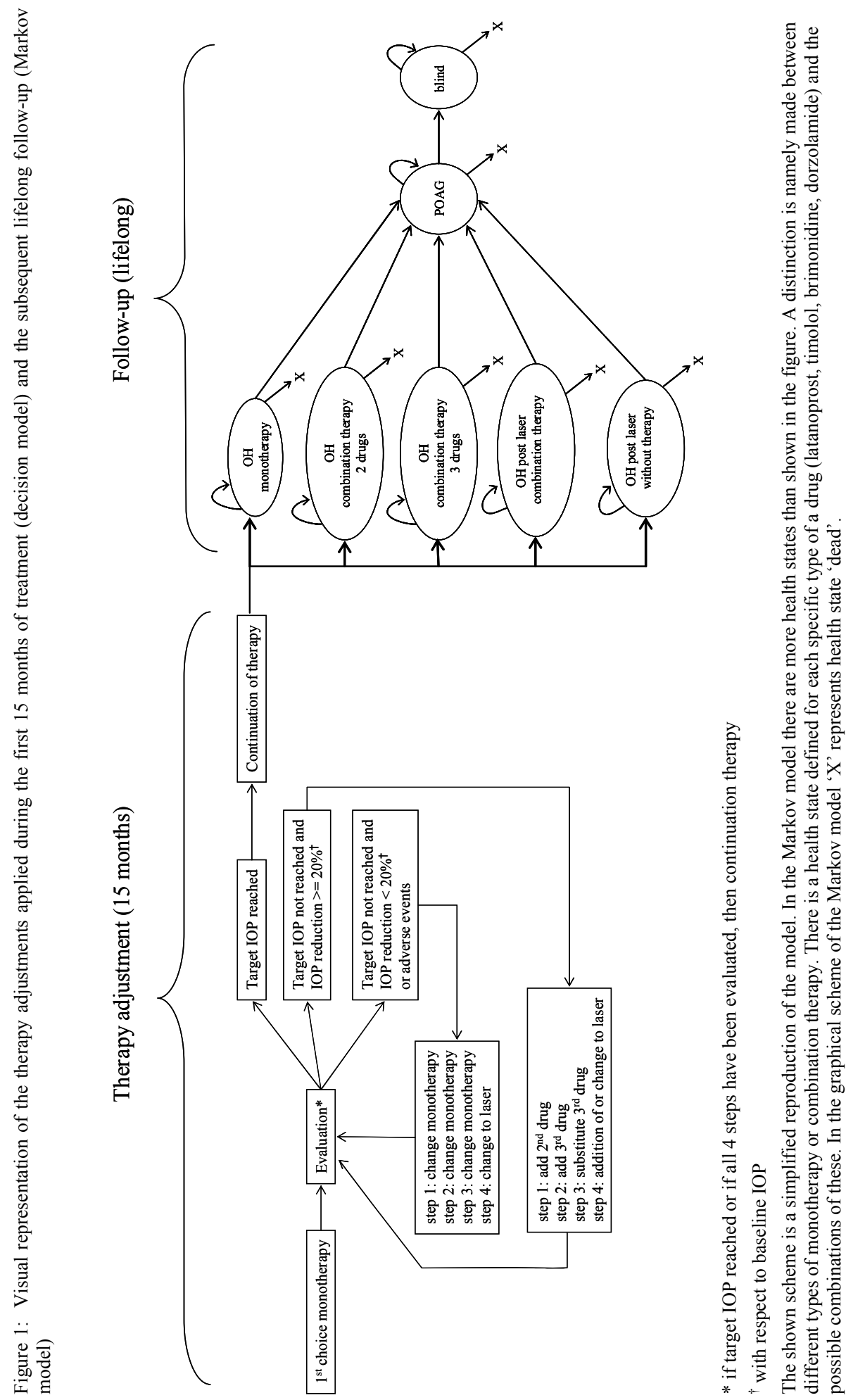




\section{Cost assignment}

The health care costs are assigned as once-only costs and state dependent costs. The once-only costs are the costs of outpatient visits, medication and laser therapy, related to the first 15 months of treatment. For each simulated patient these costs are added up. The state dependent costs are the costs related to $\mathrm{OH}$ and POAG treatment during life time follow-up in the Markov model. These costs are assigned to the health states and reflect the treatment requirements related to 6 months of treatment of a particular state. For each $\mathrm{OH}$ patient the costs involve the costs of outpatient visits and the specific costs of the prescribed medication. Once a conversion to POAG takes place, then POAG costs are assigned. These are the same for all patients and represent the average costs of a glaucoma patient in the Netherlands, including the costs of outpatient visits, perimetry, laser trabeculoplasty, surgery, and medication.

\section{Model input}

Input data and their sources are shown in Tables 1-4 and Figure 2. The age and IOP distribution for the population have been determined from the charts of 1000 initial patients, consecutively visiting a general ophthalmic practice in Maastricht (Medisch Centrum Maastricht Annadal - MCMA), starting from January 1999. The prices of medical drugs represent the prices in the Netherlands (incl. VAT). The unit prices related to outpatient visits and laser trabeculoplasty are as determined at the University Hospital Maastricht. This was done according to the micro costing method. ${ }^{9}$ The average treatment costs of a POAG patient were taken from a previous study of the authors (Eye advance online publication, 24 November 2006; doi:10.1038/sj.eye.6702637). The frequency of the health care use is modeled in accordance with the specialists' opinion and the recommendations of the American Academy of Ophthalmology. ${ }^{11}$ The survival probabilities are taken from data provided by the Dutch Central Bureau for Statistics (CBS). ${ }^{12}$ Conversion to blindness is based on an assumption that $1 \%$ of glaucoma patients per year become blind. $^{13,14}$

Figure 2: The IOP dependent yearly incidence of POAG in $\mathrm{OH}$ patients under treatment ${ }^{1,2,45-54}$

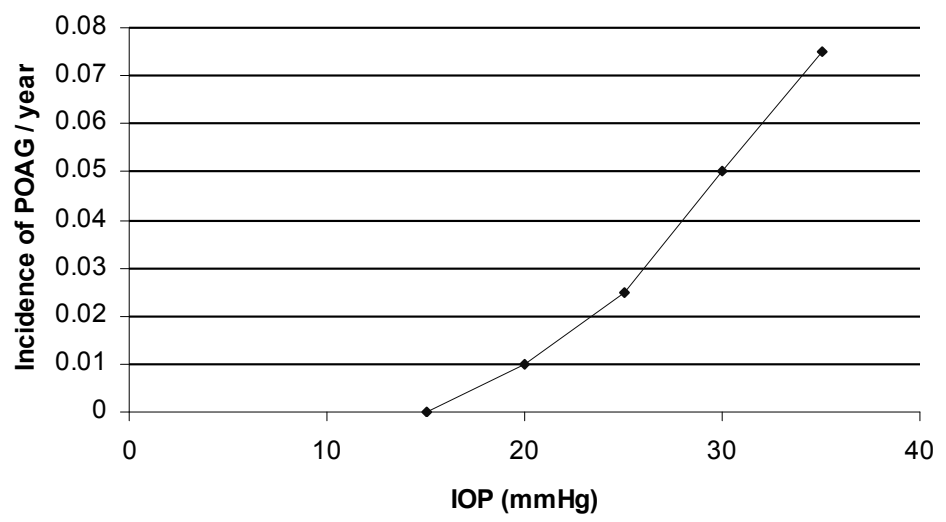


Table 1: Initial IOP of the simulated cohort ${ }^{30}$

\begin{tabular}{cc}
\hline IOP $(\mathrm{mm} \mathrm{Hg})$ & Proportion \\
\hline 22 & 0.17 \\
23 & 0.16 \\
24 & 0.15 \\
25 & 0.13 \\
26 & 0.11 \\
27 & 0.08 \\
28 & 0.05 \\
29 & 0.04 \\
30 & 0.03 \\
31 & 0.02 \\
32 & 0.02 \\
33 & 0.02 \\
34 & 0.01 \\
35 & 0.01 \\
\hline
\end{tabular}

Table 2: IOP reduction by therapy used in the simulation model $1^{8,31-35}$

\begin{tabular}{lc}
\hline Intervention & $\begin{array}{c}\text { IOP reduction }(\%) \\
(\text { mean } \pm \mathrm{SD})\end{array}$ \\
\hline Timolol $(0.5 \%)$ & $26.5 \pm 14$ \\
Latanoprost $(0.005 \%)$ & $29.5 \pm 13.4$ \\
Dorzolamide $(2 \%)$ & $19.5 \pm 13.5$ \\
Brimonidine $(0.2 \%)$ & $21 \pm 13.1$ \\
Timolol + latanoprost (add on) & $20.5 \pm 13.9$ \\
Timolol + dorzolamide (add on) & $18 \pm 12$ \\
1 drug + 1 drug or laser (add on) & $18 \pm 12$ \\
2 drugs + 1 drug or laser (add on) & $10 \pm 5$ \\
3 drugs + laser (add on) & $8 \pm 4$ \\
Laser & $30 \pm 12$ \\
\hline
\end{tabular}

Table 3: Parameters used in the simulation model $^{23,36-43}$

\begin{tabular}{lccc}
\hline Parameter & $\begin{array}{c}\text { Proportion } \\
\text { (lower bound) }\end{array}$ & $\begin{array}{c}\text { Proportion } \\
\text { (baseline) }\end{array}$ & $\begin{array}{c}\text { Proportion } \\
\text { (upper bound) }\end{array}$ \\
\hline Contraindication timolol & 0.1 & 0.2 & 0.3 \\
Side effect* timolol & 0.05 & 0.1 & 0.3 \\
Side effect* latanoprost & 0.01 & 0.03 & 0.1 \\
Side effect* dorzolamide & 0.05 & 0.15 & 0.25 \\
Side effect* brimonidine & 0.05 & 0.15 & 0.25 \\
\hline
\end{tabular}

* any side effects of medication that cause a therapy change 
Table 4: The cost prices of medication and the health care unit prices $(2001)^{44}$

\begin{tabular}{lc}
\hline & Cost price \\
\hline Timolol $(0.5 \%)$ & $5.10 € /$ month \\
Latanoprost $(0.005 \%)$ & $18.67 € /$ month \\
Dorzolamide $(2 \%)$ & $12.86 € /$ month \\
Brimonidine $(0.2 \%)$ & $14.32 € /$ month \\
Timolol + latanoprost (add on) & $22.79 € /$ month \\
Timolol + dorzolamide (add on) & $17.59 € /$ month \\
Outpatient visit $(15$ min) & $27.57 €$ \\
Outpatient visit $(10$ min) & $23.85 €$ \\
Perimetry & $80.93 €$ \\
Laser & $279.42 €$ \\
Transportation (per visit) & $2.9 €$ \\
Glaucoma therapy* & $450 € /$ year \\
\hline
\end{tabular}

* average costs of a glaucoma patient including outpatient visits, medication, perimetry, laser, and surgery

\section{Analysis}

A Monte Carlo simulation was used to sample from the age, sex, and initial IOP distributions within the cohort, and the distributions of IOP reduction through specific medication and/or laser. The analyses were performed for an initial IOP sampled from the distribution and additionally for the fixed values of the initial IOP: 25 and $30 \mathrm{~mm} \mathrm{Hg}$. The following outcomes were determined per strategy: 1) mean IOP within the cohort after 15 months after initiation of therapy 2) mean expected costs after 15 months of therapy 3) blindness through glaucoma within the lifetime follow-up 4) mean expected lifetime costs. The analysis was performed with a discount rate of $4 \%$, for both costs and effects, and without a discount. A subgroup and sensitivity analyses were performed for the fixed values of the initial IOP: 25 and $30 \mathrm{~mm} \mathrm{Hg}$, with a $4 \%$ discount rate. In a subgroup analysis the expected costs and years of blindness per strategy were determined apart for patients aged 40, 50, 60 and 70 years. In a one-way sensitivity analysis the contraindication for timolol, the side effects of medication, the cost of glaucoma therapy and the cost price of latanoprost have been varied. A two-way sensitivity analysis was carried out for the IOP lowering effect of timolol and latanoprost.

\section{Results}

Outcomes after 15 months of treatment: IOP and expected costs

The initial IOP decreased with approximately $34 \%$ from $25.4 \mathrm{~mm} \mathrm{Hg}$ (sampled mean) to $16.7( \pm 0.017) \mathrm{mm} \mathrm{Hg}$ in strategy 'start with timolol' and to $16.5( \pm 0.013)$ $\mathrm{mm} \mathrm{Hg}$ in strategy 'start with latanoprost'. For patients with a fixed initial IOP of $30 \mathrm{~mm} \mathrm{Hg}$ the IOP decrease was about $69 \%$, in both strategies to about $17.5 \mathrm{~mm}$ $\mathrm{Hg}$. The calculated costs per patient 15 months after initiation of therapy were $€ 367$ $( \pm 0.66)$ in strategy 'start with timolol' and $€ 469( \pm 0.39)$ in strategy 'start with latanoprost'. For patients with an initial IOP of $30 \mathrm{~mm}$ Hg these costs were $€ 441$ $( \pm 0.33)$ and $€ 496( \pm 0.53)$, respectively. 


\section{Outcomes within a lifetime follow-up: blindness due to glaucoma and expected costs}

In Table 5 for each strategy years of blindness due to glaucoma and expected lifetime costs per patient are given. The computed time with blindness per patient is 0.0923 (33.7 days) years in strategy 'start with timolol' and 0.0870 (31.8 days) years in strategy 'start with latanoprost' (without discount). This corresponds to approximately 1 month of blindness per patient, over a period of 18.7 years, which is the computed mean life expectancy in the cohort. The difference between the strategies is 2 days of blindness, a difference of about $6 \%$, in favor of strategy 'start with latanoprost'. For reference, a 'no treatment' simulation $(0 \%$ IOP reduction through medication and laser) showed 0.492 expected years of blindness per patient, which corresponds to approximately 6 months.

Table 5: Results of the cost-effectiveness analysis of two different strategies for initiating treatment of ocular hypertension (analyses with sampled and fixed values of the initial IOP)

\begin{tabular}{|c|c|c|}
\hline & $\begin{array}{c}\text { Strategy } \\
\text { 'start with timolol' }\end{array}$ & $\begin{array}{c}\text { Strategy } \\
\text { 'start with latanoprost' }\end{array}$ \\
\hline \multicolumn{3}{|c|}{$4 \%$ discount (costs and effects) } \\
\hline \multicolumn{3}{|c|}{ Initial IOP sampled } \\
\hline $\operatorname{costs}(€)$ & $3514 \pm 13.670 * * *$ & $4397 \pm 15.014$ \\
\hline years of blindness* & $0.0334 \pm 0.0004$ & $0.0318 \pm 0.0004$ \\
\hline incremental $\mathrm{C} / \mathrm{E}^{* *}$ & - & 536852 \\
\hline \multicolumn{3}{|c|}{ Initial IOP $=25 \mathrm{~mm} \mathrm{Hg}$} \\
\hline $\operatorname{costs}(€)$ & $3396 \pm 4.056$ & $4304 \pm 4.378$ \\
\hline years of blindness & $0.0361 \pm 0.0004$ & $0.0344 \pm 0.0003$ \\
\hline incremental $\mathrm{C} / \mathrm{E}$ & - & 547276 \\
\hline \multicolumn{3}{|c|}{ Initial IOP $=30 \mathrm{~mm} \mathrm{Hg}$} \\
\hline costs $(€)$ & $4215 \pm 6.394$ & $4583 \pm 10.708$ \\
\hline years of blindness & $0.04301 \pm 0.0002$ & $0.04296 \pm 0.0004$ \\
\hline incremental $\mathrm{C} / \mathrm{E}$ & - & 7068037 \\
\hline \multicolumn{3}{|c|}{$0 \%$ discount (costs and effects) } \\
\hline \multicolumn{3}{|l|}{ Initial IOP sampled } \\
\hline $\operatorname{costs}(€)$ & $5456 \pm 23.929$ & $6794 \pm 27.790$ \\
\hline years of blindness & $0.0923 \pm 0.0012$ & $0.0870 \pm 0.0010$ \\
\hline incremental $\mathrm{C} / \mathrm{E}$ & - & 253011 \\
\hline \multicolumn{3}{|c|}{ Initial IOP $=25 \mathrm{~mm} \mathrm{Hg}$} \\
\hline costs $(€)$ & $5269 \pm 18.760$ & $6628 \pm 17.188$ \\
\hline years of blindness & $0.0977 \pm 0.0011$ & $0.0924 \pm 0.0011$ \\
\hline incremental $\mathrm{C} / \mathrm{E}$ & - & 254150 \\
\hline \multicolumn{3}{|c|}{ Initial IOP $=30 \mathrm{~mm} \mathrm{Hg}$} \\
\hline costs $(€)$ & $6556 \pm 18.142$ & $7099 \pm 13.767$ \\
\hline years of blindness & $0.1175 \pm 0.0008$ & $0.1173 \pm 0.0012$ \\
\hline incremental $\mathrm{C} / \mathrm{E}$ & - & 2009703 \\
\hline
\end{tabular}

The values represent the expected lifetime costs and effects for a treated $\mathrm{OH}$ patient (an average computed from 5 Monte Carlo simulations of size 20000 each); * mean expected time spent in blindness per person within 18.7 years of life expectancy; ** the incremental cost-effectiveness ratio shows extra costs per year of vision saved when starting therapy with latanoprost compared to starting with timolol; *** standard deviation for the average, computed from 5 Monte Carlo simulations of size 20000 each

The calculated expected lifetime costs include the costs of the first 15 months of therapy as well. The lifetime costs are lower for strategy 'start with timolol' than for strategy 'start with latanoprost', namely $€ 5456$ against $€ 6794$ (€ 3514 against 
$€ 4397$ discounted). For patients with an initial IOP of $30 \mathrm{~mm} \mathrm{Hg}$ the difference in costs is smaller, namely $€ 6556$ against $€ 7099$ ( $€ 4215$ against $€ 4583$ discounted). The outcomes of the subgroup analysis are given in Table 6 . The difference in costs and effects between the strategies becomes smaller with an increasing age.

\section{Sensitivity analyses}

The outcomes of the sensitivity analyses are partially shown in Table 6 . The variation of the transition probabilities of contraindication for timolol and side effects of medication within the given ranges (see Table 3 ) had hardly any influence on the outcomes (data not shown). Lowering the costs of glaucoma therapy from $€ 450$ /year to $€ 350$ /year, or increasing it to $€ 600$ /year, gives only a slight decrease or increase of the lifetime costs in both strategies, about $0.8-1.5 \%$. Analyses with a reduced price of latanoprost, from $€ 18.7 /$ month to $€ 10 /$ month and $€ 6 /$ month, show a marked reduction and vanishing of the cost difference between the strategies. With a reduced price of latanoprost, for patients with an initial IOP of $30 \mathrm{~mm} \mathrm{Hg}$, in strategy 'start with latanoprost' the lifetime costs are lower than in strategy 'start with timolol'. The IOP lowering effects of timolol and latanoprost were varied within the range of a $95 \%$ confidence interval around the given value, in which the lower and upper bounds for both drugs represent about $2 \%$ more or less IOP reduction. ${ }^{8}$ A two-way sensitivity analysis with $2 \%$ more IOP reduction through latanoprost and $2 \%$ less IOP reduction through timolol shows better blindness prevention for a cohort with an initial IOP $25 \mathrm{~mm} \mathrm{Hg}$ in strategy 'start with latanoprost', and with an initial IOP $30 \mathrm{~mm} \mathrm{Hg}$ in both strategies.

\section{Cost-effectiveness}

According to the simulations strategy 'start with timolol' is cheaper than strategy 'start with latanoprost' but yields more years of blindness. In tables 5 and 6 the incremental cost-effectiveness ratios are given. These are calculated as a ratio between the difference in costs and the difference in effects between the two strategies and represent extra costs per year of vision saved when initiating therapy with latanoprost compared to initiating with timolol. If therapy is initiated with latanoprost the computed extra costs per year of vision saved in comparison to initiation with timolol amount to $€ 537000$. An analysis with a fixed initial IOP of $30 \mathrm{~mm} \mathrm{Hg}$ shows a reduced difference in costs and almost no difference in blindness between the two strategies. For such patients extra costs per year of vision saved become much higher and amount to $€ 7068000$.

The subgroup analyses per 10-years age categories show that extra costs per year of vision saved when initiating therapy with latanoprost compared to timolol, are increasing with age, from $€ 222632$ for the 40 -years old to $€ 1057025$ for the 70 -years old. When the price of latanoprost is reduced, the cost-effectiveness ratio becomes smaller and drops even to $€ 44095$, if the price is $€ 6 / \mathrm{month}$. For patients with a fixed IOP of $30 \mathrm{~mm} \mathrm{Hg}$ strategy 'start with latanoprost' then becomes cost saving. 
Table 6: Results of the subgroup and sensitivity analyses

\begin{tabular}{llccc}
\hline & \multicolumn{2}{c}{ Initial IOP $=25 \mathrm{~mm} \mathrm{Hg}$} & \multicolumn{2}{c}{ Initial IOP $=30 \mathrm{~mm} \mathrm{Hg}$} \\
\hline $4 \%$ discount (costs and effects) & $\begin{array}{l}\text { Strategy } \\
\text { 'start with } \\
\text { timolol' }\end{array}$ & $\begin{array}{c}\text { Strategy } \\
\text { 'start with } \\
\text { latanoprost' }\end{array}$ & $\begin{array}{c}\text { Strategy } \\
\text { 'start with } \\
\text { timolol' }\end{array}$ & $\begin{array}{c}\text { Strategy } \\
\text { 'start with } \\
\text { latanoprost' }\end{array}$ \\
\hline
\end{tabular}

A. Subgroup analysis

Age: 40 years

costs $(€)$

years of blindness*

incremental $\mathrm{C} / \mathrm{E}^{* *}$

Age: 50 years
costs $(€)$
years of blindness
incremental $\mathrm{C} / \mathrm{E}$

Age: 60 years

costs $(€)$

years of blindness

incremental $\mathrm{C} / \mathrm{E}$

Age: 70 years

costs $(€)$

years of blindness

incremental $\mathrm{C} / \mathrm{E}$

$2885 \pm 4.400$
$0.0145 \pm 0.000$

$4716 \pm 2.157$

$0.0749 \pm 0.0005$

$5414 \pm 1.364 * * *$

$6797 \pm 2.222$

$0.1156 \pm 0.0007$

$6712 \pm 7.813$

$0.1453 \pm 0.0004$

222632

$7261 \pm 7.620$

$0.1218 \pm 0.0006$

$5942 \pm 4.177$

$0.0712 \pm 0.0004$

334809

$5866 \pm 9.311$

$0.0892 \pm 0.0002$

$6356 \pm 14.177$

$0.0893 \pm 0.0004$

- $8786078 * * * *$

$3848 \pm 5.543$

$0.0380 \pm 0.0002$

$4874 \pm 4.547$

$0.0361 \pm 0.0003$

552352

$4804 \pm 9.425$

$0.0454 \pm 0.0003$

$5219 \pm 5.903$

$0.0452 \pm 0.0003$

3320995
$3668 \pm 1.688$
$0.0138 \pm 0.0001$
1057025

$3607 \pm 5.437$

$0.0175 \pm 0.0001$

$3929 \pm 1.861$

$0.0175 \pm 0.0000$

18182688

B. Sensitivity analysis

Cost glaucoma therapy

$350 € /$ year

costs $(€)$

years of blindness

$3347 \pm 8.779$

$4253 \pm 7.471$

$4165 \pm 5.290$

$4530 \pm 9.849$

$0.0361 \pm 0.0002$

$0.0343 \pm 0.0003$

$0.0428 \pm 0.0006$

$0.0427 \pm 0.0005$

506138

3453151

Cost glaucoma therapy

$600 € /$ year

costs $(€)$

years of blindness

$3446 \pm 10.226$

$4340 \pm 8.563$

$0.0353 \pm 0.0003$

$0.0336 \pm 0.0002$

528171

$4303 \pm 2.503$

$0.0429 \pm 0.0002$

$4671 \pm 8.284$

$0.0429 \pm 0.0002$

5226625

Cost latanoprost $0.005 \%$

$10 € /$ month

costs $(€)$

$2964 \pm 9.027$

$0.0360 \pm 0.0003$
$3326 \pm 11.926$
$0.0339 \pm 0.0004$
174394

$3666 \pm 6.358$

$0.0425 \pm 0.0001$

$3756 \pm 6.301$

$0.0425 \pm 0.0001$

incremental $\mathrm{C} / \mathrm{E}$

$2751 \pm 5.945$

$0.0359 \pm 0.0003$

$2828 \pm 5.806$

$0.0341 \pm 0.0003$

44095

years of blindness

IOP reduction: timolol $2 \%$ less

and latanoprost $2 \%$ more

costs $(€)$

years of blindness

incremental $\mathrm{C} / \mathrm{E}$

\author{
$3467 \pm 7.314$ \\ $0.0360 \pm 0.0003$
}

$3368 \pm 3.385$
$0.0428 \pm 0.0003$

$3307 \pm 4.260$

$0.0426 \pm 0.0002$

- $324031 * * * * *$
$4626 \pm 9.037$
$0.0414 \pm 0.0002$
317103
$4324 \pm 12.942$
$-$
$0.0423 \pm 0.0003$


The values represent the expected lifetime costs and effects for a treated $\mathrm{OH}$ patient (an average computed from 5 Monte Carlo simulations of size 20000 each).

* mean expected time spent in blindness per person within 18.7 years of life expectancy

** incremental cost-effectiveness ratio shows extra costs per year of vision saved when starting therapy with latanoprost compared to starting with timolol

*** standard deviation for the average, computed from 5 Monte Carlo simulations of size 20000 each

$* * * *$ higher costs, less effect in strategy 'start with latanoprost'

$* * * * *$ lower costs, more effect in strategy 'start with latanoprost'

\section{Discussion}

The results of the modeling study show that initiating therapy in $\mathrm{OH}$ patients with latanoprost brings along extremely high incremental costs, €537000 extra for saving one year of vision when compared to initiating therapy with timolol. If treatment with latanoprost only and timolol only would be compared, there would undoubtedly be a significant difference in treatment effects between those two drugs. However, a comparison of clinically based strategies, where different first therapy choice is followed by similar steps for therapy adjustments to achieve a target pressure, shows minimal difference in the achieved IOP and blindness through glaucoma between the two analyzed strategies. The computed cost difference on the other hand, is large. As the IOP reduction is similar in both strategies, with a consequence that only slight differences occur in glaucoma development and blindness, the corresponding glaucoma costs will be comparable in both strategies as well. The different $\mathrm{OH}$ therapy costs are thus responsible for the main cost difference, as confirmed by the results of the sensitivity analysis.

Many $\mathrm{OH}$ patients can reach their target pressure with timolol as well as with latanoprost. Patients whose target pressure cannot be easily reached and controlled with monotherapy need more therapy adjustments including combination therapy or laser treatment. This is however, the case in both strategies and the costs for these patients will thus be comparable. Long-term use of monotherapy with latanoprost is a largest contributor to the higher cost expenditure in the strategy 'start with latanoprost'. When starting therapy with latanoprost, the less expensive, but fairly enough sufficient, alternative for patients who can easily reach a target pressure with both drugs is not considered. This is the underlying reason why the strategy 'start with latanoprost' is not preferable from the cost-effectiveness point of view, in comparison to the strategy 'start with timolol'. The modelled simulations show that even for young $\mathrm{OH}$ patients, who have a longest life expectancy and thus most time to develop glaucoma and blindness, it is not cost-effective to initiate therapy with latanoprost.

A simulation model was used to analyze the two treatment strategies. Since we were able to incorporate data of recent, adequately performed, randomized clinical trials we believe that the results of our modelled strategies validly represent the current practice. Moreover, the long-term effects of the strategies could be assessed in a short time period. Another advantage of modeling is the evaluation of different modifications of the strategies as well, by changing the key parameters in the 
model. By applying a Monte Carlo simulation, which is run 100000 times, a reliable estimate of the clinical result of a strategy given the underlying variation is obtained (see the calculated standard deviations given in Tables 5 and 6). Extensive sensitivity analyses were performed to establish the impact of a variation of the uncertain values in the model on the outcomes and the study conclusions. It showed that these conclusions were robust. Only a reduction of the cost of latanoprost leads to a favorable cost-effectiveness ratio for the strategy 'start with latanoprost'.

To avoid modeling or programming errors a process known as 'debugging' the tree was applied. ${ }^{15}$ Further, a comparison was made with the facts known from the literature. The model showed approximately 34\% IOP reduction through medication and laser. In the Ocular Hypertension Treatment Study (OHTS), the design of which corresponds well with the modelled therapy approach, this was $22.5 \pm 9.9 \%$. However, the target pressure criterion differs, this being $24 \mathrm{~mm} \mathrm{Hg}$ in the OHTS study and $21 \mathrm{~mm} \mathrm{Hg}$ in the model. Laser treatment was not applied in the OHTS study participants. Further in the OHTS study the average IOP across follow-up visits is given, whereas the model gives a mean IOP value after the therapy adjustments. Lastly, the treatment choice was limited, when the OHTS study participants started their therapy. The yearly estimate for blindness might be slightly overestimated in the model, because no difference is made between beginning and advanced glaucoma. The age and IOP distributions of the population are verified to be consistent with the literature. ${ }^{16,17,18}$ IOP values above $35 \mathrm{~mm} \mathrm{Hg}$ were not addressed in the model, because such values are very likely to be already associated with glaucoma. The IOP reduction through specific medication is based on the best current data, namely on a meta-analysis of randomized controlled trials. ${ }^{8}$

There have been some studies published, addressing the cost-effectiveness of various treatments with glaucoma drugs. ${ }^{19,20}$ However, no sensible comparison of our results with these studies can be made, because they include treatment of glaucoma and ocular hypertension. The drug persistency in glaucoma treatment is different than in ocular hypertension. Moreover, these studies use IOP as an outcome measure. In one epidemiological study, by using a questionnaire in 1513 patients, a drug use in ocular hypertension in Belgium was established. ${ }^{21}$ This was done in 1992 and $96 \%$ of patients were using a topical beta-blocker, many other types of ocular hypotensive drugs were not available yet. A median value of five years showed that in $77 \%$ the drug therapy involved only one drug. In the model about $66 \%$ of patients maintain the originally prescribed timolol after 15 months of treatment. Another cross-sectional study in France, with retrospective data collection for the preceding 5 years, found that $82.6 \%$ of patients with ocular hypertension were using monotherapy medication. ${ }^{22}$ The majority of patients were using a beta-blocker. In the model approximately $90 \%$ of patients uses monotherapy medication. In the same study the annual treatment costs for $\mathrm{OH}$ patients were $€ 275$, $€ 376$ and $€ 476$ for patients with 0,1 , and 2 treatment changes. In the model the mean costs calculated for 12 months of treatment were approximately $€ 295$ for strategy 'start with timolol' and $€ 375$ for strategy 'start with latanoprost'. The proportion of patients with no treatment change in the model was $68 \%$ in strategy 
'start with timolol' and $77.1 \%$ in strategy ' start with latanoprost'. The average treatment costs of a POAG patient used in the model match with the outcomes of other glaucoma cost studies. ${ }^{23-29}$ The costs due to blindness in connection with the usage of disability facilities in the Netherlands could not be retrieved. Even if these costs would be added, this should not influence the outcome of the study, because there is almost no difference in blindness between the two analyzed strategies. In the model a $4 \%$ discount is rate used, while internationally a $3 \%$ rate is recommended. ${ }^{9}$ This was done due to the guidelines in the Netherlands, however, if $3 \%$ is used no substantial changes occur (data not shown). No utility analysis has been performed. The main purpose of the study was to assess and compare the impact of two different approaches of starting medication in $\mathrm{OH}$ patients. In summary we believe that the results of our modeling study can be regarded as reliable, since our model approaches clinical practice closely, we used recent estimates of treatment efficacy, and the intermediate results are in general consistent with existing reports.

\section{Conclusions}

Initiating therapy in $\mathrm{OH}$ patients with latanoprost brings along extremely high incremental costs to prevent blindness when compared to initiating therapy with timolol. Given the current cost price of latanoprost, saving one year of vision would incur $€ 537000$ of expenditures. These incremental costs are even higher for patients with a high initial IOP and are increasing with age.

\section{References}

1 Kass MA, Gordon MO, Hoff MR, et al. Topical timolol administration reduces the incidence of glaucomatous damage in ocular hypertensive individuals. A randomized, double-masked, long-term clinical trial. Archives of ophthalmology 1989;107(11):1590-8.

2 Kass MA, Heuer DK, Higginbotham EJ, et al. The Ocular Hypertension Treatment Study: a randomized trial determines that topical ocular hypotensive medication delays or prevents the onset of primary openangle glaucoma. Archives of ophthalmology 2002;120(6):701-13.

3 Leske MC, Heijl A, Hussein M, et al. Factors for glaucoma progression and the effect of treatment: the early manifest glaucoma trial. Archives of ophthalmology 2003;121(1):48-56.

4 Van der Valk R, Schouten JSAG, Webers CAB, Hendrikse F, Prins MH. Changes in glaucoma treatment and achieved IOP after introduction of new glaucoma medication. Graefes-Arch-Clin-Exp-Ophthalmol. 2006 Oct; 244(10): 1267-72

5 Azuara Blanco A, Burr J. The rising cost of glaucoma drugs. British journal of ophthalmology 2006;90(2):130-1.

6 Knox FA, Barry M, McGowan B, O’Brien C. The rising cost of glaucoma drugs in Ireland 1996-2003. British journal of ophthalmology 2006;90(2):162-5.

7 De Natale R, Draghi E, Dorigo MT. How prostaglandins have changed the medical approach to glaucoma and its costs: an observational study of 2228 patients treated with glaucoma medications. Acta ophthalmologica Scandinavica 2004;82(4):393-6.

8 Van der Valk R, Webers CAB, Schouten JSAG, Zeegers MP, Hendrikse F, Prins MH. Intraocular Pressure-Lowering Effects of All Commonly Used Glaucoma Drugs: A Meta-analysis of Randomized Clinical Trials. Ophthalmology 2005;112:1177-85.

9 Gold MR, Siegel JE, Russel LB, et al. Cost-effectiveness in Health and Medicine. First press release. New York: Oxford University Press; 1996.

10 Drummond MF, Sculpher MJ, Torrance GW, O’Brien BJ, Stoddart GL. Methods for the Economic Evaluation of Health Care Programmes, 3rd ed. Oxford: Oxford University Press, 2005. 
11 American Academy of Ophthalmology. Preferred Practice Patterns: primary open-angle glaucoma. San Francisco (CA): American Academy of Ophthalmology; 2000.

12 survival probabilities: Centraal Bureau voor de Statistiek (CBS). Statline. Available at: http://statline.cbs.nl. Accessed September 8, 2003.

13 Chen PP. Blindness in patients with treated open-angle glaucoma. Ophthalmology 2003;110:726-33.

14 Kwon YH, Kim CS, Zimmerman MB, Alward WL, Hayreh SS. Rate of visual field loss and long-term visual outcome in primary open-angle glaucoma. American journal of ophthalmology 2001; 132:47-56.

15 Detsky AS, Naglie G, Krahn MD, et al. Primer on medical decision analysis: Part 2-Building a tree. Medical decision making an international journal of the Society for Medical Decision Making 1997;17(2):126-35.

16 Koch H. Practice Patterns of the Office-Based Ophthalmologist, National Ambulatory Medical Care Survey, 1985. Advance data 1989:1-12.

17 Schappert SM. Office visits for glaucoma: United States, 1991-92. Advance data 1995:1-14.

18 Ellwein LB, Urato CJ. Use of eye care and associated charges among the Medicare population: 19911998. Archives of ophthalmology 2002;120:804-11.

19 Bernard LM, Althin R, Dhawan R, et al. Clinical and economic impacts of latanoprost $0.005 \%$ in firstline treatment of open-angle glaucoma and ocular hypertension in France. European journal of ophthalmology 2003;13 Suppl 4:S30-43.

20 Noecker RJ, Walt JG. Cost-effectiveness of monotherapy treatment of glaucoma and ocular hypertension with the lipid class of medications. American journal of ophthalmology 2006;141(1 Suppl):S15-21.

21 Walckiers D, Sartor F. Results of an epidemiological study on drug-treated intraocular hypertension in Belgium. Journal of clinical epidemiology 1996;49(4):489-93.

22 Denis P, Lafuma A, Berdeaux G. Medical predictive factors of glaucoma treatment costs. Journal of glaucoma 2004;13(4):283-90.

23 Oostenbrink JB, Rutten van Molken MP, Sluyter Opdenoordt TS. Resource use and costs of patients with glaucoma or ocular hypertension: a one-year study based on retrospective chart review in the Netherlands. Journal of glaucoma 2001; 10: 184-191.

24 Kobelt G, Jonsson L, Gerdtham U, Krieglstein GK. Direct costs of glaucoma management following initiation of medical therapy. A simulation model based on an observational study of glaucoma treatment in Germany. Graefe's archive for clinical and experimental ophthalmology 1998; 236: 811-821.

25 Kobelt G, Jonsson L. Modeling cost of treatment with new topical treatments for glaucoma. Results from France and the United Kingdom. International journal of technology assessment in health care 1999; 15: 207-219.

26 Traverso CE, Walt JG, Kelly SP, et al. Direct costs of glaucoma and severity of the disease: a multinational long term study of resource utilisation in Europe. British journal of ophthalmology 2005; 89: 12451249 .

27 Lindblom B, Nordmann JP, Sellem E, et al. A multicentre, retrospective study of resource utilization and costs associated with glaucoma management in France and Sweden. Acta ophthalmologica Scandinavica 2006; 84: 74-83.

28 Iskedjian M, Walker J, Vicente C, et al. Cost of glaucoma in Canada: analyses based on visual field and physician's assessment. Journal of glaucoma 2003; 12: 456-462.

29 Lee PP, Walt JG, Doyle JJ, et al. A multicenter, retrospective pilot study of resource use and costs associated with severity of disease in glaucoma. Archives of ophthalmology 2006; 124: 12-19.

30 Van der Horst FG, Webers CAB, Bours SJM. Transmuraal model oogzorg [Transmural Model Eyecare]. Maastricht: Datawyse; 2003; ISBN 90-74474-08-X.

31 Tuulonen A, Niva AK, Alanko HI. A controlled five-year follow-up study of laser trabeculoplasty as primary therapy for open-angle glaucoma. American journal of ophthalmology 1987; 104:334-8.

32 Ticho U, Nesher R. Laser trabeculoplasty in glaucoma. Ten-year evaluation. Archives of ophthalmology 1989; 107:844-6.

33 Odberg T, Sandvik L. The medium and long-term efficacy of primary argon laser trabeculoplasty in avoiding topical medication in open angle glaucoma. 1999; 77:176-81.

34 Ustundag C, Diestelhorst M. Efficacy of argon laser trabeculoplasty: 3-year preliminary results of a prospective placebo-controlled study. Graefe's archive for clinical and experimental ophthalmology; Albrecht von Graefes Archiv fur klinische und experimentelle Ophthalmologie 1997; 235:354-8.

35 Shingleton BJ, Richter CU, Bellows AR, Hutchinson BT, Glynn RJ. Long-term efficacy of argon laser trabeculoplasty. Ophthalmology 1987; 94:1513

36 Volksgezondheid Toekomst Verkenning 1997. De som der delen. Rijksinstituut voor Volksgezondheid en milieu. Elsevier/De Tijdstroom, Utrecht, 1997. 
37 Zhang WY, Po AL, Dua HS, Azuara Blanco A. Meta-analysis of randomised controlled trials comparing latanoprost with timolol in the treatment of patients with open angle glaucoma or ocular hypertension. British journal of ophthalmology 2001; 85:983-90.

38 Stewart WC, Garrison PM. Beta-blocker-induced complications and the patient with glaucoma. Newer treatments to help reduce systemic adverse events. Archives of internal medicine 1998; 158:221-6.

39 Hoyng PF, van Beek LM. Pharmacological therapy for glaucoma: a review. Drugs 2000; 59:411-34.

40 van Beek LM, de Keizer RJ, Polak BC, Elzenaar PR, van Haeringen NJ, Kijlstra A. Incidence of ocular side effects of topical beta blockers in the Netherlands. British journal of ophthalmology 2000; 84:856-9.

41 McMahon CD, Shaffer RN, Hoskins HD, Jr., Hetherington J, Jr. Adverse effects experienced by patients taking timolol. American journal of ophthalmology 1979; 88:736-8.

42 Perry CM, McGavin JK, Culy CR, Ibbotson T. Latanoprost : an update of its use in glaucoma and ocular hypertension. Drugs and aging 2003; 20:597-630.

43 Camras CB, Alm A, Watson P, Stjernschantz J. Latanoprost, a prostaglandin analog, for glaucoma therapy. Efficacy and safety after 1 year of treatment in 198 patients. Latanoprost Study Groups. Ophthalmology 1996; 103:1916-24.

44 Commissie Farmaceutische hulp (CFH) van het College voor zorgverzekeringen [Health Care Insurance Board]. Farmacotherapeutisch Kompas [Pharmacotherapeutic Compass] 2004; ISBN 9070918-35-8.

45 Gordon MO, Beiser JA, Brandt JD, et al. The Ocular Hypertension Treatment Study: baseline factors that predict the onset of primary open-angle glaucoma. Archives of ophthalmology 2002; 120:714-20.

46 Kamal D, Garway Heath D, Ruben S, et al. Results of the betaxolol versus placebo treatment trial in ocular hypertension. Graefe's archive for clinical and experimental ophthalmology; Albrecht von Graefes Archiv fur klinische und experimentelle Ophthalmologie 2003; 241:196-203.

47 Schulzer M, Drance SM, Douglas GR. A comparison of treated and untreated glaucoma suspects. Ophthalmology 1991; 98:301-7.

48 David R, Livingston DG, Luntz MH. Ocular hypertension--a long-term follow-up of treated and untreated patients. British journal of ophthalmology, The 1977; 61:668-74.

49 Hovding G, Aasved H. Prognostic factors in the development of manifest open angle glaucoma. A longterm follow-up study of hypertensive and normotensive eyes. Acta ophthalmologica 1986; 64:601-8.

50 Kitazawa Y, Horie T, Aoki S, Suzuki M, Nishioka K. Untreated ocular hypertension. A long-term prospective study. Archives of ophthalmology 1977; 95:1180-4.

51 Heijl A, Bengtsson B. Long-term effects of timolol therapy in ocular hypertension: a double-masked, randomised trial. Graefe's archive for clinical and experimental ophthalmology; Albrecht von Graefes Archiv fur klinische und experimentelle Ophthalmologie 2000; 238:877-83.

52 Epstein DL, Krug JH, Jr., Hertzmark E, Remis LL, Edelstein DJ. A long-term clinical trial of timolol therapy versus no treatment in the management of glaucoma suspects. Ophthalmology 1989; 96:1460-7.

53 Tanito M, Itai N, Dong J, Ohira A, Chihara E. Correlation between intraocular pressure level and optic disc changes in high-tension glaucoma suspects. Ophthalmology 2003; 110:915-21.

54 Lundberg L, Wettrell K, Linner E. Ocular hypertension. A prospective twenty-year follow-up study. Acta ophthalmologica 1987; 65:705-8. 



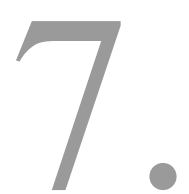

General discussion 
In this thesis the clinical effects and cost-effectiveness of early detection and treatment of ocular hypertension $(\mathrm{OH})$ and primary open-angle glaucoma (POAG) are studied. The main questions investigated are closely linked to clinical practice and are the following. (1) Should patients with $\mathrm{OH}$ or early POAG be treated? (2) Is early detection and treatment of $\mathrm{OH}$ and POAG by an ophthalmologist beneficial for the prevention of blindness? (3) Which case-finding strategy applied in the ophthalmic practice is the most cost-effective? (4) What is the clinical impact of initiation of $\mathrm{OH}$ treatment with a new type of glaucoma medication in comparison with the medication used so far? (5) Is such a strategy of initiating $\mathrm{OH}$ treatment with a new type of medication cost-effective in comparison with the existing strategy?

In studying cost-effectiveness it is difficult to take all the costs and effects properly into account because glaucoma is an irreversible slowly progressive disease and a long-term follow-up is required. In view of the absence of long-term empirical data, meta-analysis and simulation models have been used to acquire insight in these issues. Two outcome measures are of most interest for clinical practice: (1) the conversion from $\mathrm{OH}$ (i.e. an increased intraocular pressure (IOP) in the absence of structural and functional damage) to POAG, and (2) the eventual progression of POAG to blindness. Costs are associated with medical diagnosis and treatment on one side, and with blindness related impairment on the other side.

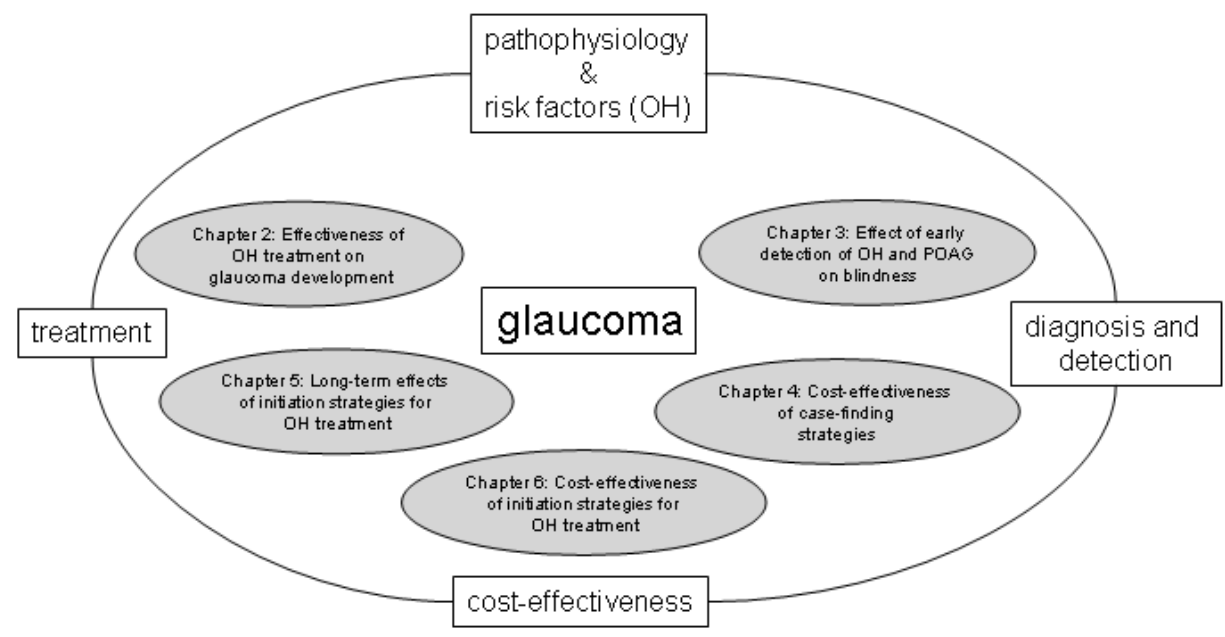

Figure 1. Framework for the illustration of the glaucoma related research in this thesis

In Figure 1 a framework is presented which illustrates the research in the various chapters of this thesis, and clarifies their interrelationships. Currently, treatment of glaucoma is aimed at its main risk factor: an increased intraocular pressure. The IOP plays a key role in its diagnosis and detection on the one hand, whereas lower- 
ing of the IOP is the only effective treatment at present on the other hand. Future developments, for instance in the area of neuroprotection, may lead to different treatment strategies.

\section{The effectiveness of $\mathrm{OH}$ treatment}

For many decades now, lowering of the IOP is the cornerstone of glaucoma treatment. Even though it is widely recognized that an elevated IOP contributes to glaucomatous optic neuropathy, there is great inter-individual variation in the susceptibility of the optic nerve to IOP-related damage. ${ }^{1}$ The Baltimore Eye Survey, which is a population-based study, indicates that only one-tenth or less of patients with an elevated IOP have glaucomatous field loss. ${ }^{2}$ Whether the IOP should be lowered in patients with ocular hypertension has repeatedly been a subject of discussion among ophthalmologists. The study described in Chapter 2 in this thesis has started in 2001. At that time, only the results of a few randomized trials were available which included $\mathrm{OH}$ patients. These studies were small in size and gave no conclusive scientific evidence on the effect of $\mathrm{OH}$ treatment. A major step forward has been the publication of the results of the Ocular Hypertension Treatment Study in 2002. ${ }^{3}$ There it was shown that topical ocular hypotensive medication is effective in delaying or preventing the onset of POAG in individuals with an elevated IOP. ${ }^{3}$ In 2005 the results of another major study, the European Glaucoma Prevention Study, became available. ${ }^{4}$ This study has also shown a protective effect of $\mathrm{OH}$ treatment although it failed to confirm this at a statistically significant level.

In this thesis, a quantification of the effect of IOP reduction in $\mathrm{OH}$ patients on the occurrence of glaucoma is given in Chapter 2, in which the results of a metaanalysis of $\mathrm{OH}$ trials are described. An advantage of this meta-analytical approach is that by combining data of several comparable studies, the results of a large number of patients can be included, and relatively small effects can be detected or excluded with confidence. ${ }^{5}$ The pooled relative risk, expressing the protective effect of IOP lowering therapy on the conversion of OH to POAG, is estimated as 0.61 (95\% confidence interval 0.45 to 0.83 ). Additional regression analysis shows that a larger medically achieved decrease in IOP is associated with a larger reduction of the risk of conversion from $\mathrm{OH}$ to glaucoma. By using a meta-regression model it is estimated that the relative risk of conversion to glaucoma decreases by $14 \%$ with each $\mathrm{mm} \mathrm{Hg}$ of IOP reduction.

The $\mathrm{OH}$ trials included in the meta-analysis all have a limited follow-up, with a maximum of 6 years. Therefore, these trials cannot directly be used to assess the impact of $\mathrm{OH}$ treatment on the prevention of glaucoma blindness. Clearly, time aspects need to be addressed when studying such long-term effects of treatment. Ocular hypertension is rare under the age of 40 and glaucoma mostly affects elderly people. Also, it is a slowly progressive disease, so many patients will not live long enough to reach the end stage and become blind. To properly take such time related 
issues into account, it is necessary to consider age and corresponding mortality rates, which change over time and are gender dependent.

In the absence of empirical data, the simulation model presented in Chapters 5 and 6 allows one to investigate time related issues as mentioned above. In this model the simulated cohort is based on the demographic characteristics of initial patients visiting an ophthalmic practice. Two strategies are modelled for initiating $\mathrm{OH}$ treatment with two different types of medication; the outcome measure is glaucoma blindness. For both treatment strategies, the expected time of blindness per patient is found to correspond with approximately 1 month over a period of 18.7 years, which is the mean life expectancy in the cohort. In a simulation where patients were only treated after conversion to glaucoma, the expected time of blindness per patient corresponds to approximately 6 months. These results indicate that $\mathrm{OH}$ treatment is beneficial for the prevention of glaucoma blindness in a population where age distribution resembles that of patients visiting an ophthalmic practice.

Currently, therapy for $\mathrm{OH}$ patients is mostly recommended when IOP is above 29 $\mathrm{mm} \mathrm{Hg}$ or when IOP exceeds $21 \mathrm{~mm} \mathrm{Hg}$ in the presence of other risk factors for POAG. ${ }^{6}$ However, most patients enrolled in the $\mathrm{OH}$ trials included in the metaanalysis had an initial IOP between $24 \mathrm{~mm} \mathrm{Hg}$ and $32 \mathrm{~mm} \mathrm{Hg}$ and only some had additional risk factors. This implies that future research may be conducted on this topic. Also, for elder patients it may well turn out that the adverse effects of treatment counterbalance the expected gain in blindness prevention, so that age dependent treatment strategies may be developed.

\section{Cost-effectiveness of early detection and treatment of $\mathrm{OH}$ and POAG}

A cost-effectiveness analysis is a form of economic evaluation where both the costs and the consequences of health programmes or treatments are examined. ${ }^{7}$ As a consequence of changes in knowledge, facilities, equipment and costs over time, the existing programmes may once in a while need to be re-evaluated, and new strategies may be developed and compared with existing ones.

Within health care an identification and a comparison of strategies for detection and/or treatment are of interest. In the past, medical treatment options in glaucoma management were limited. The economic evaluations were generally focused on the efficacy of different diagnostic tools for $\mathrm{OH}$ and $\mathrm{POAG}$ detection $^{8}$ and on the evaluation of different screening strategies in the general population. ${ }^{9,10}$ The feasibility and efficacy of a screening program is still an issue of ongoing debate and screening in the general population is not recommended at present. ${ }^{11}$ However, in the last decades many new developments in the field of glaucoma took place, including new technologies that permit earlier detection of glaucomatous structural and functional damage, and new hypotensive treatments, which allow for safer and more effective IOP reduction. In a number of well-conducted clinical trials the effectiveness of treatment has been investigated and target pressures are now play- 
ing a key part in modern therapy strategies. However, new technologies and strategies also bring along higher costs and the economic evaluation has shifted towards the cost-effectiveness of treatment.

Treatment nowadays has become more complex through the availability of a broad spectrum of hypotensive agents, and different combinations of these. These drugs differ in their IOP lowering effects, topical and systemic side-effects, and costs. New diagnostic technologies allow for a better distinction of various stages of glaucoma progression. This is favourable for early detection of $\mathrm{OH}$ and POAG and also for a set up of more sophisticated treatment strategies. Also utility scores may be measured and defined for different degrees of vision loss. By adjusting life expectancy with the utility scores, quality-adjusted life years (QALYs) can be calculated, which has become an increasingly popular outcome measure for resource allocation. ${ }^{12}$ However, utility scores do carry an element of subjectivity and are not easy to assess consistently, and the impact of the loss of vision of one eye is largely influenced by the remaining functionality of the other eye. In the recently published cost-utility analysis of the Ocular Hypertension Treatment Study, ${ }^{13}$ the impact of $\mathrm{OH}$ treatment is evaluated in terms of QALYs for a simulated cohort of patients with an initial IOP of $\geq 24 \mathrm{~mm} \mathrm{Hg}$. In the present thesis we have instead considered years of blindness as the main outcome measure.

In Chapters 4 and 6, two cost-effectiveness evaluations are presented: an evaluation of different case-finding strategies to detect $\mathrm{OH}$ and POAG by an ophthalmologist, and an evaluation of different strategies for the initiation of $\mathrm{OH}$ treatment. Both models include treatment of $\mathrm{OH}$ and $\mathrm{POAG}$, and the main outcome measure is blindness due to glaucoma. In the model in which the case-finding strategies are simulated, an interaction of both detection and treatment is taken into account. In the other presented model, initiation of $\mathrm{OH}$ treatment followed by therapy adjustments based on clinical practice is simulated. This differs from other evaluations of the new generation of hypotensive drugs which mostly involve a head-to-head comparison of two different agents. ${ }^{14,15}$

As already mentioned above, screening for glaucoma in the general population is not recommended at present. In 1968 Wilson and Jungner proposed criteria for new screening programs, adopted by the World Health Organization, which should be fulfilled before their introduction in practice. ${ }^{16}$ The most important criteria are the following. (1) The condition sought should be an important health problem for the individual and community. (2) The natural history of the disease should be adequately understood. (3) There should be an early pre-clinical phase during which the individuals with the disease can be identified. (4) There should be appropriate, acceptable, and reasonably accurate screening tests. (5) There should be an agreed policy on whom to treat as patients. (6) There should be an accepted and effective treatment which should be more effective in preventing morbidity when initiated early. (7) The costs of case finding should be economically balanced in relation to possible expenditure on medical care as a whole. Glaucoma meets many of these criteria, but not completely. Criteria 1, 3 and 4 are fulfilled, even though the screen- 
ing tests are amenable to further improvement. Criteria 2, 5, 6 and 7 are partially fulfilled and subject of ongoing discussion.

The outcomes of Chapter 4 express the consequences of ophthalmic care versus no care, dependent on the yield of case-finding in the ophthalmic practice. The most preferable strategy for glaucoma-related blindness prevention is to perform tonometry to all initial ophthalmic patients. When costs associated with the use of disability facilities due to blindness exceed $€ 1707$ per patient per year, which is most likely, this strategy not only is effective in blindness prevention but in fact becomes cost saving. This outcome is consistent with the findings of the performed systematic review in Chapter 2 and the case-referent study described in Chapter 3, which indicate that early treatment of $\mathrm{OH}$ and POAG is effective in preventing blindness due to glaucoma.

In addition, it can be noted that there are several other factors than IOP (e.g., blood supply to the optic nerve, substances toxic to the optic nerve or retina, axonal or ganglion cell metabolism, and the lamina cribrosa extracellular matrix), that may play a role in the progressive optic neuropathy of POAG. ${ }^{1}$ If one were able to identify subgroups of patients who are more susceptible to high intraocular pressure than others, treatment strategies could be applied which take this into account. This would positively influence the cost-effectiveness of the chosen strategies through an improved balancing of monitoring and treatment.

The outcomes of the model presented in Chapters 5 and 6 show that it is not preferable to start $\mathrm{OH}$ therapy with latanoprost, which gives more IOP reduction but is also more expensive, instead of timolol. Due to the concept of a target pressure, which underlies both strategies, the eventual difference in the clinical effects of the two strategies is small. When therapy is started with latanoprost, the extra costs needed for saving one year of vision in comparison with starting with timolol are very high, namely $€ 537000$. A different future cost price of latanoprost may affect this outcome.

\section{Conclusions and recommendations}

The research conducted in this thesis shows that: (1) topical hypotensive therapy reduces the risk of conversion to POAG in $\mathrm{OH}$ and a progression of visual field loss in early glaucoma, (2) early detection and treatment of $\mathrm{OH}$ and POAG is likely to be beneficial in the prevention of blindness, (3) it is most cost-effective to routinely perform tonometry to all initial ophthalmic patients to prevent blindness due to glaucoma, (4) the differences in the clinical effects of the two strategies of initiating $\mathrm{OH}$ therapy, with latanoprost or with timolol, are quite small, (5) given the current cost price of latanoprost, initiating therapy in $\mathrm{OH}$ patients with this agent brings along extremely high incremental costs to prevent blindness when compared to initiating therapy with timolol. 
Further research topics that are suggested by the outcomes of the performed studies are the following. (1) To establish more accurate guidelines for when to start $\mathrm{OH}$ treatment based on the IOP level, the presence of other risk factors and life expectancy, related to the expected gain in the prevention of blindness. (2) To identify subgroups of patients to which treatment strategies can be tailored. This may involve aspects such as the initial IOP level, risk factors, prognostic factors, severity of the disease at the moment of diagnosis, and life expectancy. (3) To identify the most cost-effective strategies for such different subgroups of patients.

\section{References}

1 American Academy of Ophthalmology Glaucoma Panel. Preferred Practice Pattern. Primary Open-Angle Glaucoma. San Francisco, CA: American Academy of Ophthalmology; 2005. Available at: www.aao.org/ppp.

2 Sommer A, Tielsch JM, Katz J, et al. Relationship between intraocular pressure and primary open angle glaucoma among white and black Americans. The Baltimore Eye Survey. Archives of ophthalmology 1991;109(8):1090-5.

3 Kass MA, Heuer DK, Higginbotham EJ, et al. The Ocular Hypertension Treatment Study: a randomized trial determines that topical ocular hypotensive medication delays or prevents the onset of primary openangle glaucoma. Archives of ophthalmology 2002;120(6):701-13.

4 Miglior S, Zeyen T, Pfeiffer N, et al. Results of the European Glaucoma Prevention Study. Ophthalmology ISE: 15494713 2005;112(3):366-75.

5 Egger M, Smith GD, Phillips AN. Meta-analysis: principles and procedures. BMJ Clinical research ed 1997;315(7121):1533-7.

6 European Glaucoma Society. Terminology and Guidelines for Glaucoma. Editrice Dogma; 2003.

7 Drummond MF, O'Brien BJ, Stoddart GL, Torrance GW. Methods for the Economic Evaluation of Health Care Programmes, 2nd ed. Oxford: Oxford University Press, 1997.

8 Eddy DM, Sanders LE, Eddy JF. The value of screening for glaucoma with tonometry. Survey of ophthalmology 1983;28(3):194-205.

9 Tuck MW, Crick RP. The cost-effectiveness of various modes of screening for primary open angle glaucoma. 1997;4(1):3-17.

10 Gottlieb LK, Schwartz B, Pauker SG. Glaucoma screening. A cost-effectiveness analysis. Survey of ophthalmology 1983;28(3):206-26.

11 Screening for glaucoma: recommendation statement. Annals of family medicine 2005; 3: 171-172.

12 Kobelt G, Jonsson B, Bergstrom A, et al. Cost-effectiveness analysis in glaucoma: what drives utility? Results from a pilot study in Sweden. Acta ophthalmologica Scandinavica 2006;84(3):363-71.

13 Kymes SM, Kass MA, Anderson DR, et al. Management of ocular hypertension: a cost-effectiveness approach from the Ocular Hypertension Treatment Study. American journal of ophthalmology 2006;141(6):997-1008.

14 Bernard LM, Althin R, Dhawan R, Grima DT, Lam A, Aballea S. Clinical and economic impacts of latanoprost $0.005 \%$ in first-line treatment of open-angle glaucoma and ocular hypertension in France. European journal of ophthalmology 2003; 13 Suppl 4:S30-43.

15 Halpern MT, Covert DW, Robin AL. Projected impact of travoprost versus both timolol and latanoprost on visual field deficit progression and costs among black glaucoma subjects. Transactions of the American Ophthalmological Society 2002; 100:109-17; discussion 117-8.

16 Wilson JMG, Jungner F.1968. Principles and practice of screening for disease. Public Health Papers. no. 34. Geneva: World Health Organization. 



\section{Summary}

In this thesis, both the clinical effectiveness and the cost-effectiveness of detection and treatment of patients with ocular hypertension $(\mathrm{OH})$ and primary open-angle glaucoma (POAG) are investigated. POAG, further referred to as glaucoma, is a progressive chronic eye disease which can ultimately lead to blindness. It has a considerable public health impact, being the second leading cause of world-wide blindness (cataract being the first). The etiology of glaucoma is unknown. It mostly affects elderly people. Individuals with ocular hypertension are at risk to develop glaucoma. In these individuals the intraocular pressure (IOP) is increased above values which clinicians consider safe. A chronic increased intraocular pressure as such causes no symptoms and can only be detected if tonometry is performed. The probability of developing glaucoma increases with higher IOP values. Other known risk factors are race, age, and family history of glaucoma.

Glaucoma is characterized by damage of the optic nerve. This leads to impairment of visual function. The disease manifests itself mostly by defects in the peripheral visual field first. Patients may not notice this for a long period. At later stages glaucoma may progress to tunnel vision and irreversible blindness. Although glaucoma cannot be cured, its progression can be reduced by treatment. As the rate of progression of the disease is higher at high IOP levels, therapy is directed towards lowering the IOP. In clinical trials it was shown that IOP lowering therapy reduces the risk of conversion to glaucoma in $\mathrm{OH}$ patients (Ocular Hypertension Treatment Study) and that it has a protective effect on a progression in POAG patients (Early Manifest Glaucoma Trial, Advanced Glaucoma Intervention Study). However, individuals vary in their ability to sustain increased IOP. Not all OH patients develop glaucoma. On the other hand, some glaucoma patients show progression despite a lowering of the intraocular pressure. IOP is therefore not the only factor that plays a role in the pathogenesis and progression of glaucoma. Other factors involved in the glaucomatous optic neuropathy are not well researched yet. IOP is at present the only factor manageable by treatment. Therapy involves hypotensive medication, laser treatment and surgery. The main therapeutic goal is to preserve visual function and to prevent the end stage of the disease. To achieve this goal it is 
important that patients are detected in time. There are several tests available for diagnosing glaucoma. The IOP can be measured, the head of the optic nerve can be visualised, and the status of the visual field can be examined. Mostly a combination of tests is necessary to confirm the diagnosis.

For an effective management of glaucoma an understanding of the treatment effects is crucial. As glaucoma is a chronic disease the long-term effects should be taken into account. This is difficult as clinical trials mostly have a limited follow-up. However, recently several large clinical trials have become available in which patients were followed for a long period. Another major issue in the management of this chronic disease are the costs of treatment. In the last decades, these have substantially risen as a consequence of the introduction of new types of topical hypotensive drugs. These drugs are expensive but they have expanded the existing treatment options. There is a broad spectrum of drugs available now. There are several options for the initiation of therapy in case of contraindication to more classical drugs. When no or too little IOP reduction is achieved with the prescribed drug or if side-effects occur, other drugs are available. Finally, there are several different drugs which can be added to the prescribed medication when larger IOP reduction than the one achieved already is required. To define ideal treatment strategies for $\mathrm{OH}$ and $\mathrm{POAG}$ patients is a complex task requiring many factors to be taken into account.

One of the key questions is whether patients with ocular hypertension should be treated or not. After all, these patients do not have glaucoma yet, at least not detectable by current diagnostic techniques. Apart from costs, treatment is accompanied by discomfort and possibly by side-effects of medication. In favor of treatment are the results presented in this thesis which show that a therapeutic lowering of IOP in these patients reduces the risk of glaucoma. To assess the effects of treatment a long-term follow-up and a comparison of the conversion rates of patients with and without treatment is required. Although in the past many $\mathrm{OH}$ patients did receive treatment, there was little evidence on its efficacy until recently. In Chapter 2 all available scientific evidence on treatment effects in ocular hypertension is presented, based on a systematic literature review. The results of nine randomized clinical trials, in which $\mathrm{OH}$ patients with and without IOP lowering treatment were followed, are combined in a meta-analysis. This analysis shows that IOP lowering therapy in $\mathrm{OH}$ patients reduces the risk of conversion to glaucoma. The calculated pooled relative risk is 0.61 (95\% confidence interval $0.45-0.83)$. In addition, it is shown that this relative risk decreases by $14 \%$ with each $\mathrm{mm} \mathrm{Hg}$ of IOP reduction. At this moment, there is insufficient knowledge to identify $\mathrm{OH}$ patients who are at greater risk to develop glaucoma if untreated. Therapy for $\mathrm{OH}$ patients is generally recommended in case of high IOP values or if other risk factors are present. However, many patients included in the $\mathrm{OH}$ trials have IOP values below the recommended cut-off point when treatment is indicated and only some have additional risk factors. This implies that future research might be directed towards this topic. 
The assumption behind strategies aimed at detecting and treating patients with ocular hypertension and early glaucoma is that this prevents blindness. In Chapter 3 a case-referent study is presented in which the effect of early detection of $\mathrm{OH}$ and POAG patients on the occurrence of glaucoma blindness is investigated. An exposure to screening tests for early detection of $\mathrm{OH}$ and POAG performed by an ophthalmologist, not based on the disease symptoms, is assessed for a group of cases and a group of referents. Cases are blind glaucoma patients. Referents represent the general population regarding the frequency of such testing. The underlying argumentation in this study is as follows. If patients undergo testing for $\mathrm{OH}$ and POAG detection while not having any disease symptoms, the disease is diagnosed and treated at an early stage. If treatment of $\mathrm{OH}$ and early glaucoma is effective in blindness prevention then one can assume that patients diagnosed at this stage will not progress to blindness. Conversely, the reason that blind patients did progress to blindness is that they were not detected (and treated) in time. The outcomes of the study confirm this supposition. Blind glaucoma patients underwent fewer screening examinations by which $\mathrm{OH}$ or POAG can be detected than the referents. The calculated relative risk is 0.57 (90\% confidence interval $0.31-1.05)$. This study shows that detecting patients with $\mathrm{OH}$ and early glaucoma in the ophthalmic practice is effective in preventing glaucoma blindness.

At present there is no recommendation for a population screening program for glaucoma. The best alternative to detect patients early is case-finding among patients visiting an ophthalmologist. There are several alternatives as to how to address this issue. An interesting question concerning case-finding in the ophthalmic practice is whether IOP should be routinely measured in all initial patients, or only in selected groups of patients having risk factors for glaucoma. Ophthalmoscopy, by which the head of the optic nerve can be viewed, is mostly included in an ophthalmic examination. Tonometry on the other hand, has no other purpose than to detect an increased IOP. This test can easily be performed without much burden for a patient. A consequence of testing with tonometry is that more patients, mainly $\mathrm{OH}$ patients, will be detected and treated. Apart from the clinical effect this has an effect on costs. In Chapter 4 the long-term costs and effects of three different casefinding strategies are studied and evaluated by use of a decision model. Tonometry is routinely performed to: (1) all initial patients, (2) high-risk patients only, or (3) no one. These strategies are compared according to the methods of a costeffectiveness analysis. It is concluded that it is most cost-effective to perform tonometry to all initial ophthalmic patients to prevent blindness due to glaucoma. Extra costs per year of vision saved are $€ 1707$ compared to strategy where tonometry is performed to no one. It is likely that costs a patient spends per year due to blindness, e.g. associated with the use of disability facilities, already exceed this amount.

The main costs in glaucoma treatment are the medication costs. The introduction of new IOP lowering drugs in the last decades has contributed to a change of the drug prescription pattern, accompanied by a considerable rise of treatment costs. For many years, non-selective beta-blockers such as timolol have been the first choice 
in treatment. Nowadays, hypotensive lipids such as latanoprost are commonly used as first-line therapy. Latanoprost gives only a slightly better IOP lowering effect than timolol. Its cost price on the other hand, is much higher. The costs and clinical effects of the drugs should both be considered when choosing the type of medication. Especially in case of a drug used for the initiation of therapy, as many patients will use it for a long period. When sufficient IOP reduction is achieved in absence of side-effects, a patient will continue on this medication. Only if necessary, a drug substitution or a drug addition will follow. For patients with ocular hypertension it is not necessary to lower the IOP to the same extent as for glaucoma patients. Therefore, given the higher price of hypotensive lipids, one could question if initiation of therapy in $\mathrm{OH}$ patients with these agents is justified.

In Chapter 5 an analysis is presented in which the long-term clinical effects of initiating $\mathrm{OH}$ therapy with timolol and with latanoprost are studied and compared. In Chapter 6 a cost-effectiveness analysis of these two strategies is given. A simulation model is used for this purpose. In this model not only therapy initiation but also the adjustments of therapy are taken into account. The difference in the achieved IOP reduction between the two strategies is small. As conversion to glaucoma depends on IOP, the difference in glaucoma blindness between the strategies is small too. On average, this is about 1 month per person in both strategies, with a mean difference between the two strategies of 2 days spent in blindness per patient. On the other hand, the difference in costs spent on therapy between the two strategies is large. This is why initiating treatment in $\mathrm{OH}$ patients with latanoprost brings along extremely high incremental costs to prevent blindness when compared to initiating therapy with timolol. Given the current cost price of latanoprost, extra costs per year of vision saved are $€ 537000$.

Chapter 7 concludes this thesis with a general discussion and an outlook on future research. Recommendations for future research are to develop more accurate guidelines for when to start $\mathrm{OH}$ treatment and to identify subgroups of patients to which treatment strategies can be tailored. 


\section{Samenvatting}

In dit proefschrift worden de klinische effecten en de kosteneffectiviteit bestudeerd van strategieën voor de detectie en de behandeling van patiënten met oculaire hypertensie (ocular hypertension, $\mathrm{OH}$ ) en primair open-kamerhoek glaucoom (primary open-angle glaucoma, POAG). Laatstgenoemde aandoening, kortweg aangeduid met glaucoom, is een progressieve chronische oogziekte die uiteindelijk kan leiden tot blindheid. Het belang voor de volksgezondheid is groot, aangezien het, na cataract, wereldwijd de tweede oorzaak van blindheid betreft. De etiologie van glaucoom is onbekend. De ziekte treft hoofdzakelijk ouderen. Patiënten met oculaire hypertensie lopen een verhoogd risico op glaucoom. Bij deze patiënten neemt de intraoculaire druk (intraocular pressure, IOP) waarden aan boven het niveau dat door clinici als veilig wordt beschouwd. Een chronisch verhoogde oogdruk kent als zodanig geen symptomen en kan alleen met tonometrie worden vastgesteld. De kans om glaucoom te ontwikkelen stijgt met de oogdruk. Andere bekende risicofactoren zijn etniciteit en leeftijd en er is een erfelijke component.

Glaucoom wordt gekarakteriseerd door beschadiging van de optische zenuw. Dit veroorzaakt vermindering van de visuele functie. Gewoonlijk manifesteert de ziekte zich initieel door uitval in het perifere gezichtsveld. Het kan lang duren voordat patiënten hier daadwerkelijk hinder van ondervinden en dit als symptoom herkennen. In een latere fase kan glaucoom zich ontwikkelen tot tunnelzien en ten slotte tot blindheid, een proces dat onomkeerbaar is. Hoewel glaucoom ongeneeslijk is, kan de progressie van glaucoom worden geremd door therapie. Aangezien de snelheid van progressie afhankelijk is van de oogdruk, is glaucoomtherapie gericht op het verlagen van de IOP. In klinische onderzoekstrials is aangetoond dat IOP verlagende therapie het risico vermindert dat $\mathrm{OH}$ patiënten glaucoom ontwikkelen (zie de Ocular Hypertension Treatment Study) en dat het bij POAG patiënten inderdaad een beschermd effect heeft t.a.v. de progressie (zie de Early Manifest Glaucoma Trial en de Advanced Glaucoma Intervention Study). Er is echter een grote spreiding in het vermogen van $\mathrm{OH}$ en POAG patiënten om een verhoogde oogdruk te verdragen. Niet alle $\mathrm{OH}$ patiënten ontwikkelen glaucoom zonder therapie, terwijl ondanks een IOP verlagende therapie sommige POAG patiënten wel 
progressie van glaucoom vertonen. Dit maakt duidelijk dat een verhoogde oogdruk niet de enige factor is in de pathogenese en de progressie van glaucoom. Momenteel is echter oogdruk de enige bekende factor in de ontwikkeling van glaucoom waarop medische behandeling gericht kan worden. Therapieën betreffen oogdrukverlagende medicatie, laserbehandeling en chirurgie. Het hoofddoel van elk van deze therapieen is het behoud van de visuele functie en het voorkomen van verdere progressie naar de eindfasen van de ziekte. Voor een succesvolle aanpak van glaucoom is het belangrijk dat patiënten in een vroegtijdig stadium worden ontdekt. Er bestaan verschillende technieken die gebruikt kunnen worden bij de diagnostiek van glaucoom: oogdrukmeting (tonometrie), visualisatie van de papil van de optische zenuw (ophthalmoscopie) en bepaling van het gezichtsveld (perimetrie). Gewoonlijk is een combinatie van deze technieken benodigd om de diagnose glaucoom te bevestigen.

Voor een effectief management van glaucoom is een gedetailleerd inzicht in de effecten van de behandelmethoden cruciaal. Aangezien glaucoom een chronische ziekte is, dient men de langetermijneffecten in ogenschouw te nemen. Dit is lastig, omdat de meeste klinische trials slechts een beperkte follow-up kennen. Recent zijn echter de resultaten van enkele grote klinische trials beschikbaar gekomen waarin patiënten over een lange periode werden gevolgd. Een ander hoofdthema voor het management van deze chronische ziekte wordt gevormd door de behandelkosten. In de laatste decennia zijn deze substantieel gestegen ten gevolge van de introductie van nieuwe types oogdrukverlagende middelen. Deze middelen zijn duur, maar ze hebben de bestaande behandelmogelijkheden verruimd. Tegenwoordig heeft men de beschikking over een breed spectrum aan middelen. Er zijn nu verschillende opties voor het starten van een therapie wanneer er contraindicaties zijn voor klassieke oogdrukverlagende middelen. Ook wanneer er geen of te weinig verlaging van de IOP wordt bereikt met een voorgeschreven middel, of wanneer bijwerkingen optreden, is alternatieve medicatie voorhanden. Ten slotte zijn er verschillende medicijnen die aan een reeds voorgeschreven medicatie kunnen worden toegevoegd wanneer een verdere verlaging van de IOP wenselijk is. Het is derhalve een gecompliceerde kwestie om tot ideale behandelstrategieën te komen voor $\mathrm{OH}$ en POAG patiënten, waarbij veel factoren in beschouwing dienen te worden genomen.

Een van de kernvragen is of patiënten met oculaire hypertensie wel of niet behandeld dienen te worden. Per slot van rekening hebben deze patiënten nog geen glaucoom, althans niet in een mate die met de huidige diagnostische technieken is vast te stellen. Behandeling gaat niet alleen gepaard met kosten, maar ook met ongemak en mogelijkerwijs met bijwerkingen van de medicatie. De resultaten van dit proefschrift wijzen op een gunstig effect van behandeling van $\mathrm{OH}$ patiënten: medicamenteuze oogdrukverlaging leidt tot een kleinere kans op het ontwikkelen van glaucoom. Om het effect van behandeling te bepalen is een langdurige followup nodig en dienen de incidenties van glaucoom bij patiënten met en zonder behandeling te worden vergeleken. Hoewel in het verleden $\mathrm{OH}$ patiënten vaak wel behandeld werden, had dit tot voor kort geen bewezen nut. In hoofdstuk 2 is alle beschikbare wetenschappelijk bewijs m.b.t. het effect van de behandeling van oculaire hypertensie samengebracht in een systematische literatuurstudie. De uitkomsten van 
negen gerandomiseerde klinische trials, waarbij $\mathrm{OH}$ patiënten met en zonder IOP verlagende behandeling werden gevolgd, zijn gecombineerd in een meta-analyse. Deze analyse toont aan dat een IOP verlagende therapie bij $\mathrm{OH}$ patiënten de kans op het ontwikkelen van glaucoom vermindert. Het gepoolde relatieve risico bedraagt 0,61 (met een $95 \%$ betrouwbaarheidsinterval van $0,45-0,83$ ). Tevens is gevonden dat het relatieve risico afneemt met $14 \%$ met iedere mm $\mathrm{Hg}$ oogdrukverlaging. Momenteel is er onvoldoende kennis beschikbaar om $\mathrm{OH}$ patiënten te identificeren die een verhoogd risico lopen op het ontwikkelen van glaucoom als behandeling uitblijft. Therapie voor $\mathrm{OH}$ patiënten wordt algemeen geadviseerd bij hoge IOP waarden of in aanwezigheid van andere risicofactoren. Veel $\mathrm{OH}$ patiënten in de trials hebben echter IOP waarden onder het niveau waarboven behandeling geadviseerd wordt, en bij lang niet iedereen is er sprake van andere risicofactoren. Verder onderzoek in deze richting is daarom gewenst.

De gedachte achter de verschillende strategieën voor het detecteren en behandelen van patiënten met oculaire hypertensie en beginnend glaucoom, is dat het uiteindelijk blindheid voorkomt. Hoofdstuk 3 beschrijft een case-referent studie waarin het effect van vroege opsporing van $\mathrm{OH}$ en POAG patiënten op het optreden van blindheid ten gevolge van glaucoom wordt onderzocht. Voor een groep 'cases' en voor een groep 'referents' wordt nagegaan in welke mate men in het verleden te maken kreeg bij de oogarts met screening tests voor de vroege opsporing van $\mathrm{OH}$ en POAG, zonder dat er directe aanleiding toe was vanwege symptomen. De groep 'cases' wordt gevormd door blinde glaucoompatiënten. De groep 'referents' representeert de algehele populatie t.a.v. de frequentie waarmee dergelijke tests worden uitgevoerd. De grondredenering in deze studie is als volgt. Als patiënten zonder symptomen tests ondergaan voor het opsporen van $\mathrm{OH}$ en $\mathrm{POAG}$, dan kan de ziekte in een vroeg stadium worden opgespoord en behandeld. Als de behandeling van $\mathrm{OH}$ en beginnende POAG effectief is ter voorkoming van blindheid, dan is te verwachten dat dergelijke patiënten gewoonlijk geen blindheid zullen ontwikkelen. Omgekeerd kan worden gepostuleerd dat de reden dat blinde glaucoompatiënten blind zijn geworden, is dat zij niet bijtijds opgespoord (en behandeld) werden. De uitkomsten van deze studie bevestigen deze veronderstelling. Blinde glaucoompatiënten ondergingen minder vaak de screening tests waarmee $\mathrm{OH}$ en POAG kunnen worden opgespoord dan de 'referents'. Het berekende relatieve risico is 0,57 (met een $90 \%$ betrouwbaarheidinterval van $0,31-1,05)$. Deze studie laat zien dat vroege opsporing van patiënten met $\mathrm{OH}$ en POAG in de oogartsenpraktijk effectief is ter voorkoming van blindheid.

Momenteel bestaat er geen aanbeveling voor een screeningsprogramma voor glaucoom onder de gehele bevolking. Het beste alternatief voor een vroege opsporing van zulke patiënten is case-finding onder de patiënten die een oogarts bezoeken. Er zijn verschillende manieren om dit onderwerp te benaderen. Een interessante vraag m.b.t. case-finding in de oogartsenpraktijk is of de IOP routinematig gemeten zou dienen te worden bij alle nieuw binnenkomende patiënten, of alleen bij een selecte groep van patiënten met risicofactoren voor glaucoom. Ophthalmoscopie, waarmee de papil van de optische zenuw kan worden bekeken, maakt normaliter deel uit van 
een ophthalmologisch onderzoek. Tonometrie dient echter alleen ter bepaling van een verhoogde oogdruk. Deze test kan eenvoudig worden uitgevoerd zonder veel ongemak voor de patiënt. Een gevolg van het routinematig testen met tonometrie is dat meer patiënten, hoofdzakelijk $\mathrm{OH}$ patiënten, zullen worden opgespoord en behandeld. Behalve een klinisch effect heeft dit ook een effect op de kosten. In hoofdstuk 4 worden de langetermijnkosten en -effecten van drie verschillende casefinding strategieën bestudeerd en geëvalueerd met behulp van een beslismodel. Hierbij wordt tonometrie routinematig uitgevoerd: (1) bij alle nieuw binnenkomende patiënten, (2) alleen bij hoogrisico patiënten, (3) bij niemand. Deze strategieën worden vergeleken met methoden uit de kosteneffectiviteitanalyse. De conclusie luidt dat het het meest kosteneffectief is ter voorkoming van blindheid t.g.v. glaucoom, om tonometrie uit te voeren bij alle nieuw binnenkomende patiënten. De extra kosten per gered jaar met zicht bedragen $€ 1.707$ in vergelijking tot de strategie waarbij tonometrie bij niemand wordt uitgevoerd. Het is aannemelijk dat de kosten die in geval van blindheid door een patiënt per jaar worden gemaakt als gevolg van deze handicap, dit bedrag ruim overstijgen.

De belangrijkste kosten bij de behandeling van glaucoom zijn de kosten van de medicatie. De introductie van de nieuwe types glaucoommiddelen heeft bijgedragen aan veranderingen in het prescriptiepatroon, en is hand in hand gegaan met een aanzienlijke toename van de behandelkosten. Lange tijd waren niet-selectieve bètablokkers zoals timolol de eerste medicijnkeuze bij behandeling. Tegenwoordig worden hypotensieve lipiden zoals latanoprost vaak gebruikt als eerstelijnstherapie. De oogdrukverlagende werking van latanoprost is slechts een weinig sterker dan die van timolol. Anderzijds ligt de kostprijs van latanoprost een stuk hoger. De kosten en de klinische effecten van medicijnen dienen beide in beschouwing te worden genomen bij de keuze van een type medicatie. Dit geldt in het bijzonder voor medicijnen waarmee de behandeling geïnitieerd wordt, aangezien veel patiënten het voor lange tijd zullen gaan gebruiken. Als voldoende IOP verlaging wordt bereikt zonder het optreden van bijwerkingen, dan zal een patiënt op de betreffende medicatie worden gehouden. Een vervanging of toevoeging van een medicijn vindt alleen plaats wanneer daartoe een noodzaak bestaat. Voor patiënten met oculaire hypertensie is het niet nodig om de IOP evenveel te verlagen als bij glaucoompatienten. Men kan zich daarom afvragen, in het licht van de hogere prijs voor hypotensieve lipiden, of het gerechtvaardigd is om de behandeling van $\mathrm{OH}$ patiënten met dergelijke middelen te initiëren.

In hoofdstuk 5 wordt een onderzoek beschreven, waarin de klinische langetermijneffecten van het initiëren van $\mathrm{OH}$ therapie met timolol en met latanoprost worden bestudeerd en vergeleken. In hoofdstuk 6 wordt een kosteneffectiviteitanalyse van deze twee strategieën gegeven. Hiertoe wordt een simulatiemodel gebruikt. In dit model wordt niet alleen met de initiatie van de therapie rekening gehouden, maar ook met de eventueel daaropvolgende aanpassingen. Het uiteindelijke verschil tussen de twee strategieën voor wat betreft de bereikte IOP verlaging is klein. Aangezien de kans op het ontwikkelen van glaucoom afhangt van de IOP, is ook het verschil in optredende blindheid t.g.v. glaucoom klein. Gemiddeld is dit ongeveer 1 
maand per persoon voor beide strategieën, met een gemiddeld verschil tussen de strategieën van 2 dagen blindheid per patiënt. Daar staat tegenover dat het verschil in behandelkosten tussen de twee strategieën groot is. Dit maakt duidelijk waarom het initiëren van de behandeling van $\mathrm{OH}$ patiënten met latanoprost extreem hoge incrementele kosten met zich meebrengt in vergelijking tot het initiëren van de behandeling met timolol. Bij de huidige kostprijs van latanoprost bedragen deze extra kosten per gered jaar met zicht $€ 537.000$.

Hoofdstuk 7 sluit dit proefschrift af met een algemene discussie en een vooruitblik op toekomstig onderzoek. Aanbevelingen voor zulk onderzoek zijn het ontwikkelen van preciezere richtlijnen die aangeven wanneer de behandeling van $\mathrm{OH}$ patiënten gestart dient te worden, evenals het identificeren van deelgroepen van patiënten waarop behandelstrategieën kunnen worden toegesneden. 



\section{Dankwoord}

Dit proefschrift was nooit tot stand gekomen zonder de hulp van anderen. Het is mij een genoegen daar even bij stil te staan en terug te kijken op de periode waarin ik bezig was met dit onderzoek.

Ten eerste en bovenal gaat mijn dank uit naar mijn copromotoren Jan Schouten en Carroll Webers voor de plezierige jaren van samenwerking. Jan, je enorme kennis van de methodologie en je liefde voor het onderzoek is zeer motiverend. Ik heb me altijd verheugd op onze gesprekken. Bedankt voor alle hulp en voor je onvoorwaardelijke bereidheid om er te zijn als ik het nodig had. Carroll, je scherpzinnigheid en je nimmer aflatende enthousiasme voor het vak oogheelkunde heeft me meer dan eens op niveau gehouden. Jullie beider spontaniteit en gevoel voor humor maakte de samenwerking prettig en nooit saai.

Mijn dank gaat natuurlijk ook uit naar mijn beide promotoren, prof. Martin Prins en prof. Fred Hendrikse. Martin, de regelmatige bijeenkomsten in de eindfase van het schrijven waren onmisbaar voor de afronding van dit werk. Bedankt voor je tijd en alle plezierige schrijfsessies. Prof. Hendrikse, de jaren die ik heb doorgebracht bij de afdeling oogheelkunde zijn zeer aangenaam geweest. De manier waarop u iedereen weet te motiveren en daarmee zorgt voor het hoge niveau van de afdeling is heel bijzonder. Behalve de professionele en educatieve momenten was er ook vaak gelegenheid voor intellectuele ontspanning, zoals de onvergetelijke party's aan het begin van elk jaar. Bedankt voor alles.

Aan de fijne werkomgeving bij de afdeling oogheelkunde hebben velen bijgedragen: stafartsen, arts-assistenten, medewerkers van het secretariaat en van de poli. In het bijzonder wil ik noemen mijn kamergenoten Henny Beckers en Noël Bauer. Dat jullie destijds hebben aangeboden mij te huisvesten op jullie (niet al te ruime) kamer waardeer ik nog steeds zeer. Ik zal jullie gezellige gezelschap blijven missen. En natuurlijk Martin Buissink. Toen je in ons eerste gesprek na een paar minuten vroeg of ik de 'Subterranean Homesick Blues' kende wist ik dat het goed zat. Astrid Hacking, bedankt voor alle support door de jaren heen. Aukje, Yanny, Suzanne en 
Rob, mede-onderzoekers op de afdeling en tevens mede-lunchgangers, het was leuk om jullie te leren kennen en met jullie op te trekken. Benjamin, bedankt voor je inzet. John, Tos, het is altijd leuk jullie weer eens op de gangen tegen te komen. Iedereen op het secretariaat, met name Ellen, bedankt voor al jullie hulp. Het is altijd gezellig om bij jullie binnen te lopen. En dank aan alle arts-assistenten en kersverse oogartsen, ik wens jullie het beste!

Het lijkt nu lang geleden, maar toen ik in september 2001 begon aan dit onderzoek was dat bij de capaciteitsgroep Epidemiologie. Ik heb er nieuwe kennis en kennissen opgedaan, veel leuke mensen leren kennen, en vriendschappen aan overgehouden. Mijn dank aan prof. Piet van den Brandt voor de mogelijkheid om bij Epidemiologie te starten. In deze fase van het onderzoek was Renée Rijnders betrokken bij het project, bedankt voor je werk en voor je gezelligheid. Maurice Zeegers en Pieter Leffers, jullie wil ik tevens bedanken voor jullie wetenschappelijke bijdragen. Jos Slangen bedank ik voor alle ondersteuning op computergebied en zijn vermogen om meteen daar te verschijnen waar hulp nodig is. Mijn voorganger op het gebied van glaucoomonderzoek was Rikkert van der Valk. Rikkert, bedankt, ook voor al die keren dat je me weer eens met de auto kwam ophalen voor een refereeravond. En dank aan Raymond, Patty, Nicky en Ludo, en alle anderen die op een of andere manier hebben meegeholpen tijdens dit onderzoek.

Een groot gedeelte van dit proefschrift gaat over modelleren en kosteneffectiviteit. De expertise op dit gebied ligt bij de afdeling Kemta van het AZM waar ik vooral heb samengewerkt met prof. Hans Severens. Hans, bedankt voor je professionele maar ook persoonlijke inzet. Op jacht naar de kosten, een niet te verwaarlozen maar moeilijk in te vullen aspect van een kosteneffectiviteitmodel, kreeg ik hulp van Manuela Joore en Gemma Vos. Hiervoor wil ik jullie allebei bedanken.

De leden van de leescommissie, prof. Limburg, prof. Luyten, prof. Knottnerus, prof. Van Schayck, dr. Busch wil ik allemaal graag bedanken voor het lezen en beoordelen van mijn proefschrift.

Carolien Bastiaenen, Peter Brouwers, mijn paranimfen. Ieder van jullie een vriend waarmee altijd veel te lachen valt. Bedankt, dat jullie deze taak hebben willen vervullen.

Een paar woorden nog aan een aantal vrienden die ik niet ongenoemd wil laten. Harry, dank voor alle muzikale gedachtewisselingen. Ik denk dat het de Gibson L00 was die het vaakst uit zijn koffer is geweest tijdens het schrijven van dit boek. Huub, een vriendschap kan ontstaan uit een onverwachte situatie, ik heb er veel aan gehad in de laatste twee jaar.

En ten slotte een plekje voor mijn familie, verspreid door Nederland, Slowakije en Tsjechië. Dat maakt het niet gemakkelijk qua taalkeuze! Dan maar eerst in het Nederlands. Jo en Netty, ik weet dat ik niet veel hoef te zeggen maar toch bedankt voor alle steun en interesse in mijn werk. Ralf, je bent al die tijd mijn grootste steun 
geweest! Je hebt me vaak genoeg moed ingepraat. Bedankt voor alle hulp en nog veel meer wat mij lief is en wat ik eigenlijk alleen voor ons wil houden. Ook bedankt voor de constante bevoorrading met de bluesnummers die mij op de been houden. Lieve Thomas, je hebt me vaak genoeg geholpen met je optimisme en je goede zin. Bovendien kwamen jouw handige computertrucjes soms goed van pas. Je hebt buitengewoon veel begrip gehad als ik weer eens geen tijd voor je had omdat ik bezig was met het proefschrift. Ik ben trots op je. Dear Kat'a, my dear sister, now that I am finishing this work, I would like more than anything that our parents would enjoy it too. But that was not meant to be. This work is dedicated to them as well. I know that you have done very much in these last two years and I was not always able to help you. Thank you for everything, d'akujem!

Andrea Peeters

Maastricht, november 2007 



\section{Curriculum vitae}

Andrea Peeters-Karovičová was born in Bratislava, Slovakia, in 1962. In 1986 she graduated in General Medicine at the Medical Faculty of the Comenius University in Bratislava. She then worked as a doctor for five years at the Radiodiagnostic Clinic of the Dérerova hospital. In 1991 she moved to Amsterdam, where in 1994 she graduated in Epidemiology at the EMGO Institute of the Free University. Currently she lives in Maastricht, where she is employed by the Maastricht University Hospital since 2001. The research in this thesis was carried out at the Department of Epidemiology of Maastricht University and at the Department of Ophthalmology of the Maastricht University Hospital. She is now working at Maastro Clinic Maastricht, studying the cost-effectiveness of particle therapy. 